AUTARQUIA ASSOCIADA À UNIVERSIDADE DE SÃO PAULO

RESSONADOR LASER EM ANEL DE ALTA POTÊNCIA E FREQUÊNCIA ÚNICA DE Nd:YAG

AMAURI AGOSTINHO FERREIRA

Orientador:

Prof. Dr. Niklaus Ursus Wetter

São Paulo 


\section{INSTITUTO DE PESQUISAS ENERGÉTICAS E NUCLEARES}

Autarquia associada à Universidade de São Paulo

RESSONADOR LASER EM ANEL DE ALTA POTÊNCIA E FREQUÊNCIA ÚNICA DE Nd:YAG

AMAURI AGOSTINHO FERREIRA

Dissertação apresentada como parte dos requisitos para obtenção do Grau de Mestre em Ciências na Área de Tecnologia Nuclear - Materiais

Orientador:

Prof. Dr. Niklaus Ursus Wetter

Versão Original 
Fonte de Financiamento: CAPES

Autorizo a reprodução e divulgação total ou parcial deste trabalho, para fins de estudo e pesquisa, desde que citada a fonte

Como citar:

AGOSTINHO FERREIRA, A. RESSONADOR LASER EM ANEL DE ALTA POTÊNCIA FREQUÊNCIA ÚNICA DE Nd: YAG. 2018. 65 p. Dissertação (Mestrado em Tecnologia Nuclear), Instituto de Pesquisas Energéticas e Nucleares, IPEN-CNEN/SP, São Paulo. Disponível em: <www.teses.usp.br> (data de consulta no formato: dd/mm/aaaa)

Ficha catalográfica elaborada pelo Sistema de geração automática da Biblioteca IPEN/USP, com os dados fornecidos pelo(a) autor(a)

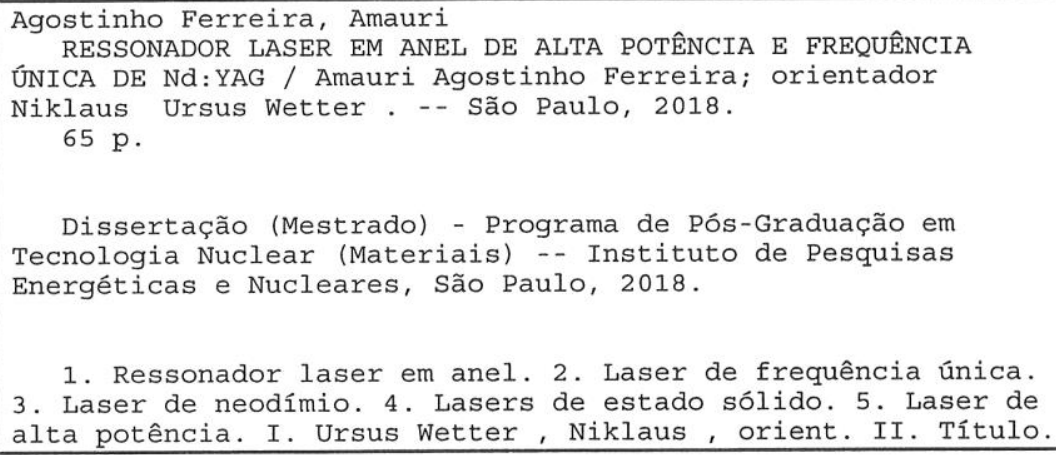

1. Ressonador laser em anel. 2. Laser de frequência única. 3. Laser de neodímio. 4. Lasers de estado sólido. 5. Laser de alta potência. I. Ursus Wetter, Niklaus, orient. II. Título. 


\section{AGRADECIMENTOS}

Agradeço ao Prof. Dr. Niklaus Ursus Wetter, pela sua orientação, total apoio, disponibilidade, pelas opiniões e críticas na realização deste trabalho de mestrado e ao Allan pelo auxílio e apoio nas tarefas de desenvolvimento do projeto.

Ao programa de Pós-graduação do IPEN/USP, pela oportunidade de realizar este trabalho e a CAPES pelo auxílio financeiro.

Aos colegas de laboratório de desenvolvimento de laser do Centro de Laser e Aplicações: Merilyn, Diego e Danilo pelo apoio importante incentivo.

A todos os funcionários do Centro de Laser e Aplicações (CLA) em especial o pessoal da oficina mecânica que sempre auxiliaram na fabricação de peças e soluções de problemas técnicos.

Por último gostaria de agradecer aos meus familiares em especial aos meus pais e irmãos, por serem um exemplo para mim, pelo seu apoio e pela paciência e colaboração da minha formação. A eles dedico este trabalho. 


\title{
RESSONADOR LASER EM ANEL DE ALTA POTÊNCIA E FREQUÊNCIA ÚNICA DE Nd:YAG
}

\begin{abstract}
RESUMO
Para a espectroscopia de alta resolução e metrologia óptica em geral, é desejável um laser com linha espectral estável e de alta potência de saída para bombear diferentes tipos de ressonadores, como osciladores paramétricos óticos (OPO - Optical Parametric Oscillator). Os lasers de frequência única disponíveis estão no alcance de potência de saída de 10 Watts, enquanto que, dependendo da aplicação e do tipo de OPO, é desejável uma maior potência (> $20 \mathrm{~W}$ ). Neste trabalho foi desenvolvido um laser de frequência única e alta potência com base em módulos de bombeio por diodos e tendo como meio ativo o granada de alumínio de ítrio dopado com neodímio (Nd:YAG). Dois bastões de Nd:YAG bombeados transversalmente por diodo, foram utilizadas em uma configuração de ressonador em anel com saída polarizada de onda continua (CW- continuous-wave), qualidade de feixe modo transversal eletromagnético $\left(\right.$ TEM $\left._{00}\right)$ e potência de saída de 105,2 W. A potência de saída alcançada é, a nosso entender, a mais alta para lasers em anel no modo fundamental transversal polarizado contínuo usando módulos Nd:YAG comuns com bombeamento lateral. $O$ ressonador permitiu a sintonização de potência em uma grande faixa dinâmica e obteve excelente qualidade de feixe, usando uma placa de meia onda entre os dois bastões para compensação de birrefringência. A operação de frequência única foi alcançada usando cristal de granada de térbio-gálio (TGG-Terbium Gallium Garnet), dois imãs e um etalon, com uma potência de saída de 51,60 W e uma largura a meia altura da curva (FWHM) espectral de aproximadamente $17 \mathrm{MHz}$.
\end{abstract}

Palavras-chave: Ressonador laser em anel, Laser de frequência única, Laser de neodímio, Lasers de estado sólido, Laser de alta potência. 


\title{
Nd:YAG SINGLE FREQUENCY HIGH POWER LASER RING
}

\section{RESONATOR}

\begin{abstract}
For high resolution spectroscopy, a high power, stable line output laser is desirable for pumping different types of optical parametric oscillator resonators (OPO). Single-frequency lasers are in the range of 10 watts of output power, while, depending on the application and the OPO type, higher power $(>20 \mathrm{~W})$ is desirable. In this work a single frequency high power laser based on diode pumping modules with $\mathrm{Nd}$ :YAG as the active medium was developed. Two Nd:YAG bars transversally pumped by diodes were used in a configuration of a CW polarized ring resonator with beam quality $\mathrm{TEM}_{00}$ and output power of 105,2 W. The output power achieved is, to our knowledge, the highest for continuous polarized fundamental mode ring lasers using standard $\mathrm{Nd}$ :YAG modules with side pumping. The resonator allowed the tuning power in a large dynamic range and obtained excellent beam quality using a half-wave plate between the two rods for birefringence compensation. The single frequency operation was achieved using a TGG (Terbium Gallium Garnet) crystal, two magnets and an etalon, with an output power of $51.60 \mathrm{~W}$ and a 17 $\mathrm{MHz}$ full width at half maximum (FWHM) spectral width.
\end{abstract}

Keywords: Ring laser resonators, Single frequency laser, Neodymium laser, Solidstate lasers, High power laser. 


\section{Sumário}

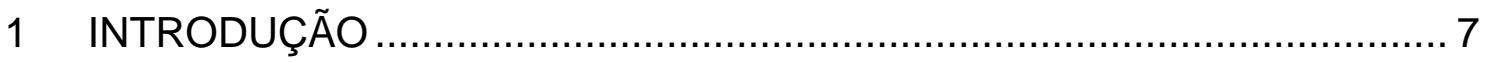

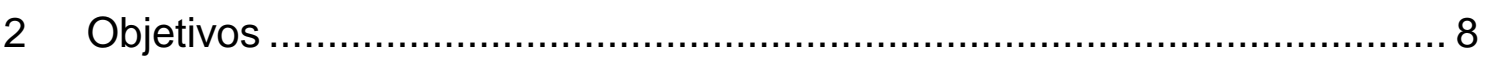

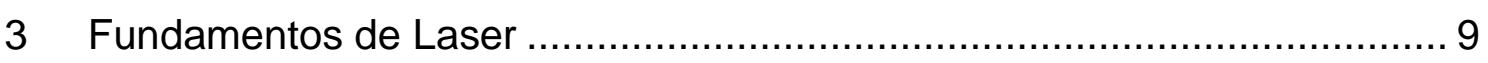

3.1 Laser de estado sólido bombeado por diodo................................... 9

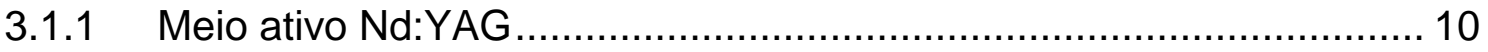

3.2 Lente térmica e birrefringência ................................................. 12

3.2.1 Geração de calor no meio ativo .............................................. 12

3.2.2 Lente térmica .................................................................. 13

3.2.3 Compensação da birrefringência ............................................. 14

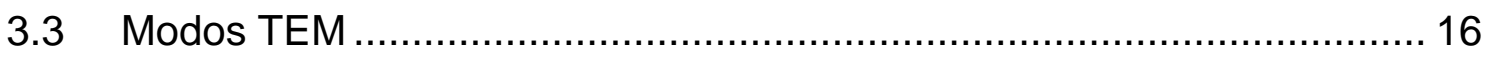

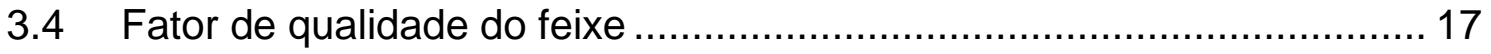

3.5 Ressonadores dinamicamente estáveis (DSR-Dynamically Stable

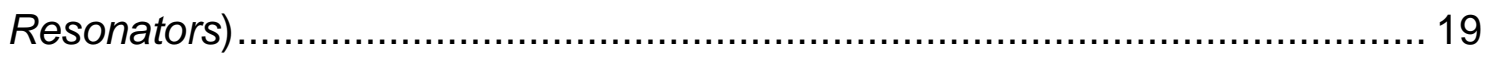

3.6 Interferômetro Fabry-Perot .................................................... 23

3.6.1 Utilização do etalon ................................................................... 23

3.7 Frequência Única ............................................................. 26

3.7.1 Modos longitudinais de um ressonador laser ............................... 26

3.7.2 Controle dos modos longitudinais .......................................... 30

3.7.3 Efeito" hole burning" espacial ............................................... 30

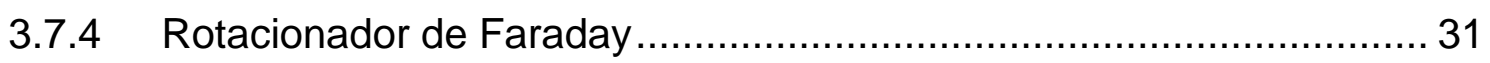

4 Materiais e Métodos ........................................................................... 33

4.1 Módulos DPSSL utilizados no trabalho ........................................... 33

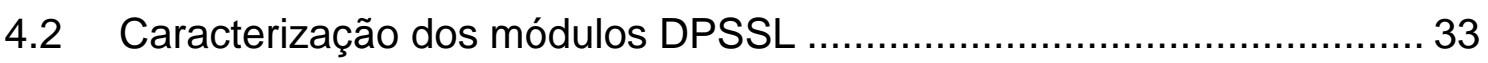

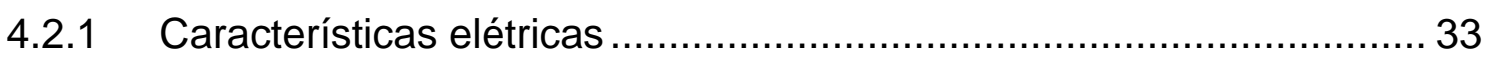

4.2.2 Caracterização das lentes térmicas .......................................... 34

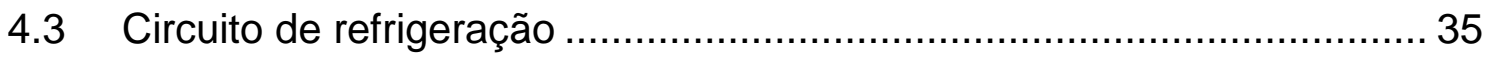

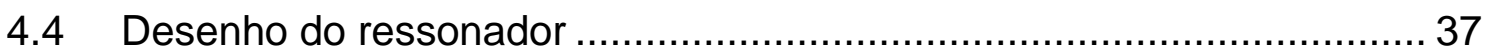

4.5 Maximização do acoplador de saída ............................................ 38

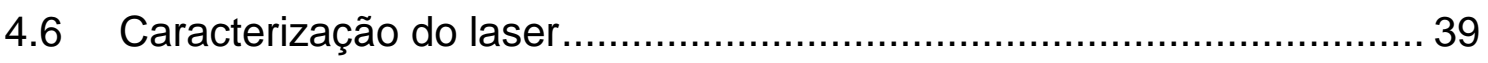


4.6.1 Medidores de potência ......................................................... 39

4.6.2 Medidas de parâmetro de qualidade do feixe ................................... 39

4.6.3 Medidas de polarização ......................................................... 41

4.7 Rotacionado de Faraday ......................................................... 43

4.8 Caracterização da emissão espectral do laser ................................. 44

4.8.1 Descrição do sistema de etalon ............................................. 45

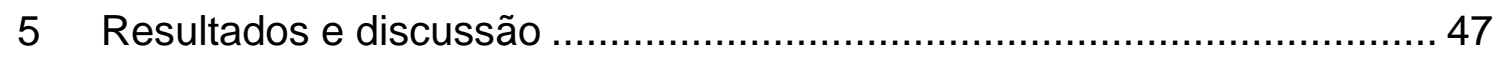

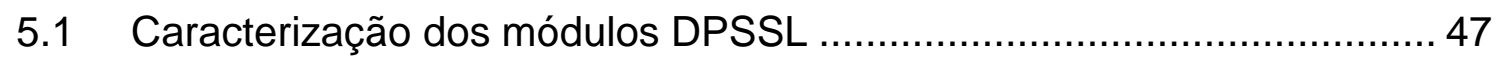

$5.1 .1 \quad$ Caracterização elétrica......................................................... 47

5.1.2 Caracterização das lentes térmicas ........................................... 47

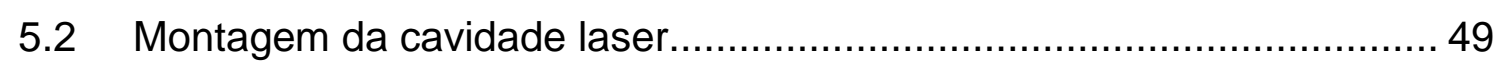

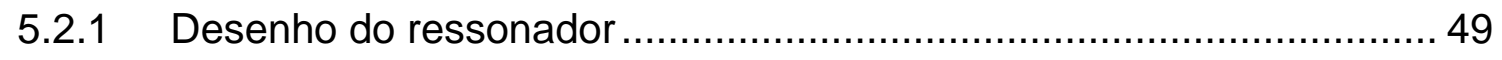

5.3 Maximização do acoplador de saída ........................................... 51

5.4 Caracterização do laser........................................................ 51

5.4.1 Grau de polarização do feixe .............................................. 51

5.4.2 Fator de qualidade do feixe .................................................. 53

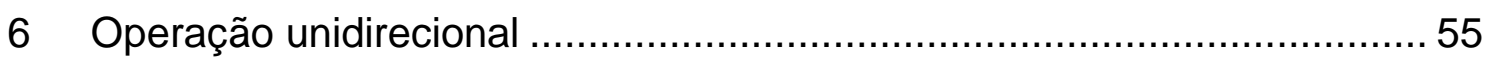

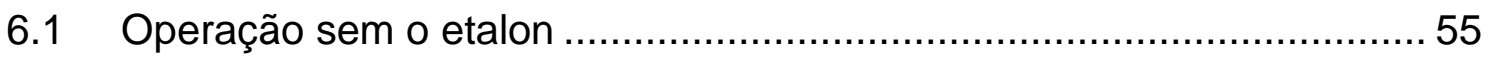

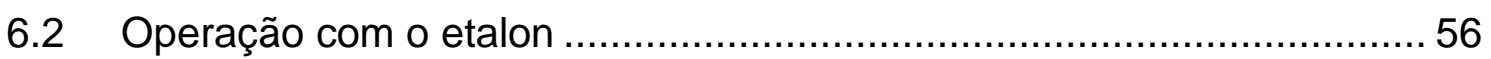

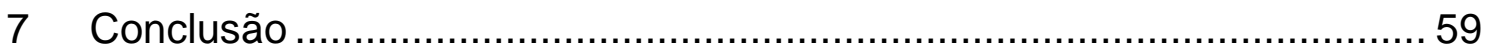

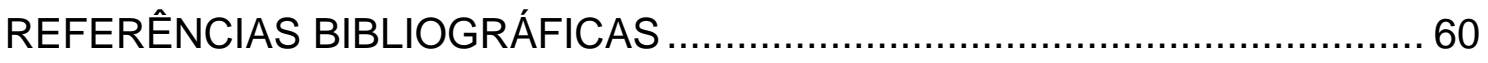




\section{INTRODUÇÃO}

A obtenção de lasers com alta potência de saída e alta qualidade de feixe tem sido um importante objetivo da pesquisa em lasers, pois há um grande esforço por parte da comunidade científica em desenvolver lasers mais eficientes, robustos e que apresentem qualidade de feixe e potência elevadas para atender a demanda em diversas áreas como processamento de matérias, sensoriamento remoto, sistemas amplificadores de potência e fontes para o bombeamento de OPO'S (optical parametrical oscillator), entre outros, por lasers que possuem alta potência boa qualidade de feixe, polarização bem definida e emissão com largura de banda estreita $[1,2]$.

Os tradicionais bastões de bombeamento lateral por diodo são uma tecnologia competitiva apesar de outros esquemas de bombeamento estarem disponíveis atualmente, isso devido a sua comprovada confiabilidade, estabilidade de potência, simplicidade e disponibilidade de baixo custo de componentes [3,4]. Devido a efeitos térmicos no cristal como lente térmica e birrefringência, que induzem distorções no feixe laser e podem levar o ressonador à estabilidade operando no modo $\mathrm{TEM}_{00}$ que geralmente requerem a inserção de filtros espacial no ressonador, como fenda ou íris para prevenir oscilações do modo de ordem mais altas [5]. Nesse caso, a eficiência de saída do laser geralmente é reduzida devido ao pequeno volume de material do meio envolvido na ação laser. Pode-se obter o modo $\mathrm{TEM}_{00}$ com grande diâmetro através das utilizações de configuração especiais de ressonador [6].

É possível obter feixes com alta pureza espectral nos ressonadores laser em anel unidirecional [7]. Com três ou mais espelhos de incidência não normal e um dispositivo não recíproco, é produzida uma onda viajante ao invés da onda estacionária, pois, o dispositivo não recíproco induz altas perdas à uma das componentes [8]. O dispositivo não recíproco consiste em um rotacionador de Faraday que contém um elemento de Faraday que consiste em cristal com elevada constante de verdet e um magneto, que gira o plano de polarização da luz incidente $[9,10]$. 


\section{Objetivos}

O objetivo deste trabalho de mestrado é a obtenção de um laser de estado sólido bombeado por diodos de alta potência utilizando dois módulos DPSSL comerciais idênticos de baixo custo. Espera-se obter as seguintes características:

- Ressonador laser em anel de Nd:YAG operando na transição de quatro níveis ${ }^{4} \mathrm{~F}_{3 / 2} \rightarrow{ }^{4} \mathrm{I}_{11 / 2}(1064 \mathrm{~nm})$;

- Boa qualidade de feixe, ou seja, fator de qualidade $\mathrm{M}^{2}$ menor que 1,5 , operando no modo fundamental TEM To $_{0}$

- Potência de saída próxima de 100 W em modo transversal único;

- Operação em frequência única. 


\section{Fundamentos de Laser}

\subsection{Laser de estado sólido bombeado por diodo}

Lasers de estado sólido têm meio ativo do tipo cristalino, vítreo ou cerâmico, apresentando uma constante evolução desde a demonstração do primeiro laser em 1960 [11]. Os primeiros lasers de estado sólido bombeados por lâmpadas de flash eram volumosos e ineficientes. O primeiro bombeado por diodo surgiu em 1964. Com o desenvolvimento dos lasers de diodo houve um grande aumento na eficiência dos lasers, pois são favoráveis para bombeamento por possuírem uma estreita banda de emissão comparadas às lâmpadas flash e por terem um espectro de emissão mais próximo do espectro de absorção do cristal que está sendo bombeado.

O campo de estudos de lasers de estado sólido foi revolucionado pelo desenvolvimento de lasers de diodo de alta potência. Tais lasers conseguem produzir alta potência além de serem baratos e compactos. Um único diodo é capaz de alcançar potências superiores a $10 \mathrm{~W}[12,13]$. Podem ser combinados em barras (diode bars) ou pilhas (stacks) atingindo potências de até $200 \mathrm{~W}$ com barras de diodo ou mesmo de $20 \mathrm{~kW}$ com pilhas diodo [14].

As altas potência de bombeamento atingidas pelos diodos possibilitam o desenvolvimento de lasers de estado sólido bombeados por diodo (diode-pumped solid-state lasers - DPSSL) que podem ter bombeamento longitudinal ou transversal. No caso de bombeamento longitudinal, os eixos dos diodos de bombeio ficam aproximadamente alinhados com o feixe laser, propiciando uma série de vantagens para a obtenção de feixes no $\mathrm{TEM}_{00}$, com o bombeio de uma região no cristal com diâmetro ligeiramente maior que o diâmetro do feixe ressonante de maneira que modos de ordens transversais mais altas não apresentem ganho [15]. Lasers com bombeamento longitudinal apresentam, porém, dificuldade para se atingir potências mais elevadas, por ser mais difícil o uso de mais de um diodo em cada lado do cristal e também podem provocar aquecimento excessivo e danos ao meio ativo ocasionando distorções termicamente induzidas. Por esse motivo, a escolha adequada do meio ativo, assim como do sistema de bombeamento e refrigeração, se fazem primordiais quando se deseja alcançar alta potência em lasers do tipo DPSSL [16]. Atualmente, há grande variedade de módulos lasers comerciais que utilizam a 
tecnologia DPSSL com bombeamento lateral como mostrado na FIG. 1, havendo grande vantagem na utilização deste tipo de dispositivo devido à possibilidade de se alcançar altas potências com estabilidade e facilidade na operação [17].
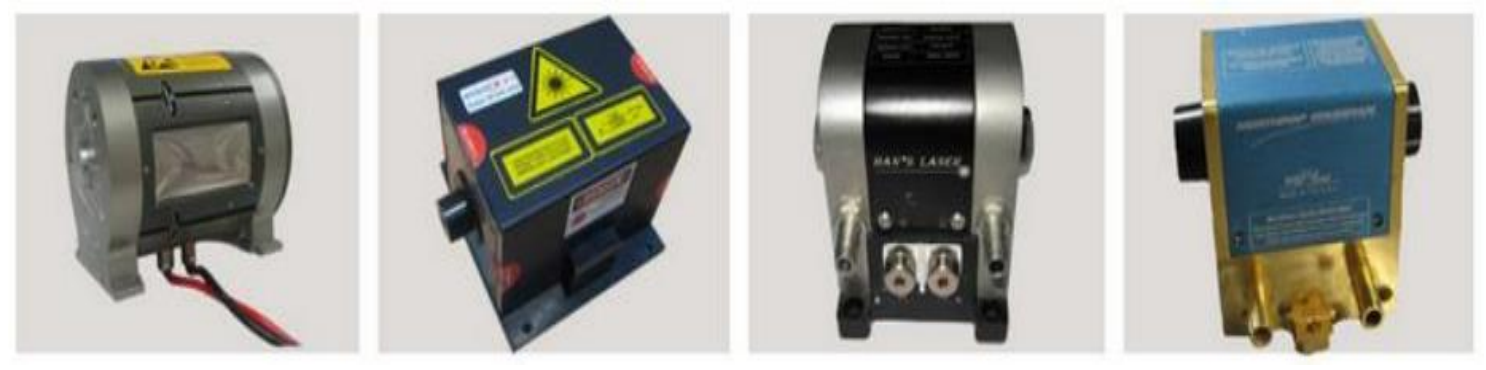

Figura 1: Variedade de módulos DPSSL que utilizam bastão laser bombeado transversalmente por arranjos de diodos semicondutor.

\subsubsection{Meio ativo Nd:YAG}

O meio sólido com base em granada de ítrio e alumínio (YAG) dopado com neodímio (Nd:YAG), é um material sintético que se tornou popular na forma de cristal laser na década de 1960. Os íons de ítrio em YAG podem ser substituídos por íons de terra rara laser-ativos sem afetar fortemente a estrutura da rede por possuírem raios atômicos similares. A FIG. 2 apresenta a estrutura cristalina do Nd:YAG. YAG é um meio hospedeiro com propriedades favoráveis, particularmente para lasers de alta potência e lasers com chaveados emitindo em $1064 \mathrm{~nm}$. As alternativas mais populares para Nd:YAG entre os meios de ganho dopados com neodímio são Nd:YVO ${ }_{4}$ e Nd:YLF $[18,19]$. Os lasers de Nd:YAG hoje em dia também competem com os lasers de Yb:YAG. O Nd:YAG é um meio de ganho de quatro níveis (exceto para a transição de $946 \mathrm{~nm}$ ), oferecendo um ganho laser mesmo para níveis moderados de excitação e intensidades de bombeamento. A largura de banda de ganho é relativamente pequena, mas isso permite uma alta eficiência de ganho e, portanto, uma potência de bombeamento de baixo limiar. Pode ser bombeado por diodos ou mesmo por lâmpadas devido à larga banda de absorção, principalmente na região de $800 \mathrm{~nm}$, e às características de quatro níveis.

O comprimento de onda de emissão Nd:YAG mais comum é $1064 \mathrm{~nm}$. Outras linhas de emissão estão em 946, 1123, 1319, 1338, 1415 e 1444 nm. Quando usado na transição de $946 \mathrm{~nm}$, o Nd:YAG é um meio de ganho de quase três níveis, exigindo intensidades de bombeamento maiores. Todas as outras 
transições são de quatro níveis, com algumas dessas, como a de $1123 \mathrm{~nm}$, sendo muito fracas, sendo difícil obter uma operação eficiente do laser nesses comprimentos de onda. Mesmo um ganho moderado requer uma alta densidade de excitação.

A FIG. 3 mostra um diagrama de níveis do Nd:YAG que é uma estrutura monocristalina usualmente usado em lasers, fabricado pelo método de crescimento de Czochralski, podendo ser utilizado também na forma cerâmica (policristalina), com disponibilidade em tamanhos grandes. As perdas de absorção e espalhamento dentro do comprimento de um cristal laser são normalmente insignificantes, mesmo para cristais relativamente longos [19] tanto para meio monocristalino quanto cerâmico. As concentrações típicas de dopagem de neodímio são da ordem de 0.6 at.\% a 1.1 at.\%. Maiores dopagens são vantajosas por reduzirem o comprimento de absorção do bombeamento. Concentrações muito altas podem levam à diminuição do tempo de vida do estado superior. Como o íon de neodímio é maior que o íon de ítrio, maiores valores de dopagem induzem mais defeitos cristalinos. De maneira geral, altas concentrações de dopagem são desejadas para a operação chaveada por possibilitar grande capacidade de armazenamento de energia, enquanto que para a operação em modo contínuo são utilizadas baixas concentrações de dopagem, que permitem boa qualidade de feixe.

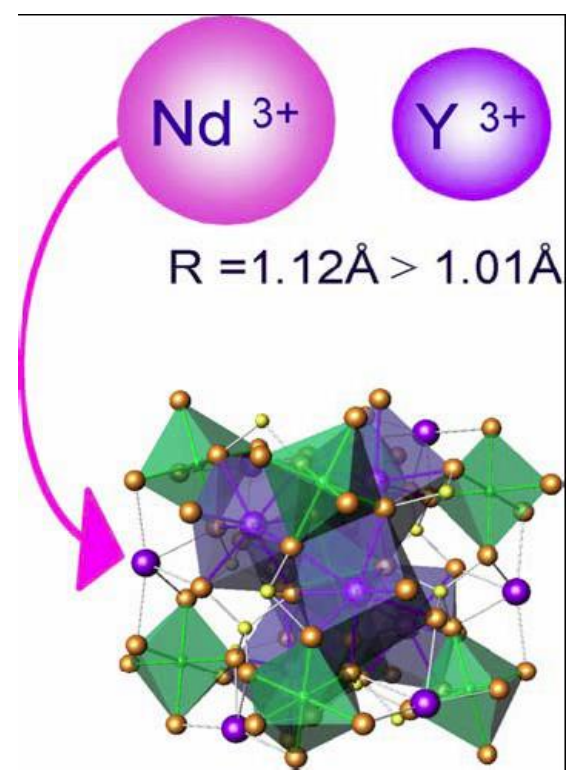

Figura 2: Estrutura atômica de Nd:YAG: os íons substituem os $\mathrm{Y}^{3+}$ na matriz [19]. 


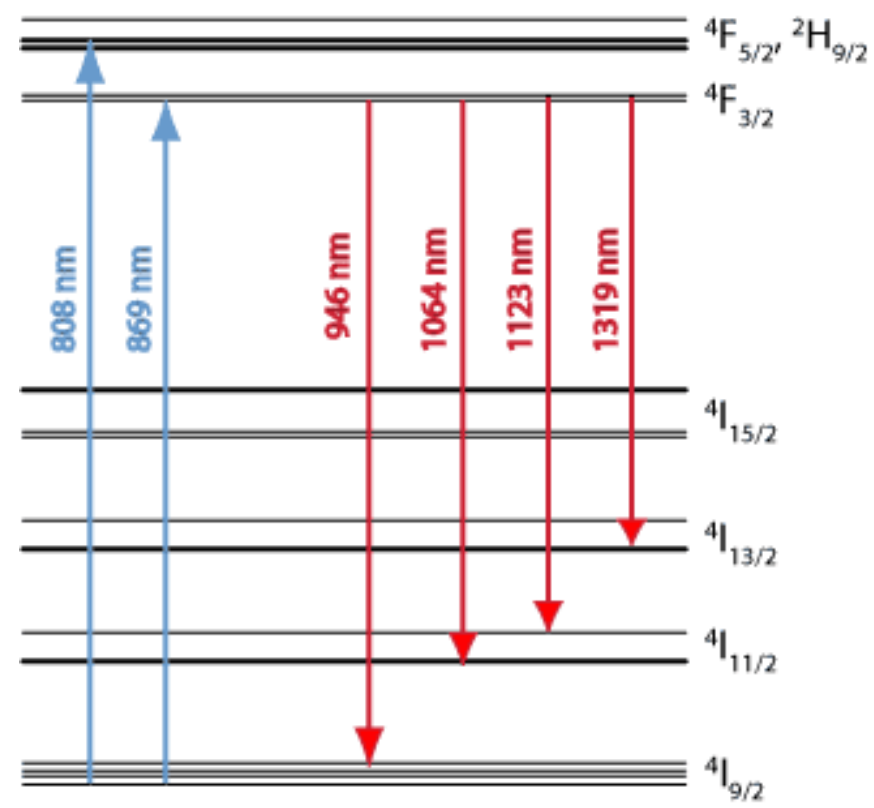

Figura 3: Estrutura de nível de energia e transições comuns de bombeamento e laser do íon de neodímio trivalente em Nd:YAG [20].

\subsection{Lente térmica e birrefringência}

\subsubsection{Geração de calor no meio ativo}

A potência de bombeamento alta, necessária para se conseguir um laser de alta potência, inevitavelmente gera tensões térmicas no meio de ganho independe da sua geometria. No processo de bombeamento óptico em um material laser de estado sólido é gerado calor por várias razões:

A diferença de energia dos fótons entre a banda de absorção e o nível superior são perdidos em forma de calor para o hospedeiro da rede causando o chamado aquecimento de defeito quântico.

No caso de bombeamento por lâmpada, a ampla distribuição espectral da lâmpada de arco ou flash é tal que há uma absorção considerável pelo material hospedeiro, principalmente no ultravioleta.

A remoção eficiente de calor reduz os efeitos térmicos que são causados pelos gradientes de temperatura em toda a área ativa do meio laser, que geralmente demanda considerações de design para sistemas de alta potência. Uma das mudanças no bombeamento laser foi à transição das lâmpadas flash para o bombeamento com diodo semicondutor reduzindo o calor residual dissipado no meio laser devido à alta eficiência do processo de bombeamento, já que permite o bombeamento direto no nível laser superior [17]. 
O aquecimento de defeito quântico é reduzido devido ao fato de o comprimento de onda de bombeio ser mais próximo do comprimento de onda de emissão laser. Com isso, o aquecimento do material hospedeiro provocado pela radiação localizada fora das bandas de absorção dos íons ativos é completamente eliminado. Entretanto, os problemas térmicos ainda persistem especialmente devido as transições não radioativas que ocorrem devido à diferença de energia entre o nível de bombeamento (808nm) e o de emissão (1064nm) (defeito quântico) e devido a processos de conversão ascendente [21].

\subsubsection{Lente térmica}

O bastão laser de geometria cilíndrica tem geração de calor volumétrica durante a ação laser graças aos efeitos discutidos acima, e a remoção deste calor ocorre pela condução para o sistema de refrigeração através de sua superfície [22].

Em lasers de alta potência, o aquecimento do cristal laser causa uma lente térmica que é resultado de mecanismos combinados com o meio de ganho sendo mais quente no eixo do feixe em comparação com regiões externas, havendo um gradiente transversal do índice de refração $n$ graças à dependência deste com a temperatura. Mudanças de índice causadas por tensões mecânicas induzindo termicamente (efeito fotoelástico) [23]. Finalmente a tensões mecânicas também podem levar ao abaulamento das faces do meio de ganho, de modo que estes também causam a lente térmica. Estes três efeitos combinados dão origem ao fenômeno conhecido como lente térmica, que é caracterizado pela indução no bastão de comportamento tal como de uma lente cuja distância focal é dada por [23].

$$
f_{R, \varnothing}=\frac{K A}{P_{h}}\left(\frac{1}{2} \frac{d n}{d T}+\alpha C_{R, \varnothing} n_{0}^{3}+\frac{\alpha r_{0}\left(n_{0}-1\right)}{n_{0 l}}\right),^{-1}
$$

Onde A é a área da secção transversal do bastão, $P_{h}$ o calor dissipado no bastão, $\frac{d n}{d T}$ a variação do índice de refração do cristal com a temperatura, $n_{0}$ o índice de refração no centro do bastão, $K$ condutividade térmica, le $r_{0}$ comprimento e raio do bastão, $\alpha$ coeficiente de expansão térmica, $C_{R, \emptyset} \circ$ coeficiente fotoelástico que tem duas componentes, radial $(R)$ e tangencial $(\varnothing)$ para determinado bastão. 
Os termos da expressão (1) correspondem aos três efeitos descritos acima: a variação do índice de refração com a temperatura, o efeito fotoelástico e o efeito da curvatura induzida na superfície do bastão.

As componentes $R$ e $\emptyset$ da distância focal correspondem às distâncias focais para as polarizações radial ou tangencial. Este efeito é conhecido como bifocalização decorrente da birrefringência térmica que tem grande impacto na limitação do funcionamento de ressonador laser operando no modo $\mathrm{TEM}_{00}$ sendo necessário por vezes a adoção de técnicas de compensação de birrefringência para a operação no modo fundamental [24].

\subsubsection{Compensação da birrefringência}

A birrefringência induzida termicamente em meios ativos isotrópicos como é o caso da matriz YAG e a não uniformidade da distribuição de temperatura no cristal pode causar perdas substanciais no cristal por depolarização em feixes polarizados, além de gerar duas distâncias focais para a lente térmica induzidas. No caso de operações no modo TEM 00 as perdas por depolarização aumentam na medida em que se aumenta a potência de bombeamento e podem alcançar $25 \%$ da potência total [8]. As perdas por depolarização são um dos fatores limitantes para obtenção de lasers de alta potência operando no modo fundamental e polarizado, além de causar uma grande redução na eficiência do laser.

Para contornar o problema da bifocalização induzida pela birrefringência existem técnicas de compensação de birrefringência que consistem basicamente em fazer com que os feixes que passam pelo bastão com uma determinada polarização, radial ou tangencial, passem por um elemento rotacionador de polarização (geralmente uma placa de meia onda) e passem pelo mesmo meio ou por outro meio idêntico com a polarização radial ou tangencial trocadas com relação à primeira passagem, e na mesma posição em que passaram na primeira vez, compensando assim o efeito total da birrefringência.

Em lasers de dois bastões de Nd:YAG idênticos a forma mais utilizada para compensar a birrefringência é o uso de uma placa de $\lambda / 2$ entre dois bastões combinada com a inserção de um polarizador para obtenção de polarização linear $[25,26]$. No caso de um único bastão com um elemento 
polarizador intracavidade, uma placa de $\lambda / 4$ é inserida [27,28]. Este tipo de esquema foi proposto por Clarkson et al [29]. Este esquema de compensação é ilustrado na FIG. 4 um feixe que incidente linearmente polarizado na direção y (a) incide sobre o bastão numa região do bastão a $45^{\circ}$ do eixo $\mathrm{x}$, e suas componentes radial e tangencial sofrerão o efeito das lentes térmica distintas (b). Estas componentes, ambas de mesmo módulo, incidirão a $45^{\circ}$ do eixo rápido da placa de $N / 2$ (c) e terão suas componentes no eixo lento invertidas, de modo que estas duas componentes emergirão da placa de $\lambda / 2$ trocadas (d) e incidirão no segundo bastão, idêntico ao primeiro, na mesma região que incidiram no primeiro bastão (e), de modo que agora a componente que sofreu lente térmica tangencial no primeiro bastão sofrerá lente térmica radial e assim reciprocamente. $O$ feixe que emerge do segundo bastão (f) preserva a polarização original (quadro A1).

A compensação da birrefringência é completa para os raios que incidem nas regiões do bastão a $45^{\circ}$ dos eixos e nula para os que incidem nos eixos $x$ e $y$, havendo algum grau de compensação para as componentes que incidem nas regiões em outros ângulos. Para que haja uma compensação efetiva da birrefringência em lasers com dois bastões, deve-se utilizar dois bastões com um telescópio entre eles de forma que os planos principais dos cristais estejam mapeados um no outro com o racionado de polarização entre eles ou alternativamente pode-se manter os bastões tão próximo quanto possível com a placa de $\lambda / 2$ entre eles.

No quadro B2 podemos ver a onda polarizada antes de entrar no bastão 1, e após a onda passar pelo bastão 1 as componentes radial e tangencial sofrem uma defasagem devido à birrefringência termicamente induzida. Esta defasagem gera uma componente na polarização perpendicular à polarização inicial, que geraria perda (perda por despolarização quando o feixe passasse pelo elemento polarizador) caso não fosse compensada. As componentes radial e tangencial são invertidas após a onda passar pela placa de $\lambda / 2$ e a defasagem que estas componentes sofrerão ao passar pelo segundo bastão serão invertidas com relação ao que ocorreu no primeiro bastão, de modo que o feixe emerge do segundo bastão sem defasagem entre as componentes radial e tangencial, e sem a componente na polarização perpendicular à direção de polarização do feixe e consequentemente eliminando a perda por despolarização para os feixes que incidem nestas regiões do bastão. 


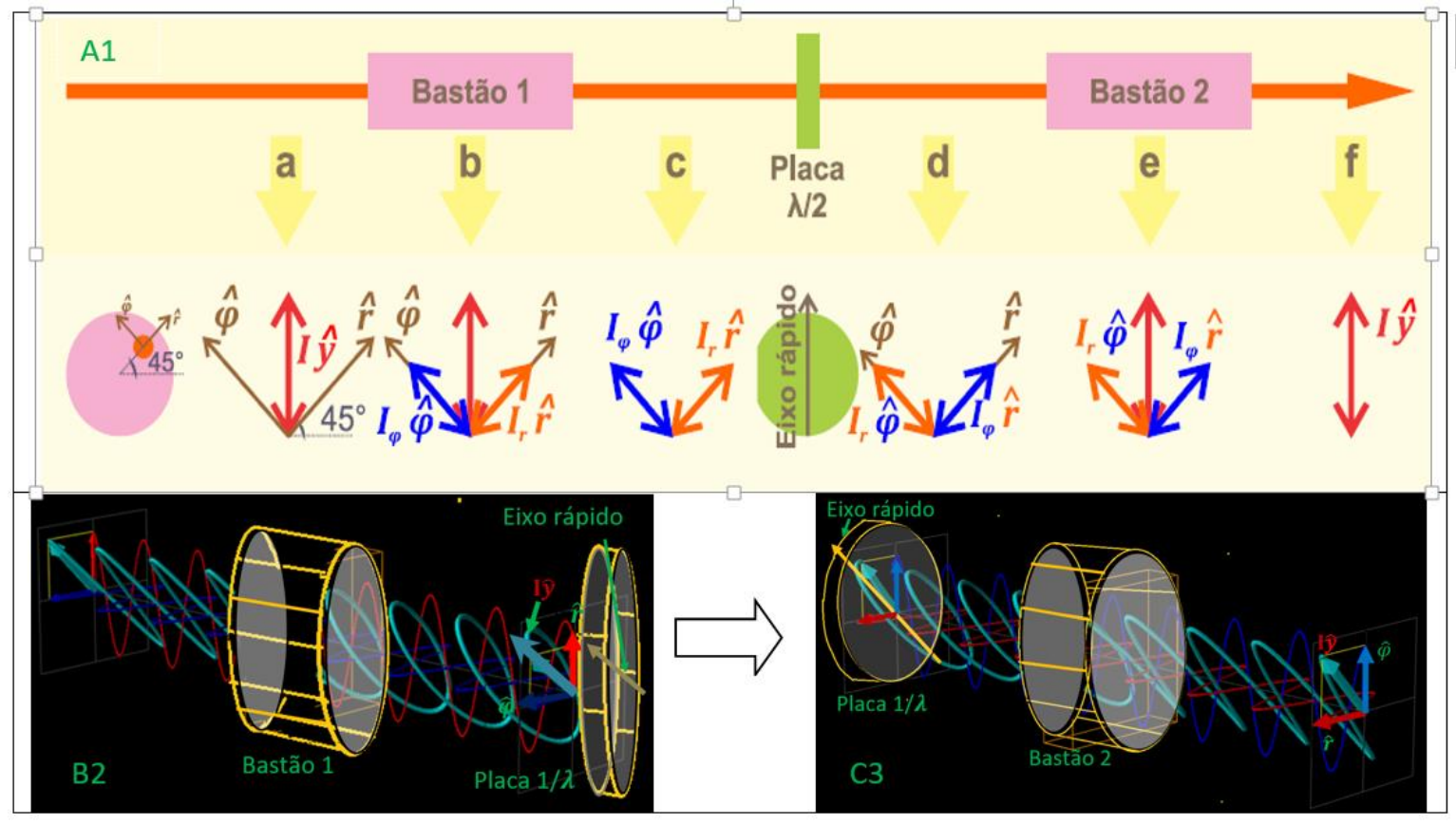

Figura 4: Esquema de compensação da birrefringência com placa de $\lambda / 2$ entre dois bastões. No quadro $\mathrm{A} 1$ é mostrado uma perspectiva $2 \mathrm{D}$, nos quadros $\mathrm{B} 2$ e $\mathrm{C} 3$ são mostrados em perspectivas 3D. No quadro B2 a onda entra linearmente polarizada no bastão 1 onde sofre índices de refração diferentes nas componentes radial e tangencial. Após o bastão 1 a onda é elipticamente polarizada. No quadro C3 é mostrado primeiramente a inversão do atraso de onda da componente radial pela componente tangencial após a passar pela placa de $\lambda / 2$. Como a onda sofre no segundo bastão o mesmo atraso relativo entre radial e tangencial como no primeiro bastão, a birrefringência é compensada e a onda emerge linearmente polarizada do segundo bastão.

\subsection{Modos TEM}

As soluções para o campo eletromagnético propagando-se dentro de um ressonador laser admitem a existência de diferentes modos, tanto longitudinais quanto transversais em relação à direção de propagação. Os modos longitudinais diferem quanto às frequências, enquanto os modos transversais diferem também pela distribuição espacial do campo eletromagnético na direção perpendicular à propagação. A distribuição do campo elétrico na direção transversal pode ser escrita em coordenadas cartesianas designada por $\mathrm{TEM}_{\mathrm{mn}}$, utilizados quando as condições de contorno tem simetria cartesianas, com os inteiros $\mathrm{m}$ e $\mathrm{n}$ representado o número de nós nas direções horizontais e vertical de intensidade zero transversais ao eixo de propagação $T E M_{p l}$ em coordenadas cilíndricas, utilizados quando as condições tem simetrias cilíndricas. O perfil de intensidade é descrito por um produto de dois polinômios de Hermite de ordem $\mathrm{m}$ 
e $\mathrm{n}$ funções gaussianas para retangulares, e para coordenadas cilíndricas é representado por polinômio de Laguerre.

Em coordenas cilíndricas os modos são designados por $\mathrm{TEM}_{\mathrm{pl}}$ em que p e I são as ordens e índices dos polinômios de Laguerre e correspondem aos nós de intensidade nas direções radial e angular. O modo de menor ordem é $\mathrm{TEM}_{00}$ que tem um perfil de intensidade gaussiano com um máximo no eixo do laser. Os modos transversais são responsáveis pelas características de propagação do feixe como divergência, diâmetro e distribuição de energia no feixe [23]. A representação dos modos laser transversais eletromagnéticos em coordenadas cilíndricas (esquerda) e cartesianas (direita) é mostrado na FIG. 5.

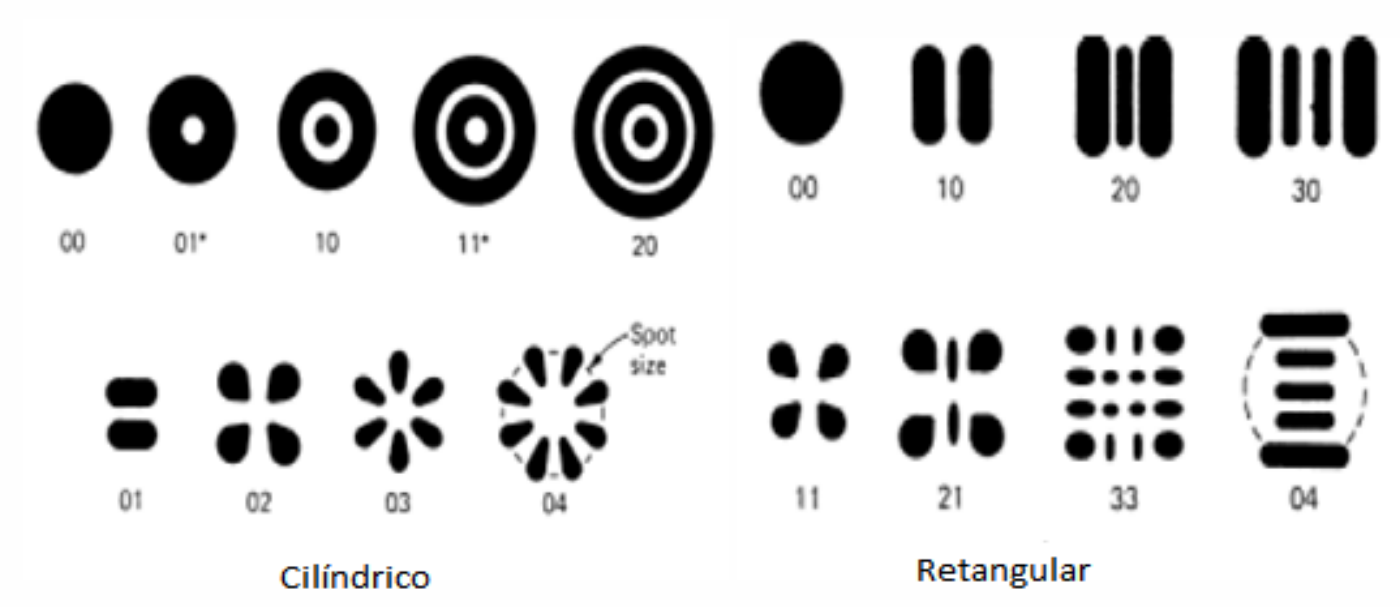

Figura 5: Representação dos modos laser transversais eletromagnéticos em coordenadas cilíndricas (esquerda) e cartesianas (direita). Imagem extraída de Koechner [23].

\subsection{Fator de qualidade do feixe}

O modo transversal eletromagnético fundamental de um oscilador óptico, denominado $\mathrm{TEM}_{00}$, é o mais próximo à noção de raio da óptica geométrica que a natureza permite, devido à natureza ondulatória da luz e à difração, sendo também chamado de feixe limitado pela difração. Define-se o termo spot size ou cintura do feixe $w$ para o raio em que a intensidade do feixe decai de $1 / \mathrm{e}^{2}$. Para feixe $\mathrm{TEM}_{00}$ a spot size pode ser dada por:

$$
w(Z)^{2}=w_{0}^{2}\left[1+\left(Z / z_{R}\right)^{2}\right],
$$

onde $Z_{R}$ é parâmetro de Rayleigh, definido por:

$$
Z_{R}=\frac{\pi w_{0}^{2}}{\lambda}
$$


sendo $w_{0}$ a cintura mínima do feixe na posição $\mathrm{z}=0$, como visto na FIG. 6. O ângulo de divergência no campo distante á dado por [17]:

$$
\Theta=\frac{2 \lambda}{\pi w_{0}},
$$

considerando feixes de modos transversais de ordens altas, define-se o fator $\mathrm{M}$ tal que o ângulo de difração e o diâmetro sejam $M$ vezes maiores que o feixe ideal:

$$
\begin{gathered}
\Theta=M \theta_{0}, \\
\mathrm{D}=M D_{0},
\end{gathered}
$$

onde $\theta_{0}$ e $D_{0}$ são o ângulo de divergência e o diâmetro do feixe ideal (TEM $\left.\mathrm{M}_{00}\right)$. Não é suficiente caracterizar o feixe laser só pela divergência ou diâmetro, pois este pode ser reduzido com um telescópio. A propriedade que não pode ser corrigida é o brilho [17]. O teorema do brilho diz que o produto do ângulo de divergência no campo distante pelo diâmetro é constante:

$$
\Theta D=M^{2} \theta_{0} D_{0}
$$

Onde $\Theta D$ é o produto de parâmetros do feixe (bpp- beam parameter product) dado em mm.rad e $\theta_{0} D_{0}=\frac{4 \lambda}{\pi}$ é o bpp do feixe limitado pela difração, e $M^{2}$ é um parâmetro adimensional. Um laser operando no $\mathrm{TEM}_{00}$ é caracterizado por $M^{2}=1$. O valor de $M^{2}$ expressa quantas vezes o bpp de um feixe real é o bpp de um feixe limitado pela difração. Na FIG 5 é mostrado um feixe real em comparação com um feixe gaussiano ideal [17].

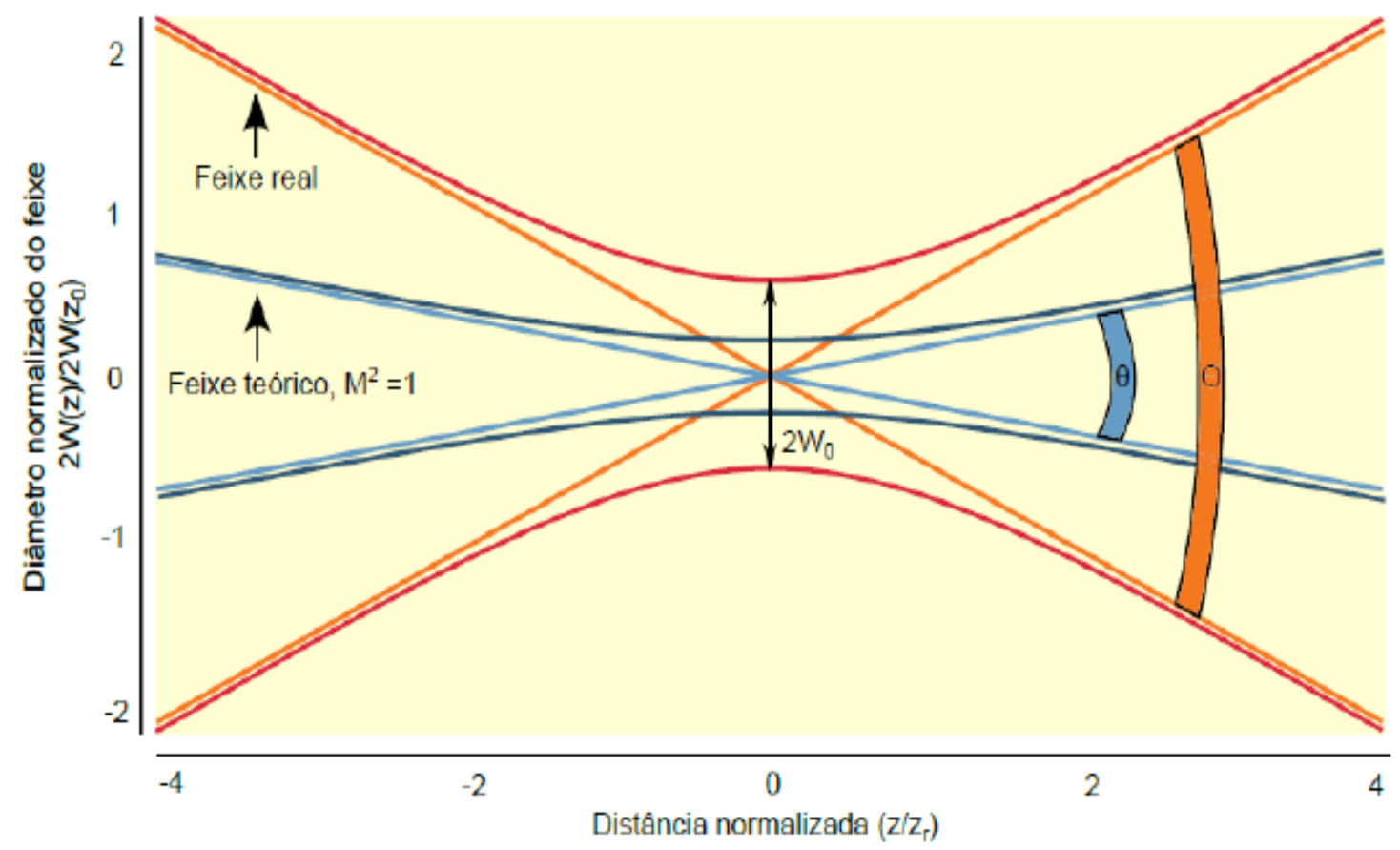

Figura 6: Comparação de um feixe teórico e de um feixe real. 
Embora um laser possa emitir um feixe de boa qualidade, elementos ópticos utilizados (espelhos, divisores de feixe, etc.), ou os compósitos nas superfícies deles podem gerar perturbações na frente de onda do feixe. Nesse caso, além do modo fundamental TEM 00 modos de ordem superior podem estar presentes. A técnica predominante utilizada para análise de propagação de feixes laser é a medição do parâmetro de "qualidade de feixe" $\mathrm{M}^{2}$. Tal técnica baseia-se em medidas da evolução longitudinal do segundo momento do perfil de intensidade do feixe [30].

\subsection{Ressonadores dinamicamente estáveis (DSR-Dynamically Stable}

\section{Resonators)}

Lasers operando no modo fundamental $\mathrm{TEM}_{00}$, usualmente requerem o uso de aberturas espaciais no ressonador laser, como uma fenda ou íris, para evitar oscilações dos modos de ordens mais altas. Nesse caso, devido ao pequeno volume de material ativo envolvido na ação laser, a eficiência de saída do laser geralmente acaba sendo baixa. Um maior diâmetro de modo TEM 00 pode ser obtido usando configurações espaciais de ressonador, no qual a não aplicação de critérios adequados ao design do ressonador, tornará o mesmo muito sensível à flutuação do comprimento focal das lentes térmicas e a perturbações de alinhamento dos espelhos [31].

O desenho e procedimentos devem permitir a construção de equipamentos com estabilidade mecânica necessária a ser atingida para ressonadores conhecidos como dinamicamente estáveis sobre uma grande faixa de potências, com flutuação de módulo e volume de bastão laser mantido sobre controle apropriado, e que apresentem reduzida variação da cintura do feixe laser no bastão, com pequena flutuação da potência de saída em função de variação do comprimento focal da lente térmica [23,32].

O bastão laser é considerado como uma lente espessa de distância focal descrita na equação (1), na qual a distância $h$ das extremidades focais com valor $h=l / 2 n_{0}$ onde $n_{0}$ é o índice de refração do material. São mostradas na FIG. 7 (b) as simplificações assumidas na modelagem utilizada para os ressonadores dinamicamente estáveis em que se considera o comprimento total (L) do ressonador diminuído pelo tamanho da parte central do bastão compreendida 
entre seus planos principais, com comprimento correspondente a $l \cdot\left(1-1 / n_{0}\right)$. Descrito em [32].

(a)

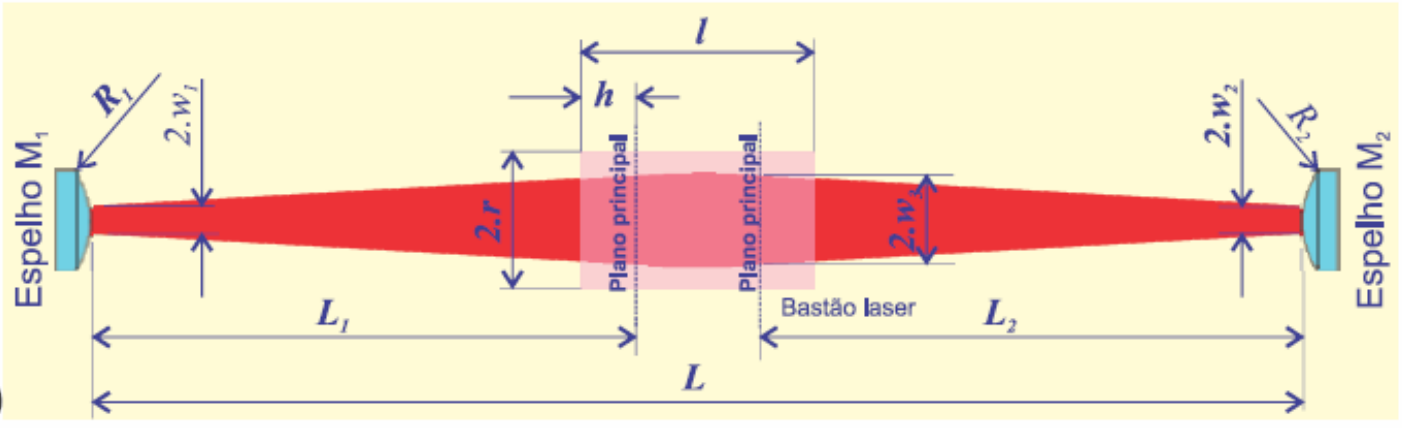

(b)

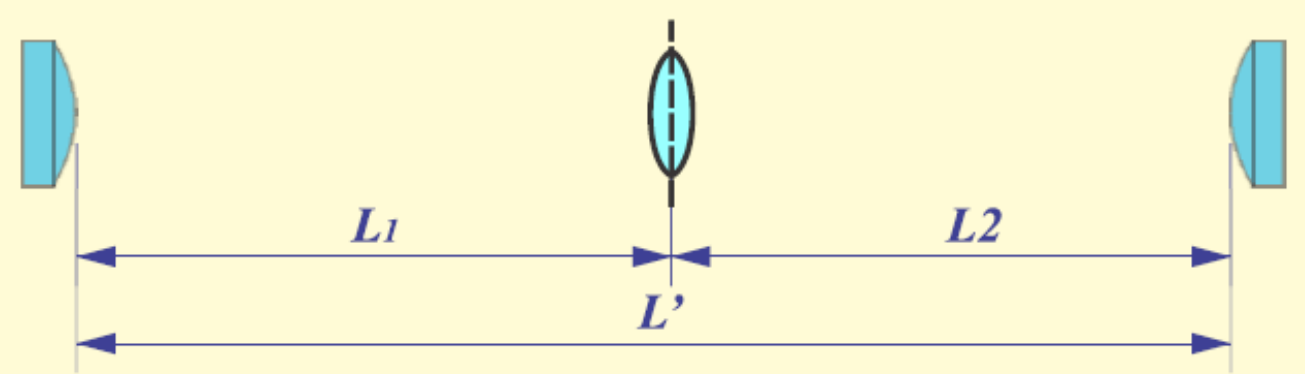

Figura 7: (a) Definições utilizadas para o estudo dos ressonadores: $R_{1} R_{2}$ : raios dos espelhos $L_{1}$ e $\mathrm{L}_{2}$ : distancias dos planos principais do cristal, $w_{1}$ e $w_{2}$ raios do feixe laser nos espelhos e $w_{3}$ nos planos principais do cristal e (b) simplificação adotada na modelagem utilizada no estudo dos ressonadores dinamicamente estáveis (DSR-Dynamically Stable Resonators).

Para construirmos um ressonador estável, a radiação deve ser confinada dentro do mesmo, após inúmeros passes. Utilizando o formalismo de matrizes ABCD [33], é possível escrever a matriz para uma viagem de ida e volta. O teorema de Sylvester diz que se os elementos da matriz não divergirem quando ela for elevada à enésima potência com $n$ tendendo ao infinito, se chegará à condição de estabilidade [34] para um ressonador simplificado mostrado na FIG. 7.

$$
-1 \leq \frac{A+D}{2} \leq 1
$$

Onde $A$ e $D$ são os elementos da matriz ABCD. Esta condição pode ser escrita em função de parâmetros geométricos g1.g2 para cada espelho. Para ressonadores lineares:

$$
0 \leq g_{1} \cdot g_{2} \leq-1
$$

onde, para o ressonador simplificado da FIG. 7b com $f$ distância focal da lente térmica,

$$
g_{i}=1-\frac{L_{(3-i)}}{f}-\frac{L^{\prime}}{R_{i}}, i=1,2
$$


Essa condição de estabilidade pode ser representada num gráfico como exemplificado na FIG. 8 onde apenas os ressonadores compreendidos entre os eixos $\mathrm{g} 1=0$ ou g2 = 0 e a hipérbole g1.g2=1 são estáveis.

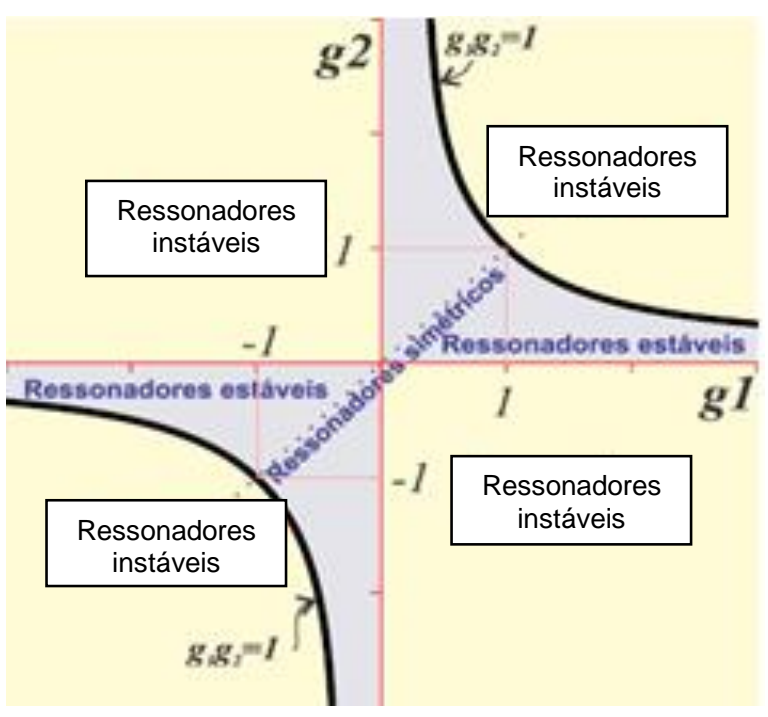

Figura 8: Zonas de estabilidades em função dos parâmetros geométricos.

Considerando-se um ressonador com um bastão de distância focal variável e os demais parâmetros fixos, o diagrama de estabilidade é percorrido por uma linha reta como mostrado na FIG. 9.a. É mostrado na FIG.9b o valor do raio do feixe ressonante no plano do bastão, $w_{3}$, à medida que se aumenta 0 poder dióptrico do bastão como resultado do aumento da potência dióptrica. O DSR sempre tem duas zonas de estabilidade de mesma largura dentro dos quais o raio do feixe laser TEM $\mathrm{T}_{00}$ no bastão $w_{3}$ sempre tem um valor mínimo $w_{30}$ que é insensível a flutuações no comprimento focal da lente térmica e uma relação com a largura das zonas de estabilidade pode ser utilizada para predizer seu tamanho [10]:

$$
w_{30}^{2}=\frac{2 \lambda}{\pi} \frac{1}{\left[{ }^{11 / f}\right]}
$$

Onde $f$ é o comprimento da lente térmica e $\lambda$ o comprimento de onda. Com a potência de saída do laser sendo aproximadamente proporcional ao volume do material envolvido na ação laser e ao valor de $w_{3}{ }^{2}$, de modo que ao se buscar obter maiores potências, desejam-se maiores valores de $w_{3}$. A cintura estacionária $w_{30}$ também implica em uma potência de saída estável e insensível a mudanças de comprimento focal da lente térmica, onde $\left(d w_{30}\right) / d(1 / f)=0$, ou seja, o valor da cintura não varia com a distância focal e consequentemente com a corrente neste ponto. $\mathrm{O}$ valor de $w_{30}$ em operações no modo $\mathrm{TEM}_{00}$ deve ser grande o suficiente para evitar que modos de ordem mais alta sejam estáveis. Estando disposto a trabalhar com uma zona de estabilidade suficientemente pequena é possível obter qualquer valor de raio do feixe no bastão segundo a relação (11). No entanto a birrefringência impõe um limite ao máximo valor da 
cintura laser estacionária no bastão, pois os valores encontrados na literatura de $\mathrm{f}_{\varphi} / \mathrm{f}_{\mathrm{r}}$ são de aproximadamente 1,2 [33], o que implica na menor largura da zona de estabilidade dada por:

$$
\Delta 1 / f \approx 0,181 . f
$$

onde o valor máximo de $w_{30}$ capaz de acomodar ambas as polarizações tangencial e radial dentro da zona de estabilidade é dado por:

$$
w_{30}^{2} \approx 3,5 . \lambda . f
$$

Para ressonadores em anel, Silvestri et al [34] demonstrou que sempre existe uma única zona de estabilidade e que o valor de $w_{30}^{2}$ é o dobro do valor dado pela eq. 8, implicando no máximo valor de w30 dado por:

$$
w_{30}^{2} \approx 7 . \lambda . f
$$

Para ressonadores em anel Silvestri et al [34] demonstrou que a cintura do feixe no bastão é definida por:

$$
w_{4}^{2} \text { anel }=(2 \lambda \backslash \pi)^{2} \frac{B^{2}}{4-(A+D-B / f)^{2}}
$$

Onde apresenta sempre um único intervalo de estabilidade cuja cintura estacionaria no bastão é o dobro da cintura para laser com onda estacionaria:

$$
w_{30}^{2} \text { anel }=(4 \lambda \backslash \pi)[\Delta(1 / f)]^{-1}
$$

Onde $A, B$ e $D$ são os elementos da matriz $A B C D$ que representam todos os componentes do ressonador que estão após a lente térmica do ressonador, ou seja, para uma viajem de ida do feixe no ressonador em anel, começando em um plano inicial, passando primeiro pela lente térmica do bastão e em seguida por todos os demais elementos do ressonador chegando novamente ao plano inicial. $O$ valor máximo da cintura $w_{30}$ no bastão em cristais de Nd:YAG que pode ser atingido é de $1,1 \mathrm{~mm}$ para ressonadores lineares [5], devido à birrefringência induzida a despeito do tamanho do bastão laser, limitando-se a potência de saída para a operação no modo $\mathrm{TEM}_{00}$ apesar de atuais técnicas de crescimento de cristal permitirem a obtenção de bastões de Nd:YAG com grandes diâmetros [35]. O valor de distância focal da lente térmica na potência máxima do conjunto de 2 módulos é de $12,5 \mathrm{~cm}$, usando a eq. 13 e eq. 14 temos $w_{3 \max }=682$ $\mu \mathrm{m}$ e $w_{3 \max }=964 \mu \mathrm{m}$, o que nos dá um valor da razão entre o raio do bastão $(1,5$ $\mathrm{mm}$ ) e do feixe no bastão de 2,19 e 1,5. Valores recomendados pela literatura são de 1,2 a 2 para operação no modo fundamental. 
(a)

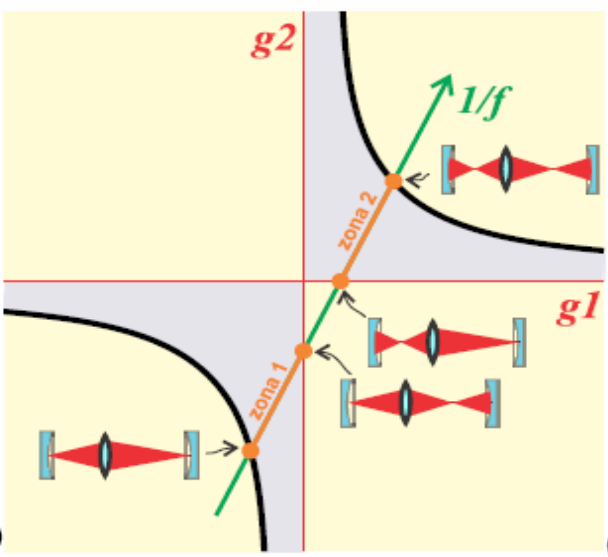

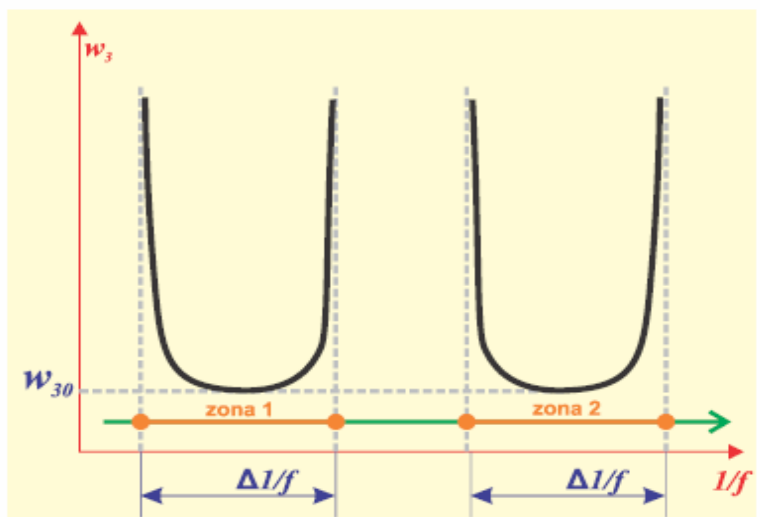

(b)

Figura 9: (a) exemplo de linha percorrida por um ressonador no diagrama de estabilidade ao se variar a dioptria da lente térmica ilustrando as configurações do ressonador nos limites de estabilidade e (b) cintura do laser no bastão ao se percorrer esta linha.

\subsection{Interferômetro Fabry-Perot}

\subsubsection{Utilização do etalon}

Como faz parte dos objetivos desse projeto a operação em frequência única, será necessário o uso de um interferômetro Fabry-Pérot. Um exemplo conhecido é o etalon que geralmente é feito de uma placa transparente com duas superfícies ou dois espelhos altamente refletores paralelos. O etalon é amplamente usado em telecomunicações, lasers e espectroscopia para controlar e medir os comprimentos de onda de luz. Desenvolvimentos recentes na técnica de fabricação permitem a criação de interferômetros Fabry-Pérot muito precisos [36]. Os ressonadores laser apresentam frequências de ressonância em torno da frequência principal, essas frequências correspondem às soluções da equação com a condição de contorno que permitem nós no plano dos espelhos. A largura da linha laser definirá quais modos serão amplificados. A inserção do etalon na cavidade laser permitirá a redução dos modos longitudinais do laser com redução da largura de linha.

O Interferômetro Fabry-Perot é baseado em reflexões múltiplas entre duas superfícies planas e paralelas, o dispositivo é usado para controle de modo longitudinal e como instrumento para medir largura da linha. Consideraremos uma versão particularmente simples do interferômetro Fabry-Perot, que consiste em uma placa sólida com superfícies planas e paralelas ilustrado na FIG.10. 


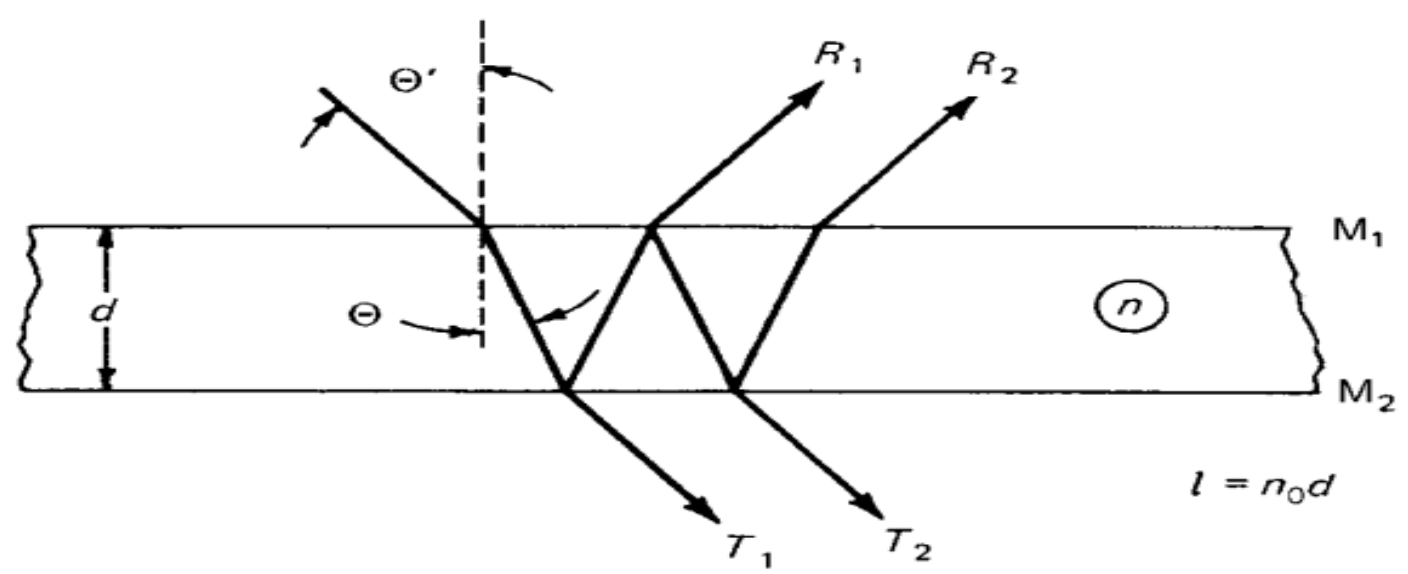

Figura 10: Interferência de uma onda plana em uma placa paralela [17].

As reflexões múltiplas que ocorrem entre as superfícies refletoras M1 e M2 causam componentes individuais. Se todas as componentes que deixam M2 somarem em fase ocorre interferência construtiva em M2, já para as componentes refletidas de M1 interferem destrutivamente e a energia incidente é transmitida pelo etalon. Para cada conjunto de onda transmitido, a fase da função de onda difere o dobro do percurso. Essa diferença é dada por:

$$
\varphi=\left(\frac{2 \pi}{\lambda}\right) 2 n_{0} d \cos \Theta
$$

onde $n_{0} d$ é a espessura óptica entre as duas superfícies refletoras, $\Theta=$ $\Theta^{\prime} / n_{0}$ é o ângulo do feixe no material, e $\lambda$ é o comprimento de onda. $\mathrm{A}$ transmissão do ressonador de Fabry-Perot é definida por [17]:

$$
T=\left[1+\frac{2 R^{\prime}}{\left(1-R^{\prime}\right)^{2}} \operatorname{sen}^{2}\left(\frac{\varphi}{2}\right)\right],^{-1}
$$

O $R^{\prime}$ é a refletividade de cada uma das duas superfícies. O valor máximo da transmissão, $T_{\max }=1$, ocorre quando as diferenças do comprimento do caminho entre os feixes transmitidos são números múltiplos do comprimento de onda.

$$
2 n_{0} d \cos \Theta=m \lambda, \quad m=1,2,3 \ldots
$$

A refletividade do ressonador pode ser expressa por [17]:

$$
R=\left(1+\frac{\left(1-R^{\prime}\right)^{2}}{4 \operatorname{Rsen}^{2}(\varphi / 2)}\right)^{-1}
$$


o valor máximo da refletividade é definido por:

$$
R_{\max }=\frac{4 R^{\prime}}{\left(1+R^{\prime}\right)^{2}}
$$

que é obtido quando a diferença de comprimento de caminho do feixe de luz é igual a múltiplos de meia onda.

$$
2 n_{0} d \cos \Theta=\frac{m \lambda}{2}, \quad m=1,3,5 \ldots
$$

A FIG. 11 ilustra as propriedades de transmissão e reflexão do etalon. $\mathrm{Na}$ ausência de perdas de absorção, transmissão e a reflexão de um etalon são complementares no sentido que $R+T=1$. A finesse é a razão entre o FSR e o FWHM defina por:

$$
F=\pi\left[2 \operatorname{arcsen}\left(\frac{2+4 R^{\prime}}{\left(1-R^{\prime}\right)^{2}}\right)^{-1 / 2}\right]^{-1} \approx \frac{\pi\left(R^{\prime}\right)^{1 / 2}}{\left(1-R^{\prime}\right)}
$$

e a resolução do etalon é dada por:

$$
\delta v=\mathrm{c} / 2 \mathrm{LF}
$$

Pode ser usada a aproximação $R^{\prime}>0.5$ para pequenos valores de $R^{\prime}$ e finesse de valor próximo de $F \approx 2$ e a eq. 18 é reduzido para:

$$
R=R_{\max } \operatorname{sen}^{2}(\varphi / 2)
$$

Vimos na eq. 22 que a condição de ressonância do etalon depende do comprimento de onda $\lambda$ e espessura ótica da por nd e ângulo do feixe $\Theta$.

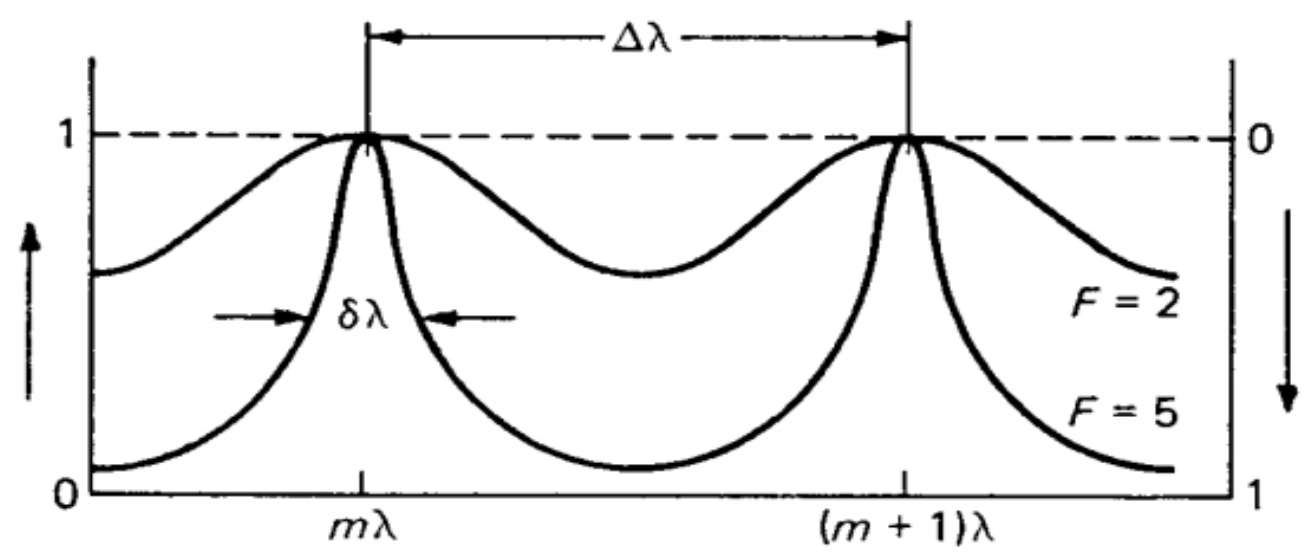

Figura 11: intensidade dos feixes refletidos e transmitidos em função da diferença de fase [17]. 
A faixa espectral livre (FSR) é dada por:

$$
\Delta \lambda=\frac{\lambda_{0}^{2}}{2 n_{0} d \cos \Theta} \quad \text { ou } \quad \Delta v=\frac{C}{2 n_{0} d \cos \Theta}
$$

\subsection{Frequência Única}

\subsubsection{Modos longitudinais de um ressonador laser}

A saída espectral de um laser é determinada pela largura de banda de ganho do material ativo e as propriedades do ressonador, onde existem modos longitudinais, que são soluções para o ressonador. Normalmente, dentro da largura espectral de fluorescência do material laser, há muitos picos dos modos longitudinais. De acordo com a eq. 26 podemos determinar a separação dos modos longitudinais em cavidade laser de comprimento $L$.

$$
\Delta v=\frac{C}{2 L} \quad \text { ou } \quad \Delta \lambda=\frac{\lambda_{0}^{2}}{2 L}
$$

No caso do etalon é usada a eq. 18 onde n é o índice de refração do etalon e $\Delta v$ a separação dos modos longitudinais do Nd:YAG. Usando a eq. 26 é possível determinar a distância, L, entre as duas lâminas do interferômetro.

$$
\Delta v=\mathrm{C} / 2 \mathrm{Ln},
$$

Para um ressonador de comprimento $L=50 \mathrm{~cm}$, os modos longitudinais adjacentes são separados por $v=300 \mathrm{MHz}$. Por exemplo, os lasers de $\mathrm{Nd}$ :YAG possuem uma largura de linha de fluorescência de $120 \mathrm{GHz}$. Dependendo do limiar do laser e da intensidade de bombeio o ressonador pode ter, por exemplo uma banda de ganho da ordem de $12 \mathrm{GHz}$. Assim, cerca de 40 modos longitudinais podem oscilar dentro do ressonador descrito acima.

Se a reflexão das suas superfícies for diferente, assim como em uma cavidade laser, a refletividade $R^{\prime}$ na eq. 23 será a média geométrica dos dois espelhos $R^{\prime}=\left(R_{1} R_{2}\right)^{1 / 2}$. Usando valores típicos para uma cavidade laser de $R_{1}=0.8$ e $R_{2}=1.0$ e substituído esses números na eq. 23 e eq. 24 temos $\mathrm{F}=26.5$ e $\delta v=11.3 \mathrm{MHz}$ para finesse e faixa espectral livre do ressonador, como mostrado pela FIG. 12. 


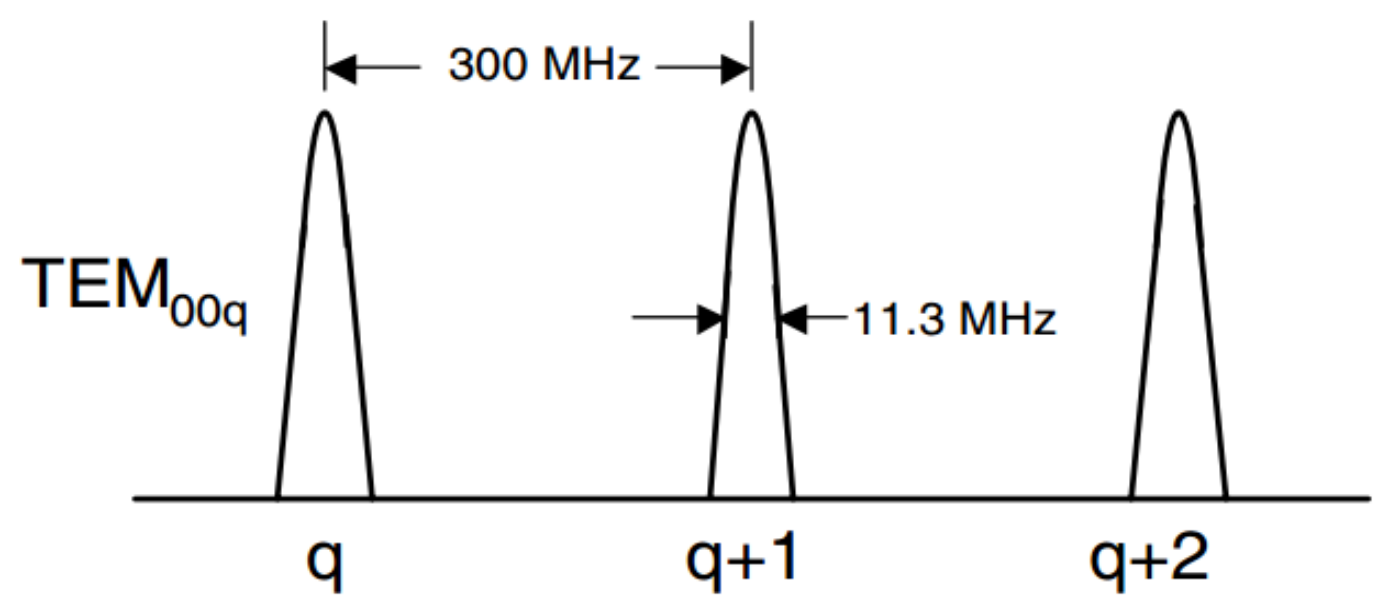

Figura 12: Modos longitudinais em um ressonador composto por espelhos separados por $50 \mathrm{~cm}$ de refletividade de $80 \%$ e $100 \%$ [17].

$\mathrm{Na}$ presença de vários modos transversais TEM ocorrem frequências adicionais de ressonância na cavidade laser. A frequência de separação de $T E M_{p l q}$ de diferentes modos transversais dentro de um ressonador é dada por [17]:

$$
\Delta v=\left(\frac{C}{2 L}\right)\left[\Delta q+\left(\frac{1}{\pi}\right) \Delta(2 p+l) \arccos \left(1-\frac{L}{R}\right)\right]
$$

onde $L$ é o comprimento do ressonador e $R$ o raio de curvatura para ambos espelhos, o termo à direita $\Delta q$ dá o intervalo de frequência dos modos axiais e o termo $\Delta(2 p+l)$ descreve a separação das frequências de ressonância de diferentes modos transversais $T E M_{p l}$. Observe que a frequência de ressonância depende de $(2 p+l)$, e não de $\mathrm{p}$ e $l$ separadamente, portanto, a frequência de degeneração surge quando $\Delta(2 p+l)$ é equivalente para diferentes modos. Ao substituir $\Delta(2 p+l)$ por $(\mathrm{m}+\mathrm{n})$, as frequências da cavidade para modos transversais são obtidas em coordenadas cartesianas. Da eq. 28 segue-se que a frequência de separação entre os modos transversais não é apenas uma função de separação dos espelhos, como é no caso dos modos longitudinais, mas depende também da curvatura dos espelhos. Para um ressonador plano paralelo curto ou de raio de curvatura longo $(L<<R)$, o segundo termo dentro dos parâmetros da eq. 28 torna-se pequeno em comparação com $\Delta q$. Neste caso, o espectro do modo ressonante pelo espaçamento do modo axial é relativamente grande com tamanho de $\mathrm{c} / 2 \mathrm{~L}$, com cada modo axial envolvido por um conjunto de 
ressonâncias de modos transversal, como mostra a FIG. 13. Por exemplo, se o ressonador de $50 \mathrm{~cm}$ de comprimento mencionado anteriormente, tiver dois espelhos com curvaturas de $5 \mathrm{~m}$, terá espectro de ressonância de $v / \mathrm{MHz}=300 \mathrm{q}$ $+43(2 \mathrm{p}+l)$. Por causa dessas ressonâncias adicionais ocorrem frequências com modos transversais de ordem superior.

A técnica para reduzir a saída espectral de um laser requer necessariamente operação no modo $T E M_{00}$. Se um laser estiver operando sem nenhum elemento seletor de modos no ressonador, então, a saída espectral consistirá em um grande número de frequências discretas determinadas pelos modos transversais e axiais. A largura de linha da transição do laser limita o número de modos que têm ganho suficiente para oscilar. A frequência de ressonância de um ressonador óptico e a linha de fluorescência do material ativo são demonstradas por um diagrama na FIG. 14. A emissão laser ocorre nos comprimento de onda em que o produto do ganho da transição laser e a refletividade dos espelhos excedem a unidade.
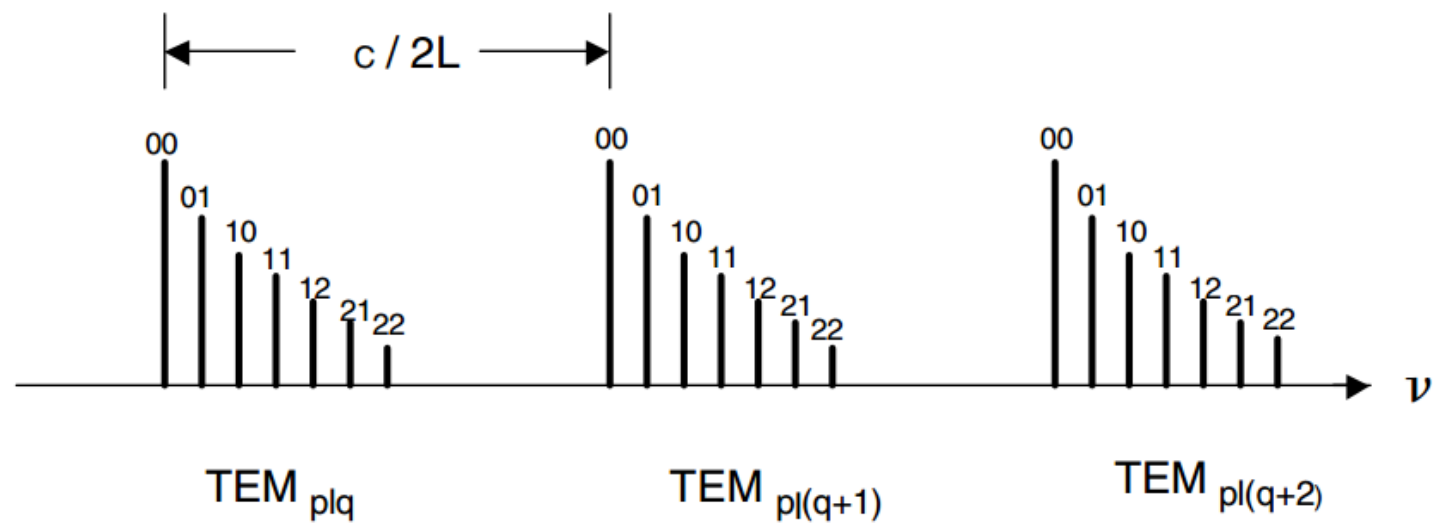

Figura 13: Frequência de ressonância de um ressonador contendo transição transversal de modos de ordem superior [17]. 

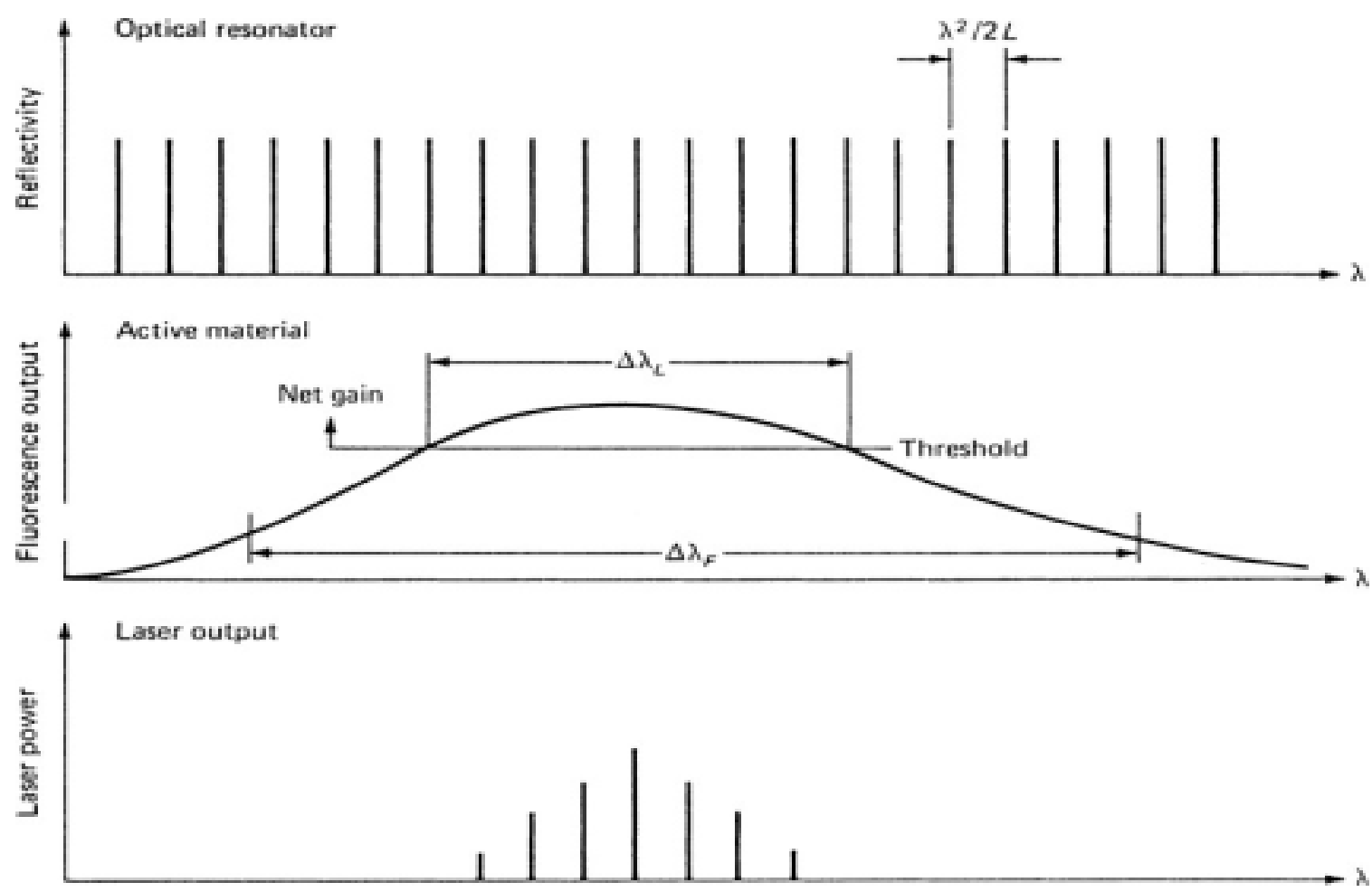

Figura 14: llustração dos modos longitudinais do ressonador (topo) largura de linha de florescência (centro) e modos estáveis em um ressonador laser [17].

No exemplo mostrado, o laser oscilava em sete modos axiais. O feixe emitido a partir de um laser, que emite um número discreto de comprimento de onda relacionado é fortemente modulado. A situação pode ser ilustrada no caso mais simples de duas ondas que viajam sobrepostas, cujo comprimento de onda é especificado pelos modos axiais adjacentes [15,17]. Essa situação é mostrada na FIG. 15.

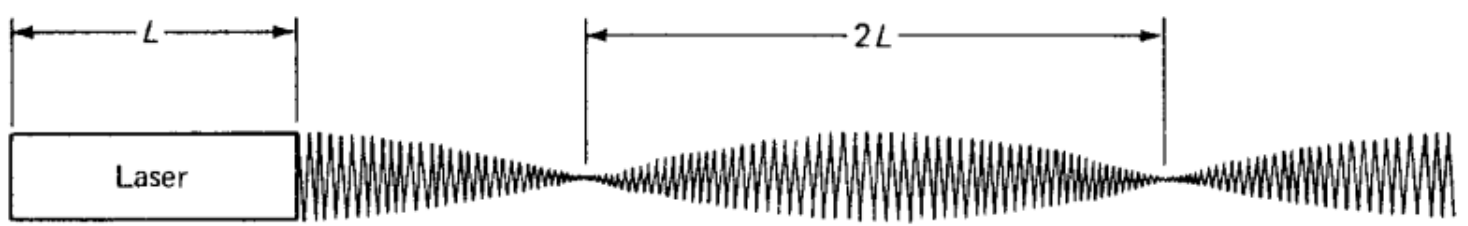

Figura 15: Modelação de amplitude de um laser raio laser devido á emissão dois modos longitudinais adjacentes [17]. 


\subsubsection{Controle dos modos longitudinais}

Para uso nos ressonadores laser, o etalon é inserido com pequeno ângulo fazendo com que nenhuma outra ressonância seja formada com outras superfícies no ressonador principal. Se o etalon estiver desalinhado funcionará simplesmente como um filtro de transmissão não tendo perda de reflexão para frequências correspondentes ao seu máximo de transmissão. Os máximos de transmissão podem ser sintonizados na região central do ganho de curva alterando o ângulo de inclinação. Os picos de transmissão de um etalon com índice de refração $n=1,5$ e espessura $d=1 \mathrm{~cm}$ são separados por $10 \mathrm{GHz}$ de acordo com eq. 24. Se por exemplo o etalon tem uma finesse $\mathrm{F}=10$, a largura espectral é de $1 \mathrm{GHz}$, o que é consideravelmente mais estreito do que a banda de ganho de $12 \mathrm{GHz}$ de um laser Nd:YAG típico. A saída do laser será composta por modos longitudinais, que se enquadram na faixa de transmissão do etalon, portanto, um estreitamento da largura de linha do laser é observado. Embora as técnicas mencionadas reduzam a largura de linha de um laser, só é possível obter a saída do laser composta por modos longitudinais em ressonador muito curto, portanto, os modos axiais são espaçados suficientemente distantes para o controle do modo axial. A configuração do laser em anel evita o efeito chamando hole burning $[37,38]$.

\subsubsection{Efeito" hole burning" espacial}

O efeito de "hole burning" espacial decorre da existência de saturação de ganho no meio ativo do laser geradas pela periodicidade dos nós da onda estacionária do campo elétrico, que é nulo na região dos ventres [39]. Deste modo o ganho de um modo com frequência levemente diferente é muito maior, exatamente por possuir maior sobreposição das regiões de maior intensidade com as regiões não saturadas do meio ativo. Como resultado há um alargamento espacial do laser ao ganho obtido para este comprimento de onda ligeiramente diferentes do comprimento central [40,41]. O efeito é ilustrado na FIG. 16. 


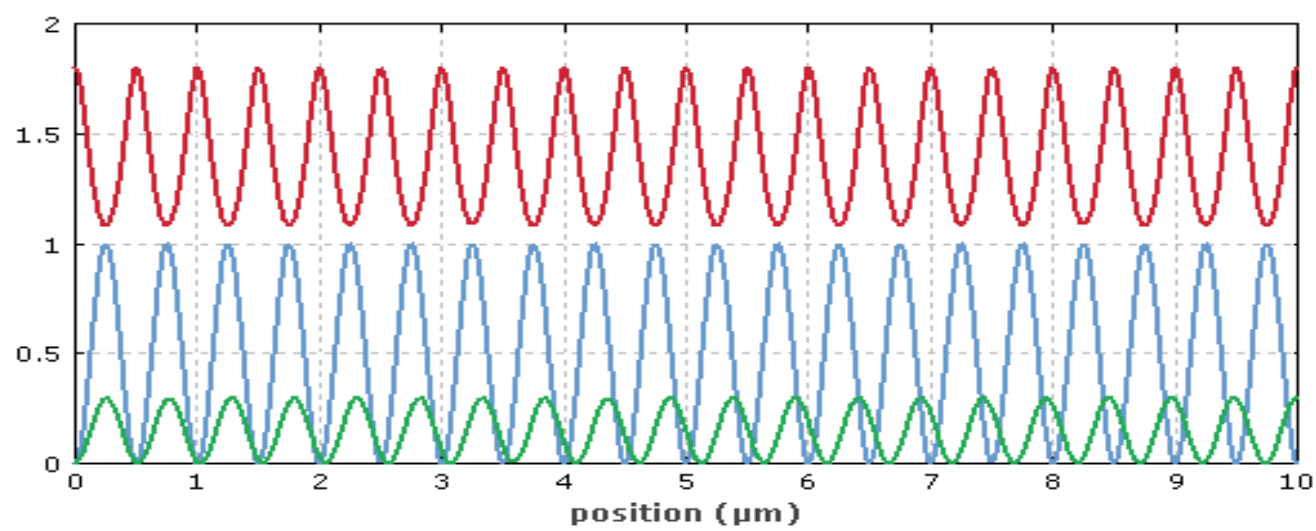

Figura 16: llustração do efeito "hole burning" espacial em um cristal laser. Um feixe intenso com padrão de onda estacionaria (linha azul) satura o ganho (linha vermelha). Este ganho é muito menor que o ganho da linha verde, que corresponde ao feixe menos intenso que tem comprimento de onda ligeiramente diferente (https://www.rp-photonics.com/spatial_hole_burning.html).

Para a obtenção de um laser com frequência única é necessário que o ressonador seja em anel, pois terá uma onda viajante sendo possível eliminar o efeito hole burning e que o comprimento do ressonador seja curto para diminuir o número de modos oscilantes.

\subsubsection{Rotacionador de Faraday}

Rotacionadores de Faraday (FIG. 17) são usados como isoladores óticos em experimentos com laser, onde os mesmos permitem a passagem de luz somente em um sentido devido a interação entre à luz e um campo magnético interno do material dielétrico [42]. O efeito Faraday é resultado da ressonância ferromagnética. Esta ressonância faz com que as ondas sejam decompostas em dois raios polarizados circularmente e se propaguem com diferentes velocidades, sendo essa propriedade conhecida como birrefringência circular [43]. Os raios podem ser recombinados após o surgimento do meio. No entanto, devido à diferença de velocidade de propagação, eles estarão com um deslocamento de fase, resultando em uma rotação do ângulo de polarização linear. O TGG é um cristal de granada de térbio-gálio (Tb3Ga5O12) com uma alta constante ótica chamada de constante de Verdet, que resulta no efeito de Faraday que é um efeito cromático (isto é, depende do comprimento de onda). Com laser de comprimento de onda de $632 \mathrm{~nm}$ a constante tem o valor de -134 rad.(T.m)-1, e para comprimento de onda de $1064 \mathrm{~nm}$ cai para -40 rad.(T.m)-1. Na eq. 30 é mostrada a relação entre o ângulo de rotação da polarização $\Phi$ e 0 campo 
magnético $B$ em um material diamagnético. Onde $V$ é a constante de Verdet, $\mathrm{d} o$ comprimento do cristal e B o campo magnético [10].

$$
\Phi=\mathrm{VdB}
$$

Isoladores ópticos podem ser encontrados no mercado, existindo diversos fornecedores. Na FIG. 18 é mostrado como exemplo o isolador modelo IO-5-1064-VHP produzido pela Thorlabs. Um dos objetivos desse trabalho é o desenvolvimento de um laser frequência única, sendo necessário o uso de um isolador óptico intracavidade. Optou-se pela produção do dispositivo, usando um cristal TGG [44], imã de neodímio por ter uma grande densidade de campo magnético e uma caixa de alumínio usinada devido à necessidade de ser um material que suporte alta temperatura e que não interaja com o campo magnético do imã [45].

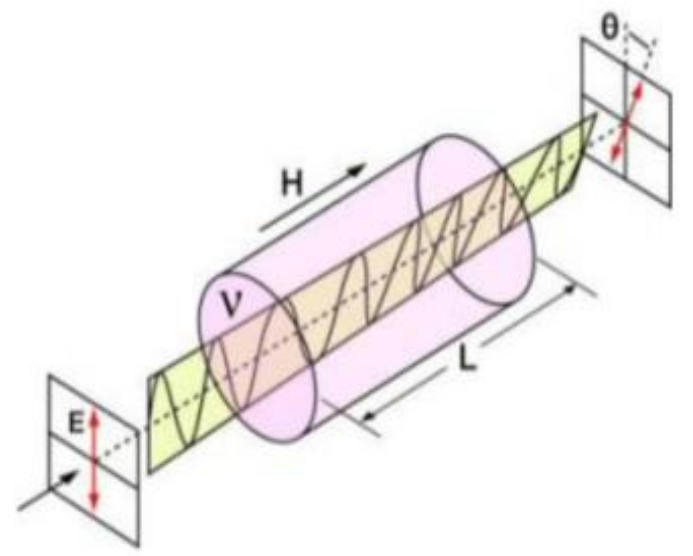

Figura 17: Efeito Faraday (http:www.thorlabs.com).

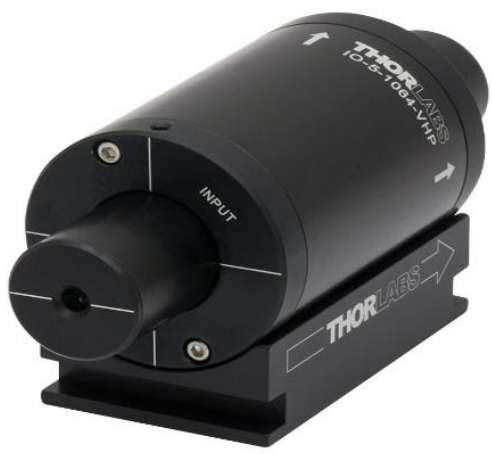

Figura 18: Isolador óptico modelo IO-5-1064-VHP (http:www.thorlabs.com). 


\section{$4 \quad$ Materiais e Métodos}

\subsection{Módulos DPSSL utilizados no trabalho}

Neste trabalho foram utilizados módulos DPSSL (FIG.19) fornecidos pela empresa HTOE. Eles apresentam potência nominal de $75 \mathrm{~W}$ possuindo um cristal de Nd:YAG com dimensões de $\varnothing 3 \mathrm{~mm} \times 78 \mathrm{~mm}$ e dopagem de 0,6 at.\% de $\mathrm{Nd}$, os quais são bombeados lateralmente por 12 barras de diodos de 18,7 W ópticos cada, dispostas em grupos de 4 barras a $120^{\circ}$ um do outro, fornecendo uma potência óptica de aproximadamente $225 \mathrm{~W}$ por módulo e possuindo resfriamento com água.

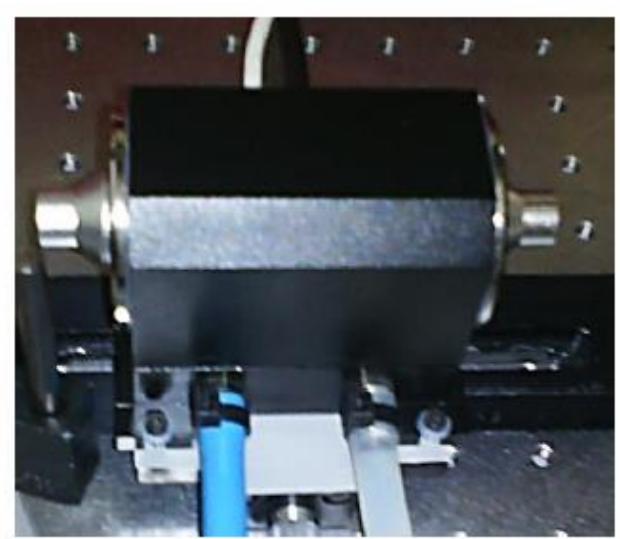

Figura 19: Módulo utilizado no projeto DPSSL.

\subsection{Caracterização dos módulos DPSSL}

\subsubsection{Características elétricas}

Os dois módulos utilizados neste projeto foram caracterizados eletricamente com objetivo de obter as potências elétricas e ópticas de bombeio correspondentes a cada valor de corrente elétrica aplicada aos módulos. Foram feitos registros de valores de tensão elétrica na fonte de potência dos módulos para diversos valores de corrente. Afim de obter a resistividade do circuito, foi feito um ajuste na parte linear da curva tensão vs. corrente, cujo coeficiente angular corresponde à parte resistiva do circuito. Do valor da potência elétrica total fornecida pela fonte foi deduzida a potência dissipada de forma resistiva para se obter a potência elétrica disponível para conversão óptica. Para obtenção da potência óptica de bombeio foi utilizado um valor de eficiência de conversão eletro-óptico de $47 \%$. 


\subsubsection{Caracterização das lentes térmicas}

A caracterização das lentes térmicas foi feita utilizando uma montagem com um feixe expandido de hélio-neônio que passava pelo cristal bombeado, movimentando-se um anteparo até que o feixe fosse focalizado sobre ele, como mostrado na FIG. 20 e utilizando-se o anteparo para fazer a leitura da distância de focalização do feixe até o plano principal do módulo através de uma escala. A caracterização por componentes de polarização radial ou tangencial dos módulos, foi feita através de um procedimento utilizando a combinação de fendas e de um polarizador, que possibilitou selecionar a componente radial e tangencial, alinhando-se o polarizador com o eixo paralelo à fenda para se selecionar a componente radial, ou perpendicular à fenda para a seleção da componente tangencial [46]. Com a orientação das fendas é possível a seleção de diferentes orientações das regiões de incidência no cristal. Foram feitas medidas para as orientações horizontal e vertical da fenda. Da mesma maneira mediu-se as distâncias focais de cada componente, ajustando à distância do anteparo até que se observasse a focalização de feixe e fazendo-se a leitura da distância. $O$ esquema utilizado é demonstrado na FIG. 20, e na FIG. 21 pode-se ver a montagem no laboratório do experimento.

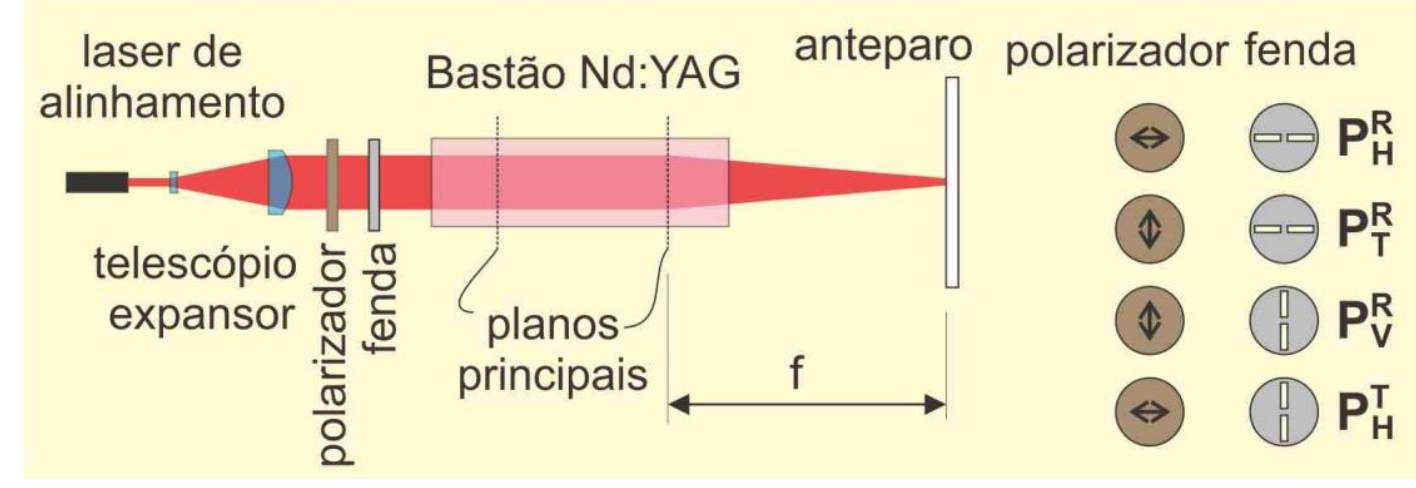

Figura 20: Montagem utilizada na determinação da lente térmica das componentes de polarização tangencial ou radial para as posições horizontal ou vertical selecionadas conforme alinhamento da fenda e do polarizador como mostrado a direita da figura. 


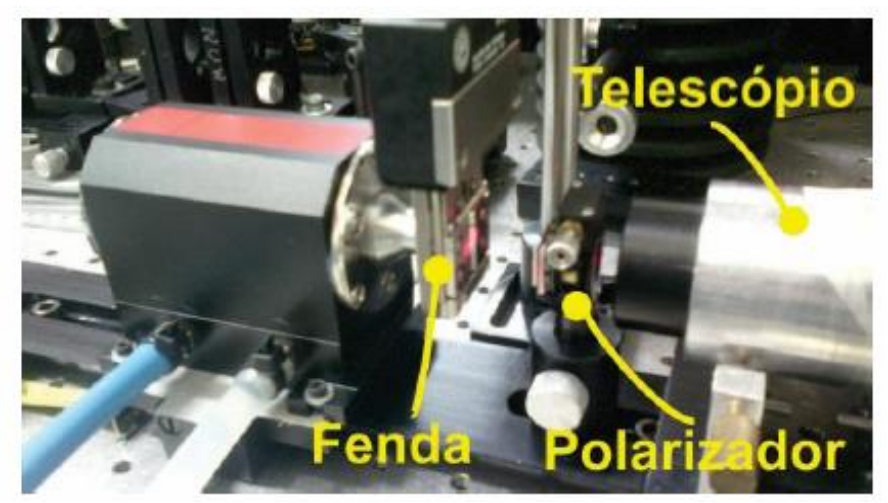

Figura 21: Montagem utilizada para medição das lentes térmicas.

\subsection{Circuito de refrigeração}

Para o trabalho simultâneo com dois módulos foram encontradas dificuldades quanto ao sistema de refrigeração, que tem como importante requisito para a operação segura dos módulos DPSSL, que o fluxo mínimo de água de refrigeração seja de pelo menos $4 \mathrm{I} \cdot \mathrm{min}^{-1}$. Para que a temperatura fosse igual em cada um dois módulos, o circuito de refrigeração deveria ser conectado em paralelo, porém não seria possível garantir o fluxo mínimo em cada um dos módulos nestas condições, pois o aumento da resistência ao fluxo no circuito de um dos módulos, causada por obstrução, dobra dos tubos ou qualquer outro fato, a maior parte do fluxo passaria a circular pelo circuito do outro módulo e o fluxo do circuito do módulo com obstrução poderia ficar abaixo do valor mínimo, causando a queima dos diodos. Optou-se por ligar o circuito de refrigeração dos dois módulos em série para garantir o fluxo mínimo de água para ambos, com o possível problema de não se ter a mesma temperatura da água nos dois módulos, pois a água que entraria no segundo módulo já teria sua temperatura aumentada após ter trocado calor no primeiro módulo. O sistema de refrigeração conta com sensores do tipo PT100 (termorresistências de platina) ao longo do circuito de refrigeração. Esses sensores podem medir três temperaturas ao longo do circuito de refrigeração: a temperatura do reservatório de água da unidade de refrigeração (chiller), cuja leitura de sensor integrado ao equipamento podia ser obtida diretamente em seu painel, sendo esta a temperatura de seu reservatório e correspondente da água que entra no primeiro módulo; a temperatura da água que saia do primeiro módulo e entrava no segundo módulo, medida por um dos sensores instalados no circuito; a temperatura da água que saía do segundo feito 
pelo outro sensor instalado. Na FIG. 22 é mostrado o esquema do circuito com a utilização de dois módulos DPSSL. O sistema também conta com sensores de fluxo tipo fluxostatos que foram ligados ao interlock das fontes dos módulos para interromper a operação caso o circuito de refrigeração fosse desligado ou se rompesse. Os sensores de temperatura e o medidor de fluxo ficam em uma pequena central de modo a se ter mais facilidade e segurança na operação que pode ser visto na FIG. 23. Cada um dos módulos consumia uma potência elétrica da fonte de $532 \mathrm{~W}$ na corrente máxima, sendo fornecidos $1064 \mathrm{~W}$ pelas fontes na operação dos dois módulos. Esse equipamento tem capacidade de refrigerar a $20^{\circ} \mathrm{C}$ os módulos que recebem uma potência da fonte de $1000 \mathrm{~W}$.

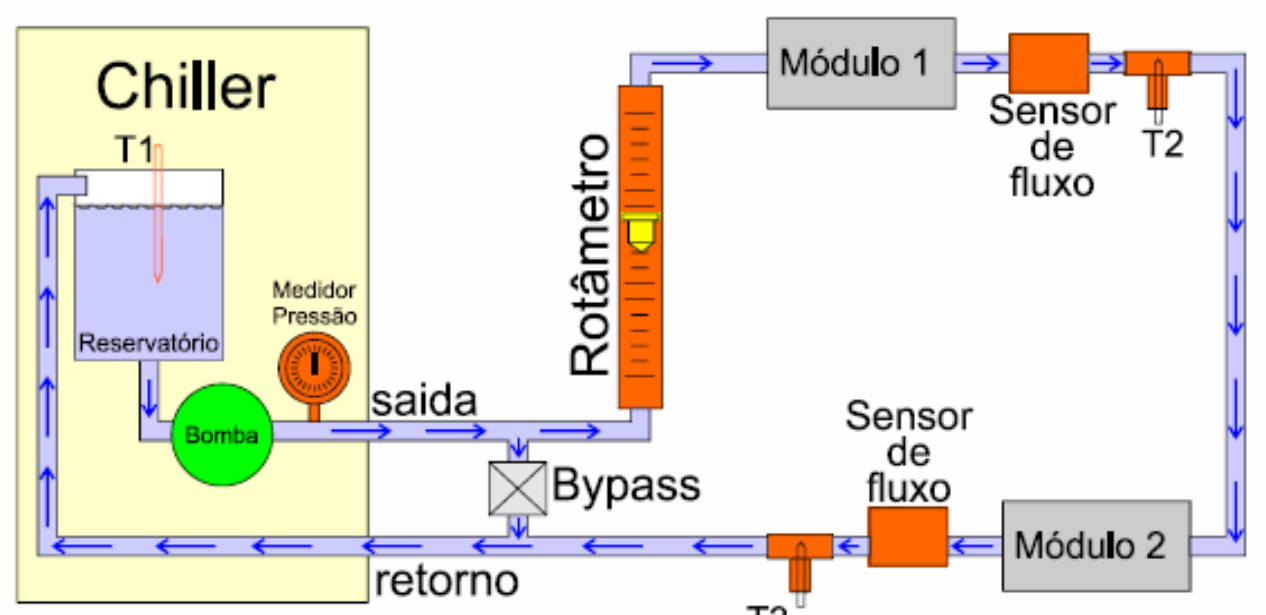

T3

Figura 22: Esquema do circuito de refrigeração com sensores para dois módulos DPSSL. 


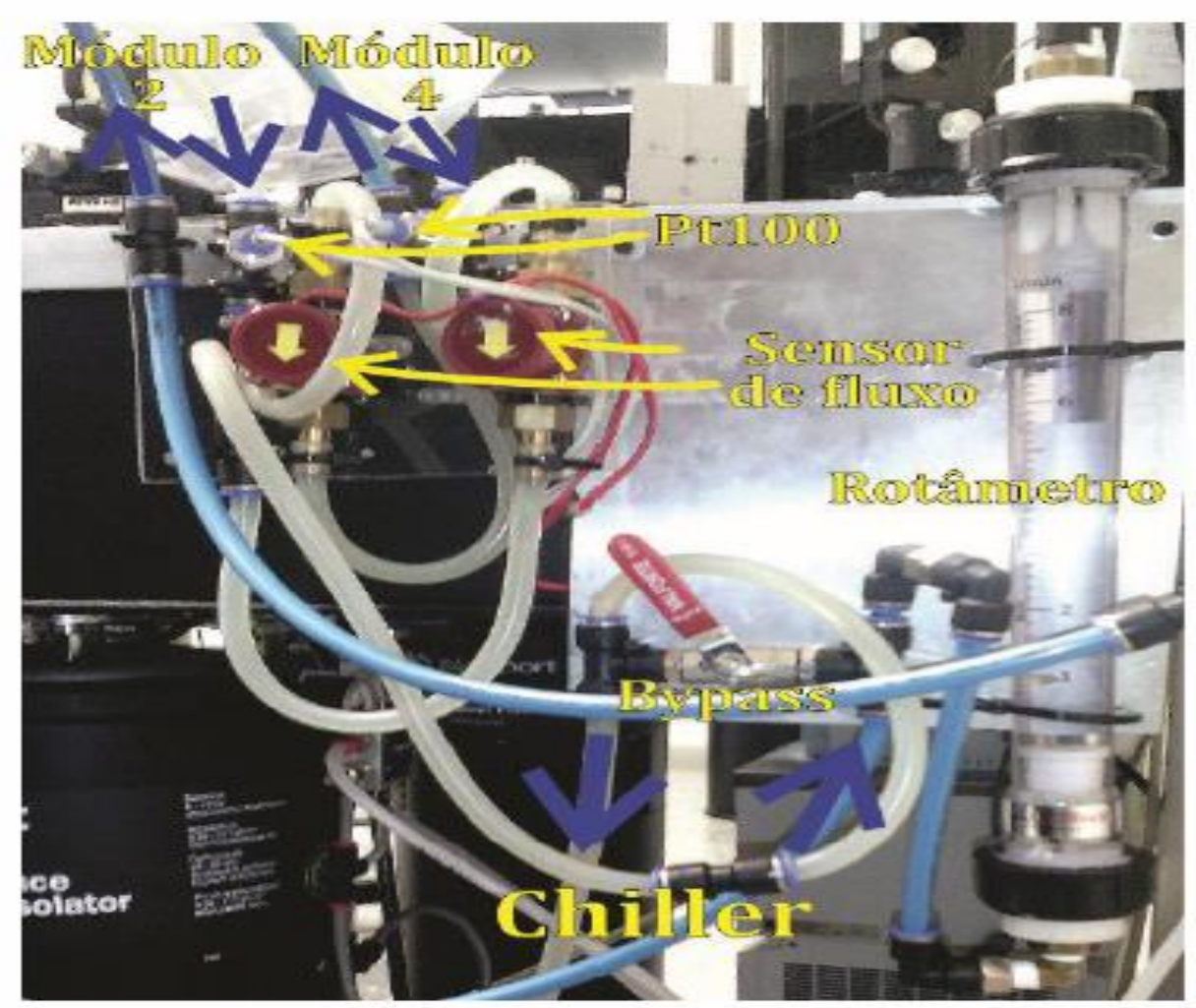

Figura 23: Sensores do sistema de refrigeração agrupados.

\subsection{Desenho do ressonador}

A lente térmica é um dos principais problemas que os projetistas das cavidades lasers de estado sólido devem considerar. O ressonador deste projeto foi desenhado utilizando o programa de computador chamado LASCAD fornecido pela empresa Konkand Altmann, que realiza simulação ABCD de feixes gaussianos. O software contém todas as ferramentas de simulação necessárias para modelar com precisão o desempenho de um ressonador laser, ajudando a economizar tempo e custo. Observou-se nas simulações feitas no LASCAD que um ressonador simétrico composto por quatro espelhos, sendo 2 espelhos curvos $\left(M_{1}\right.$ e $\left.M_{2}\right)$ e dois espelhos planos, que é possível ajustar a largura da zona de estabilidade através da distância entre os espelhos, e a posição da zona também pode ser alterada de maneira independente alterando-se a distância entre os espelhos $M_{1}$ e $M_{2}$ e os planos principais do cristal que ficam entre as linhas pontilhadas em cada modulo mostrado no desenho do ressonador na FIG. 24. Deste modo é possível sintonizar a faixa principal de estabilidade de modo a comportar exatamente a lente térmica do módulo, além de ser possível ajuste fino com obtenção de uma condição otimizada durante operação. 


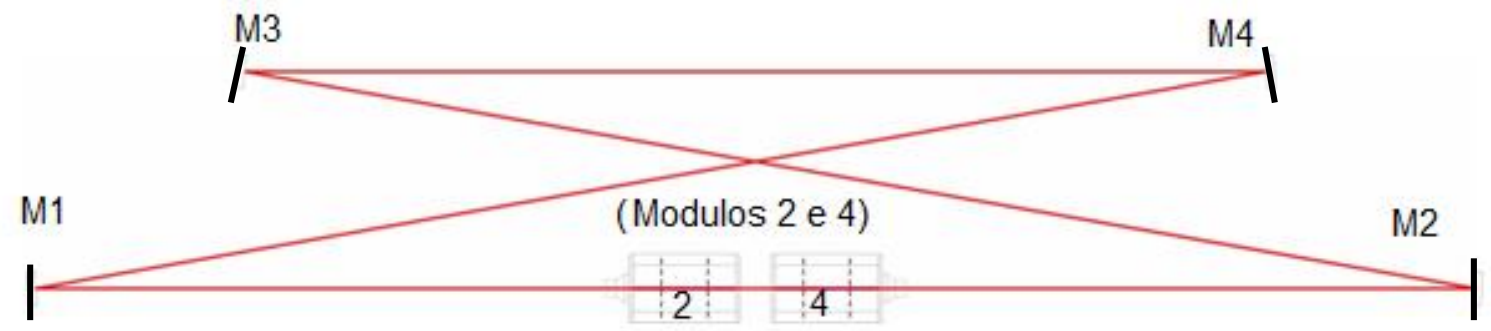

Figura 24: Desenho do ressonador.

\subsection{Maximização do acoplador de saída}

Após a montagem do ressonador laser, foram realizados vários testes com diferentes acopladores de saída, utilizando a corrente elétrica máxima recomendada pelo fabricante que é $20 \mathrm{~A}$, afim de determinar o acoplador que tornasse esse tipo de ressonador laser, o mais eficiente possível. A potência de saída de um ressonador em função da refletividade do acoplador de saída é dada pela eq. 31. Onde A é área da seção transversal do bastão e $I_{S}$ é a intensidade de saturação [17].

$$
P_{\text {out }}=\mathrm{A}\left(\frac{1-R}{1+R}\right) I_{S}\left(\frac{2 g_{o l}}{\delta-\ln \mathrm{r}}-1\right) .
$$

A FIG. 25. Mostra uma curva típica. Um ressonador sempre apresenta um máximo de potência para um valor de refletividade:

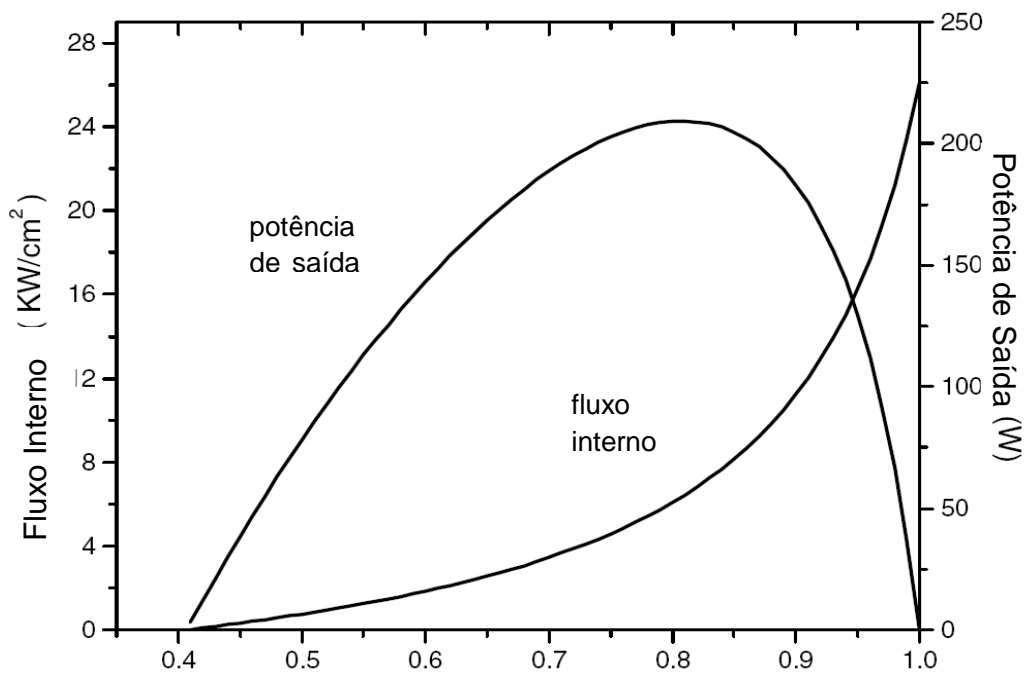

Figura 25: Potência de saída do laser e fluxo total dentro do ressonador como uma função dos espelhos refletividade. Parâmetros: $I_{5}=2.9 \mathrm{KW} / \mathrm{cm}^{2}, \mathrm{~g}_{0} \mathrm{~L}=1, \delta=0.1, \mathrm{~A}=0.4 \mathrm{~cm}^{2}$ [17]. 


\subsection{Caracterização do laser}

\subsubsection{Medidores de potência}

Para efetuar medidas de potência foram utilizados dois detectores, sendo um thorlabs S322-C (FIG.26.a) usado para medir a potência total do laser, onde o mesmo foi colocado atrás do acoplador de saída, medindo a potência máxima do laser. O outro medidor utilizado na determinação da polarização do feixe laser foi o Coherent OP-2 VIS (FIG.26.b). O medidor de potência thorlabs S322-C é um medidor tipo térmico para potência máximo de $200 \mathrm{~W}$ de forma contínua e $250 \mathrm{~W}$ de forma intermitente e com limiar de dano de $4 \mathrm{~kW} / \mathrm{cm}-2$, refrigerado por cooler. Conectou-se este cabeçote de medição a um medidor de potência que registra o valor de forma digital em uma taxa de aproximadamente 3 medidas por segundo. As medidas foram feitas em uma taxa de 1 minuto após a estabilização, registrando-se os valores médio e desvios padrão correspondentes. De modo a se evitar que uma possível focalização do feixe sobre a superfície absorvedora excedesse seu limiar de dano, foi utilizada uma lente plano côncava de distância focal $-2.5 \mathrm{~cm}$ antes do detector na realização das medidas.

(a)

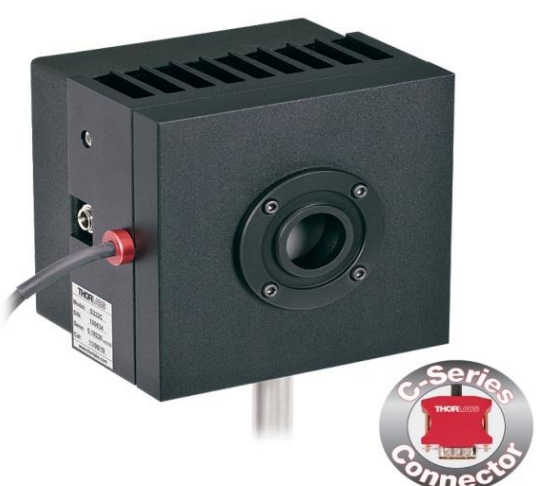

(b)

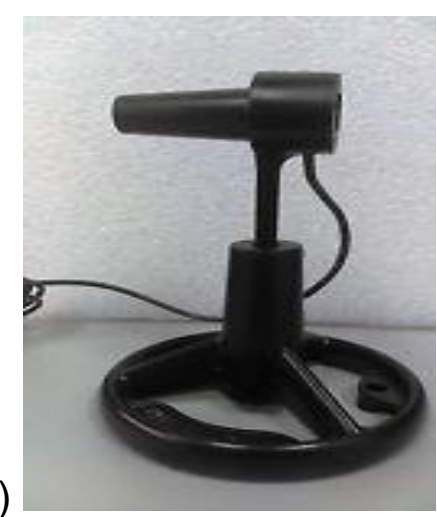

Figura 26: (a) Medidor de potência modelo thorlabs S322-C (http:www.thorlabs.com) e (b) medidor de potência Coherent OP-2 VIS (http:www.Coherent.com).

\subsubsection{Medidas de parâmetro de qualidade do feixe}

Para a caracterização do feixe utilizou-se um sistema de medição de varredura por vendas com sensor de silício (Dataray Beamscope P8) (FIG.27). Este dispositivo contém duas fendas de $5 \mu \mathrm{m}$ de largura dispostas a $90^{\circ}$ uma da outra e que estão a $45^{\circ}$ da direção do movimento de varredura das fendas. 
Um perfil de intensidade para cada orientação das fendas é construído nos dois eixos ortogonais utilizando o registro da intensidade do feixe laser que é feito através de um sensor de silício, que está sob as fendas. Para uma boa resolução recomenda-se que a fenda seja no mínimo $1 / 5$ do diâmetro do feixe, correspondendo à medição de feixes com no mínimo $25 \mu \mathrm{m}$ para a utilização desta fenda. O feixe atenuado é focalizado por uma lente plano-convexa, o sensor faz a medida ao longo de um plano sendo posicionado sucessivamente ao longo de diferentes planos z. Uma íris foi colocada antes da lente para evitar ruídos e obter uma medida com melhor qualidade. $O$ fator de qualidade foi obtido a partir de ajustes feitos de maneira automática pelo software do equipamento, onde as medidas dos diâmetros são feitas de acordo com o segundo momento que deve ser usado na definição de raio do feixe em função da distância porque desta maneira o produto da divergência pelo raio é conservado para um feixe não gaussiano (misturado de modos TEM). O feixe gaussiano equivalente somente é apropriado para um feixe $\mathrm{TEM}_{00}$. Os diâmetros de segundo momento nas direções $x$ e $y 4 \sigma_{x}(z)$ e $4 \sigma_{y}(z)$ são definidos por [31]:

$$
\begin{aligned}
& \sigma_{x}(z)^{2}=\frac{\int_{-\infty}^{+\infty} \int_{-\infty}^{+\infty}(x-\bar{x})^{2} I(x, y, z) d x d y}{\int_{-\infty}^{+\infty} \int_{-\infty}^{+\infty} I(x, y, z) d x d y} \\
& \sigma_{x}(y)^{2}=\frac{\int_{-\infty}^{+\infty} \int_{-\infty}^{+\infty}(y-\bar{y})^{2} I(x, y, z) d x d y}{\int_{-\infty}^{+\infty} \int_{-\infty}^{+\infty} I(x, y, z) d x d y}
\end{aligned}
$$

onde $\bar{x}$ e $\bar{y}$ são as coordenadas do centroide da destribuição da intensidade $I$.

O fator de qualidade foi obtido a partir de ajuste da equação (3) aos valores de do diâmetro $4 \sigma$. Este ajuste era feito de maneira automática pelo software do equipamento.

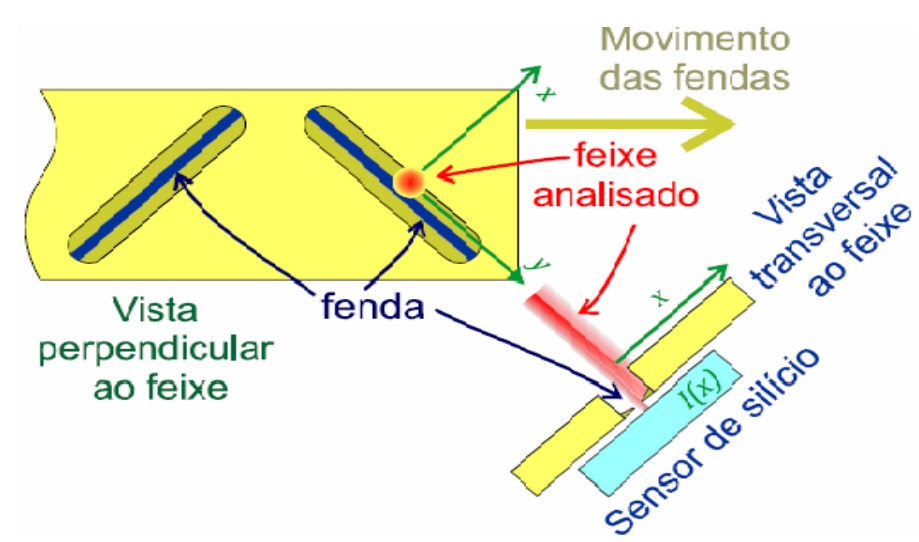

Figura 27: Esquema da medição por varredura de fendas. 


\subsubsection{Medidas de polarização}

Em geral a polarização pode apresentar componentes de polarização linear e circular no sentido horário e anti-horário, definindo-se o vetor de Stokes com 4 componentes, onde o mesmo fornece uma descrição completa de qualquer estado de polarização da luz e seus parâmetros são exatamente estas quantidades que são observadas [47].

$$
\mathrm{S}=\left(\begin{array}{ccc}
I_{H} & + & I_{V} \\
I_{H} & - & I_{V} \\
I_{+45^{\circ}} & - & I_{-45^{\circ}} \\
I_{R} & - & I_{L}
\end{array}\right)
$$

Onde $I_{H}$ e $I_{V}$ são as intensidades na polarização horizontal e vertical, respectivamente, $I_{+45}$ e $I_{-45}$ intensidade nas polarizações a 45 graus positivos e negativos do eixo vertical $I_{R}$ e $I_{L}$ são as componentes de polarização circular nos sentidos horário e anti-horário.

$$
\begin{aligned}
& S_{0}=I\left(0^{0}, 0^{0}\right)+I\left(0^{0}, 90^{\circ}\right) \\
& S_{1}=I\left(0^{0}, 0^{0}\right)-I\left(0^{0}, 90^{\circ}\right) \\
& S_{2}=I\left(0^{0}, 45^{0}\right)-I\left(0^{0}, 135^{0}\right) \\
& S_{3}=I\left(45^{\circ}, 45^{\circ}\right)+I\left(45^{\circ}, 135^{\circ}\right)
\end{aligned}
$$

Define-se o grau de polarização (DOP - Degree of polarization) de uma maneira geral por:

$$
D O P=\frac{\sqrt{S_{1}^{2}+S_{2}^{2}+S_{3}^{2}}}{S_{0}}
$$

que no caso de possuir apenas componentes de polarização linear pode-se reduzir a:

$$
D O P=\frac{I_{\|}-I_{\perp}}{I_{\|}+I_{\perp}}
$$

Podemos ter a porcentagem de polarização através:

$$
\mathrm{pol}=\frac{I_{\|}}{I_{\|}+I_{\perp}}
$$

Onde $I_{\|}$e $I_{\perp}$ são as intensidades medidas com o polarizador analisador posicionado em ângulo paralelo e perpendicular, respectivamente ao eixo de 
maior intensidade após o analisado. A FIG. 28 mostra o arranjo experimental para determinar a polarização do laser, onde é possível observar na figura, dois feixes representados por setas de cor vermelha e azul. Na FIG. 29 são representados as duas ondas viajantes dentro do ressonador e o feixe 1 e feixe dois que saem no espelho M3 onde foi realizada a medida de polarização e o espelho M4 (acoplador de saída) onde é medido a potência total. O medidor Coherent OP-2 VIS foi posicionado atrás do espelho M3 do ressonador, altamente refletor e com um polarizador glan-Thompson, que ficava entre o medidor e o espelho do ressonador, por onde sai uma potência muito baixa e com feixe pequeno em relação ao acoplador de saída, facilitando a medida da polarização do laser.

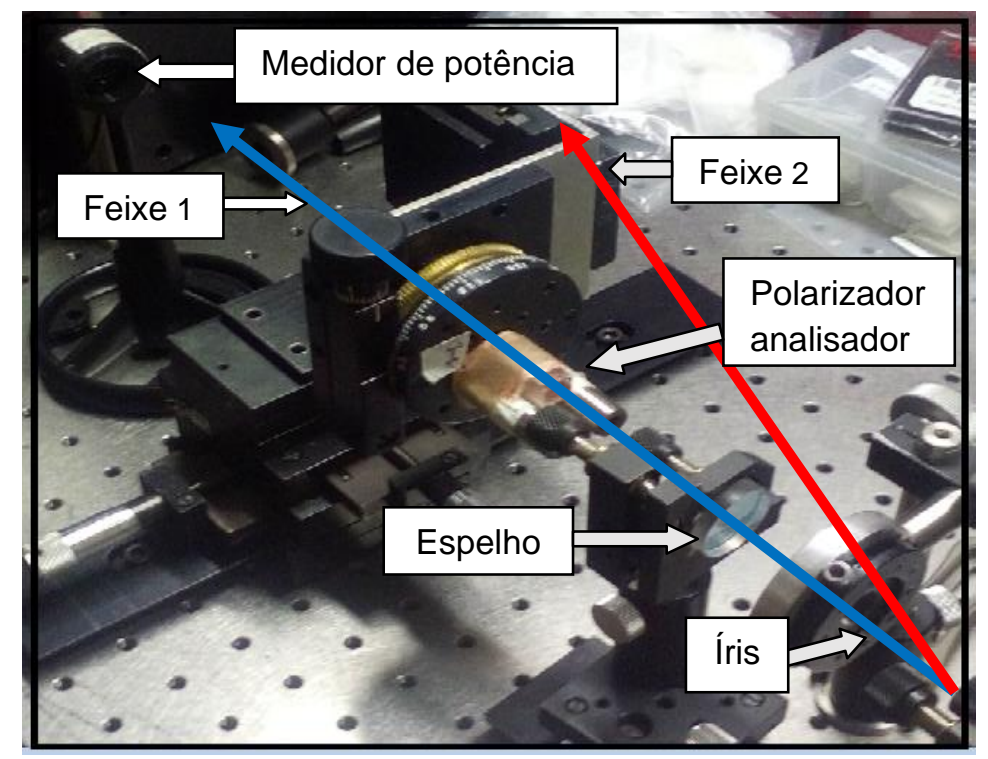

Figura 28: Arranjo experimental para determinar a polarização do laser.

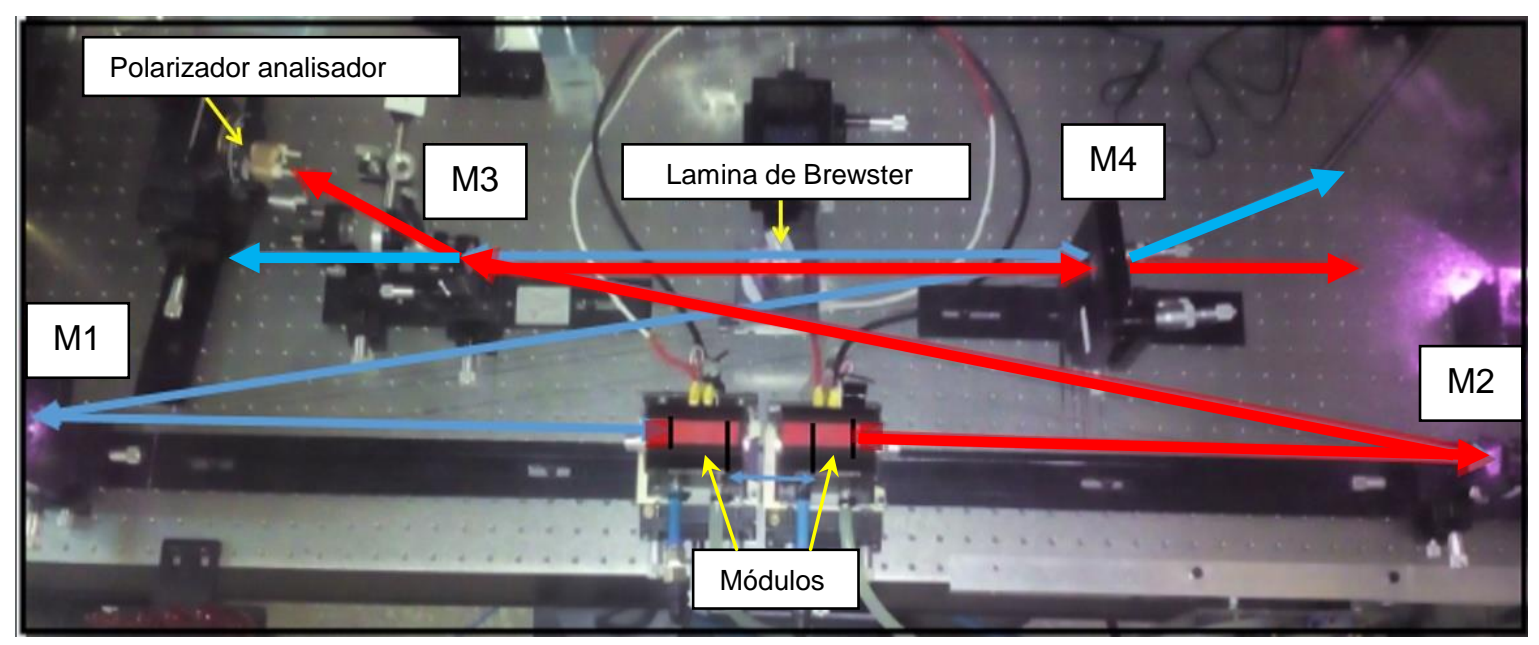

Figura 29: Arranjo experimental da cavidade laser em funcionamento. 


\subsection{Rotacionado de Faraday}

Para a operação unidirecional foi construído um rotacionador demonstrado na FIG. 30 e FIG. 31, que é formado por uma caixa de alumínio, onde ficam dois imãs em formato de cilindro furado cada um com diâmetro interno de $7 \mathrm{~mm}$, diâmetro externo de $32 \mathrm{~mm}$ e $6,4 \mathrm{~mm}$ de espessura, um tubo de latão onde o TGG que tem $\mathrm{n}=1,95$ (índice de refração), $6 \mathrm{~mm}$ de comprimento e $5 \mathrm{~mm}$ diâmetro é preso. O valor do deslocamento angular medido com uma corrente de 20 A, um imã e um laser de He-Ne de comprimento de onda $632.8 \mathrm{~nm}$, onde a constante de Verdet é 134 rad.(T.m) ${ }^{-1}[48]$ foi de $40^{\circ}$. Como o comprimento de onda do nosso laser é de $1064 \mathrm{~nm}$, a constante de Verdet é -40 rad.(T.m) ${ }^{-1}$ [48]. Utilizando a eq. 28 a previsão é de obter um deslocamento de $12^{\circ}$.

No laboratório havia dois cristais TGG disponíveis. Com isso foi feito outro rotacionador de Faraday idêntico ao anterior, para duplicar o deslocamento angular, porém esse segundo TGG apresentava irregularidade na superfície tornando muito difícil o alinhamento, com isso a operação foi realizada com apenas um cristal.

(a)

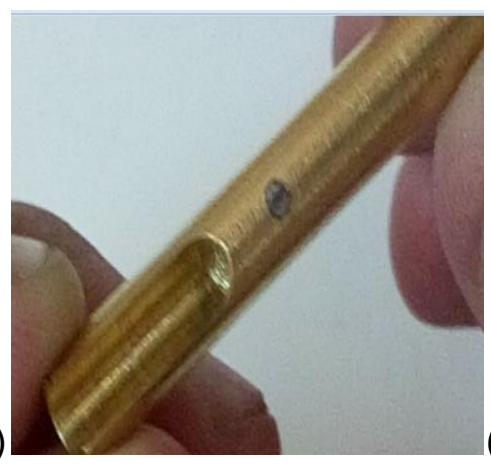

(b)

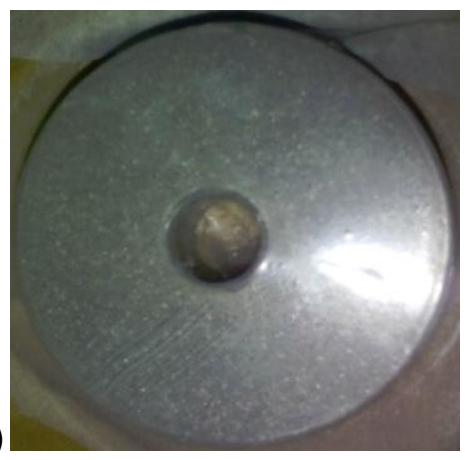

Figura 30: (a) Tubo de latão que serve para fixar o TGG e (b) imã de neodímio.

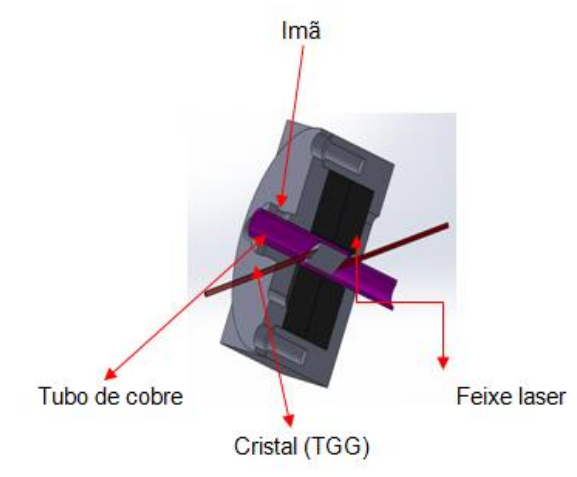

(a)

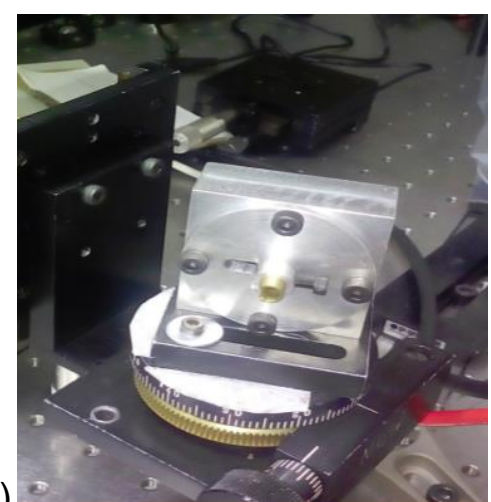

(b)

Figura 31: (a) Projeto e (b) montagem final do suporte para o cristal TGG e o imã 


\subsection{Caracterização da emissão espectral do laser}

Na realização da caracterização da emissão espectral laser foi utilizado um sistema de etalon Fabry-Perot (HIFASE, Burleigh-) de alta resolução, conectado a um osciloscópio (DS4034, Rigol).

O sistema tem uma varredura por piezoelétrico que combina alta finesse $(F)$ com a $(F S R)$ variável continuamente. Sua principal aplicação é a análise espectral de fontes laser. Também pode ser usado como um filtro FabryPerot no estudo dos sistemas de comunicação óptica. O sistema consiste de uma cabeça óptica, contendo um etalon e a óptica de mode-matching (casamento de modo), e um controlador eletrônico que fornece os recursos de digitalização e estabilização. A cabeça óptica no etalon usa espelho esférico, cujo raio de curvatura ( $r$ ) é muito maior do que o espaçamento entre os espelhos. A configuração do espelho esférico oferece duas vantagens em relação aos espelhos planos. Primeiro, o efeito de focalização dos espelhos curvos que resulta em um modo com um pequeno diâmetro na superfície do espelho, minimizando a possível degradação da finesse devido às imperfeições da superfície do espelho. Em segundo lugar, não é necessário manter o paralelismo do espelho, portanto, o alinhamento se torna mais simples do que para espelhos planos.

Estas vantagens também são válidas para ressonadores confocais, mais comum, para o qual $r=d$. No entanto, esta condição confocal pode ser alcançada apenas para um único espaçamento para um determinado conjunto de espelhos. Esse sistema de etalon oferece espaçamento ajustável continuamente com o FSR variando em uma faixa de 100: 1 com o mesmo conjunto de espelhos. Para evitar transmissões espúrias, ou transmissões que não correspondem a frequências presentes no feixe laser de entrada, é necessário um casamento de modo ao longo do raio do espelho esférico usando um procedimento sistemático para alcançar o casamento de modo, usando apenas os ajustes disponíveis na cabeça óptica. Uma vez que o modo de correspondência é alcançado em um determinado (FSR), a separação do espelho pode ser facilmente alterada sem perder o sinal, e o sistema pode ser rapidamente ajustado. Essa capacidade é particularmente importante para o estudo de fontes com frequências múltiplas, 
pois possibilita o estudo do espectro na resolução máxima sem a possível confusão de ordens sobrepostas.

A resolução espectral de qualquer interferômetro é FSR / F. Para uma determinada FSR, a resolução torna-se maior para espelhos de finesse superiores. Por sua vez, maior finesse requer maior refletividade $(R)$ nos espelhos. Existem dois limites na busca de refletividade arbitrariamente elevada. Um deles é devido ao fato de que, além de certo ponto, a finesse devida à refletividade é diminuída pelas limitações do polimento dos espelhos. O outro limite é que uma maior refletividade diminui a transmissão do etalon uma vez que a absorção do revestimento e as perdas de espalhamento do substrato são ampliadas por um fator de $(1-\mathrm{R})^{-1}$. Finesse de até $10^{5}$ já foram relatados para substratos super-polidos com revestimentos de baixa perda[49]. No entanto, tais espelhos são sensíveis ao meio ambiente e geralmente são montados em caixas hermeticamente fechadas que inibem mudanças fáceis no FSR.

\subsubsection{Descrição do sistema de etalon}

Na FIG. 32 é mostrado um esquema do sistema, composto por: uma cabeça ótica que consiste em ajuste do feixe laser através da parte ótica e mecânica para realizar casamento de modo (modo-matching), que consiste em focalizar o feixe laser de modo que ele tenha o mesmo valor de cintura e posição da cintura do etalon; lentes de entrada tem uma entrada focal de $25 \mathrm{~mm}$ predefinido para fornecer um feixe colimado para uma lente focalizada; zoom óptico com uma distância focal continuamente ajustável girando o anel da escala, que vai de $12,5 \mathrm{~mm}$ para $75,0 \mathrm{~mm}$, onde o zoom óptico e a lente de entrada juntos de um sistema de telescópio de Galileu com um fator de expansão variando de 5 até 3; Lente de focalização com uma distância focal $148 \mathrm{~mm}$ que é usada para focar um feixe laser entrando no interferômetro, onde a lente tem 10 $\mathrm{mm}$ de ajuste fino disponível e um ajuste grosso de $30 \mathrm{~mm}$, e um Interferômetro (etalon) é um detector integral realizando nas montagens de posições $X, Y, \theta, \emptyset$ com ajustes precisos para realizar o casamento de modo (mode-matching). Para um comprimento de onda de $1064 \mathrm{~nm}$ a finesse do equipamento informada pelo fabricante é de 2000 e o FSR vai de15 GHz até $1500 \mathrm{GHz}$. O equipamento tem uma precisão de $7,5 \mathrm{MHz}$ equivalente a $28,3024 \mathrm{fm}$. 


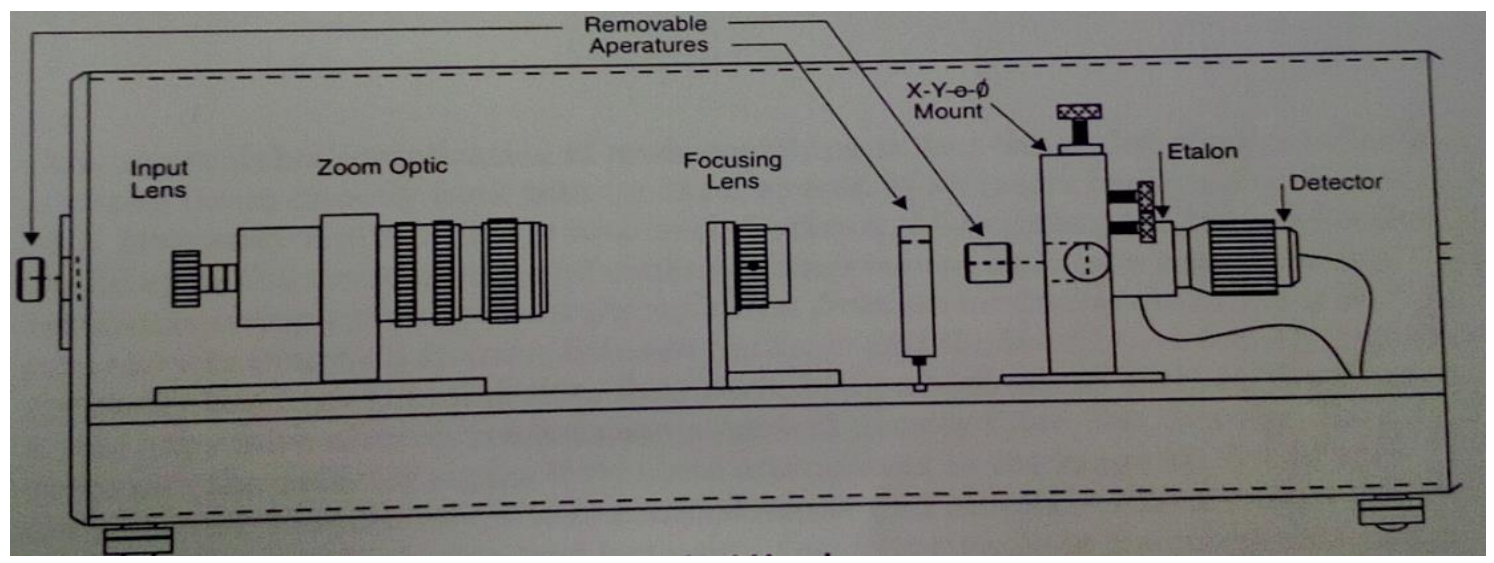

Figura 32: Equipamento etalon (Burleigh-HIFASE). 


\section{$5 \quad$ Resultados e discussão}

\subsection{Caracterização dos módulos DPSSL}

\subsubsection{Caracterização elétrica}

Na FIG. 33a é mostrada a curva de tensão vs. Corrente, e FIG. 33b correspondente curva de potência de bombeio em função da corrente elétrica obtida para o módulo 2 .

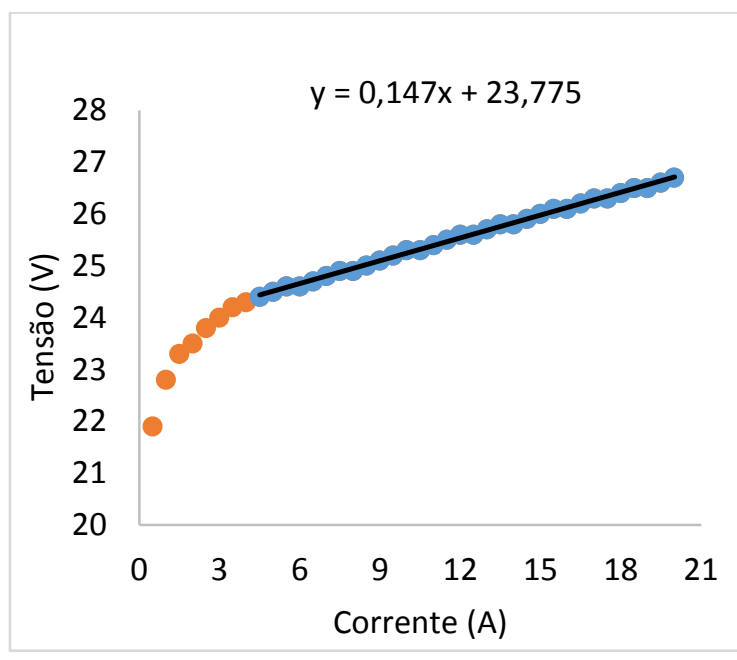

(a)

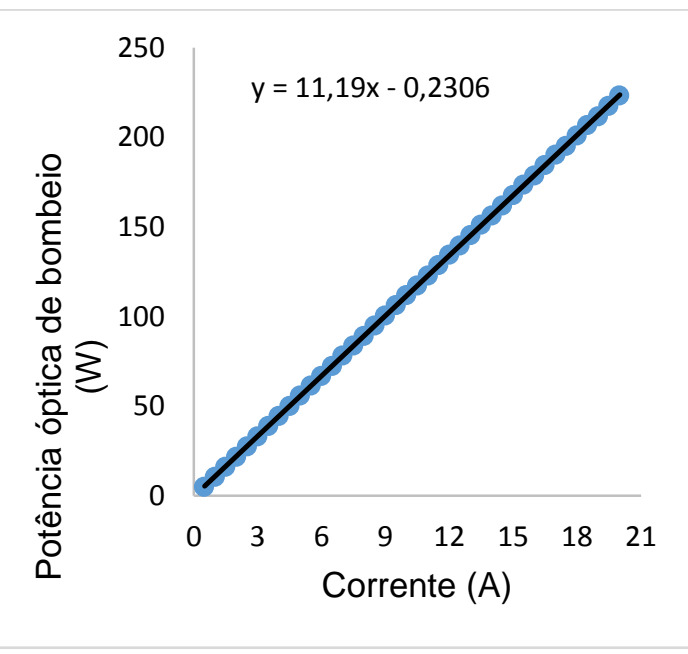

(b)

Figura 33: (a) Curva de tensão vs. corrente elétrica e (b) curva de potência de bombeio em função da corrente elétrica obtida para a operação conjunta dos modulo 2.

\subsubsection{Caracterização das lentes térmicas}

Na FIG. 34a e FIG. 34b é mostrada a distância focal da lente térmica para cada valor de corrente elétrica do módulo 2, e para o conjunto dos módulos 2 e 4. Para operações com dois módulos que estavam posicionados de modo a deixar uma distância de $7,2 \mathrm{~cm}$ entre os planos principais resultando num espaço de $1,6 \mathrm{~cm}$ entre eles, suficiente para a introdução de uma placa de $\lambda / 2$ montada em um dispositivo de rotação como pode ser visto na FIG. 21. A caracterização das lentes térmicas por componente de polarização para cada corrente elétrica do módulo 2, módulo 4 e na operação conjunta destes dois módulos é mostrada nas FIG. 34 e FIG. 35. 
(a)
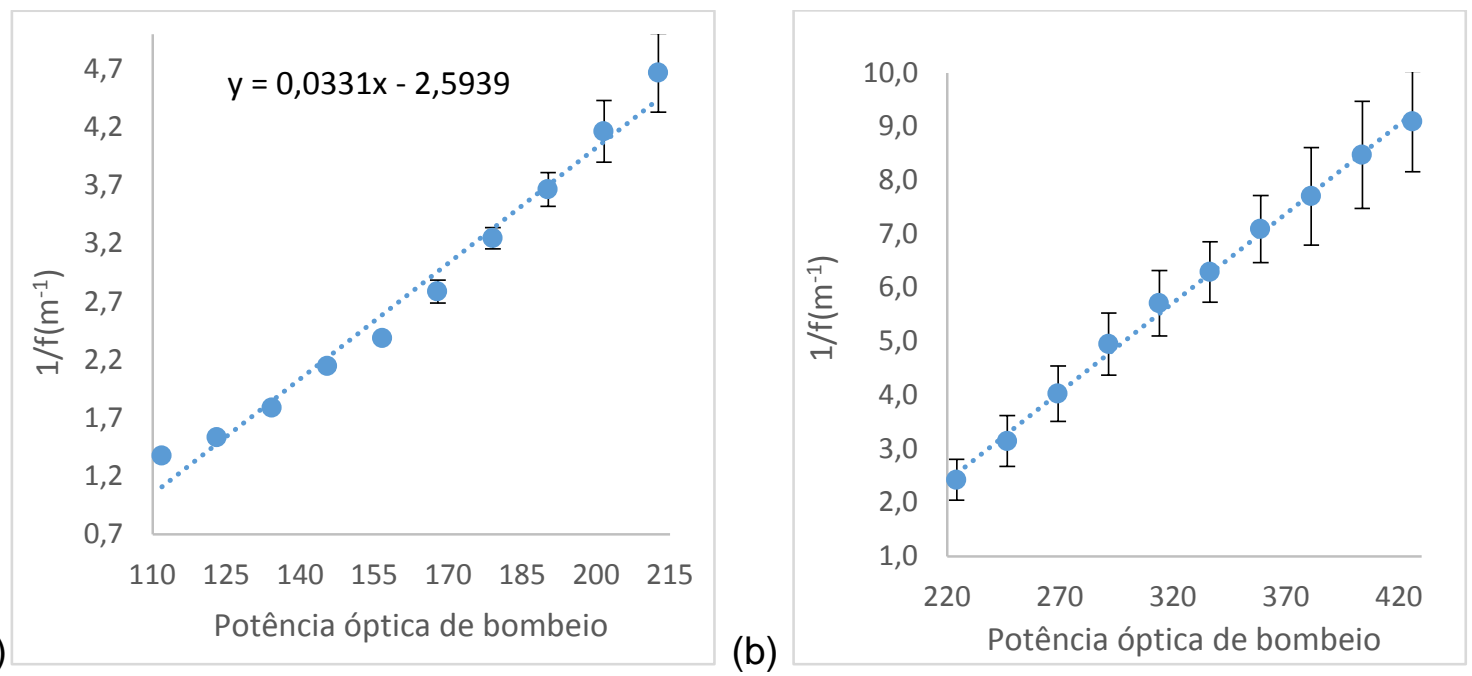

Figura 34: (a) Comprimento focal das lentes térmicas para o módulo 2 (b) comprimento focal das lentes térmicas para o conjunto dos módulos 2 e 4 operando em conjunto com espaçamento $72 \mathrm{~mm}$ entre os planos principias.

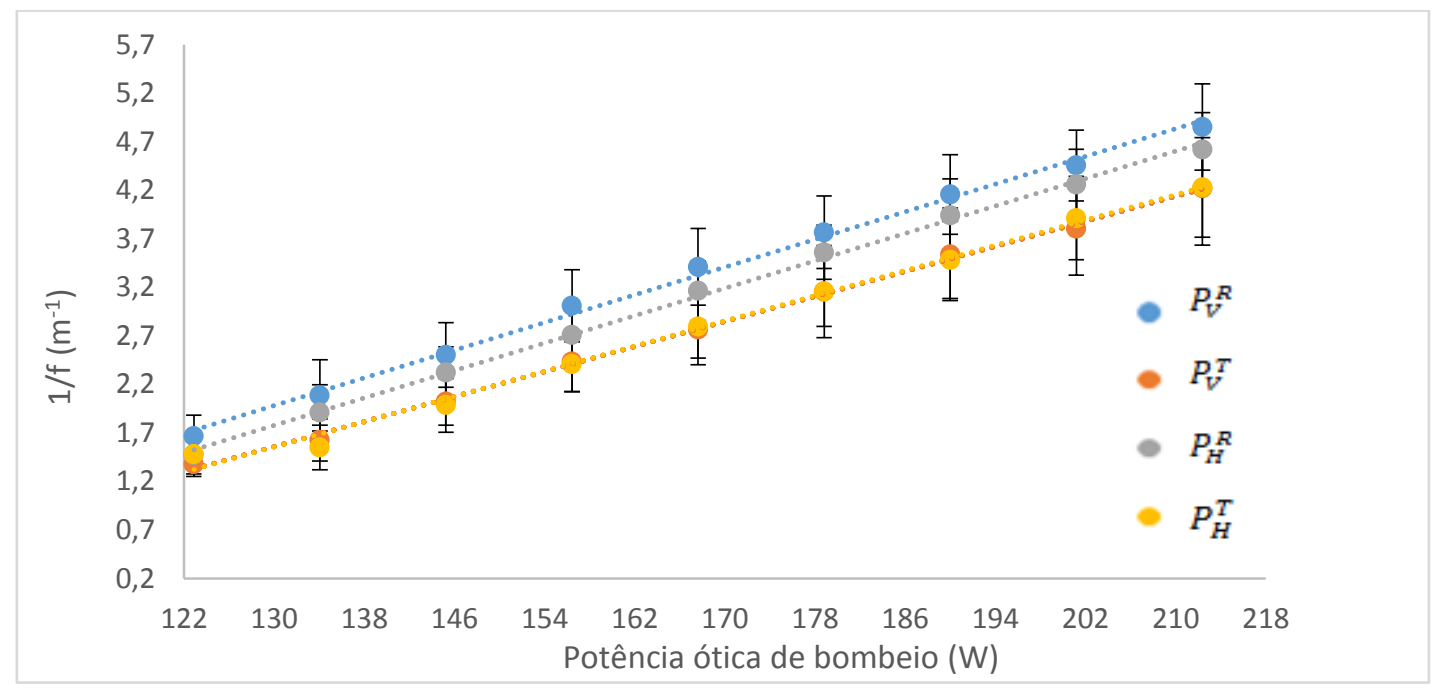

Figura 35: Caracterização da lente térmica por componente de polarização do modulo 2.

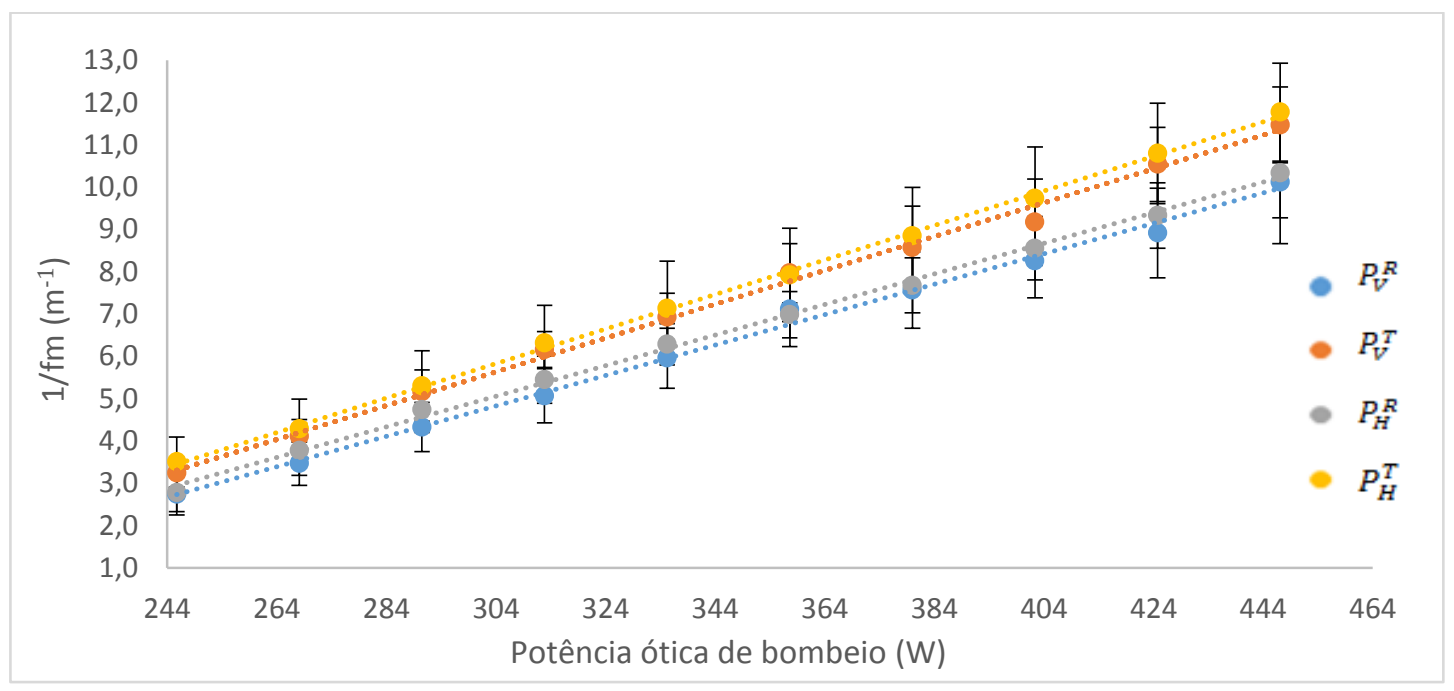

Figura 36: Caracterização da lente térmica por componente de polarização para o conjunto dos módulos 2 e 4 operando em conjunto com espaçamento $72 \mathrm{~mm}$ entre os planos principais. 


\subsection{Montagem da cavidade laser}

\subsubsection{Desenho do ressonador}

Na FIG.37 é mostrado o esquema do ressonador simulado no LASCAD para dois módulos e quatro espelhos, onde M4 é o acoplador de saída. As dimensões ficaram com os seguintes valores: Os espelho M1 e M2 tem raio 500 mm, M3 e M4 espelhos planos, distância entre $M_{1}$ e $M_{2}$ de120 cm $(D a=53 \mathrm{~cm})$, distância entre $M_{3}$ e $M_{4}$ de $52,9 \mathrm{~cm}(\mathrm{Dc}=26,45 \mathrm{~cm})$, distância entre $\mathrm{M}_{2}$ e $\mathrm{M}_{3}$ ou M1 e M4, de $87,7 \mathrm{~cm}(\mathrm{Db}=43,85 \mathrm{~cm})$ e $\alpha=10^{\circ}$. Deixou-se um espaço entre os módulos de $1,6 \mathrm{~cm}$ o que resultou numa distância de $7,2 \mathrm{~cm}$ entre os planos principais indicada pela seta entre os dois modos. Na FIG. 38 e FIG. 39 é mostrada a plotagem da cintura do modo fundamental ao longo do ressonador e simulação do intervalo de estabilidade dos módulos realizado no LASCAD.

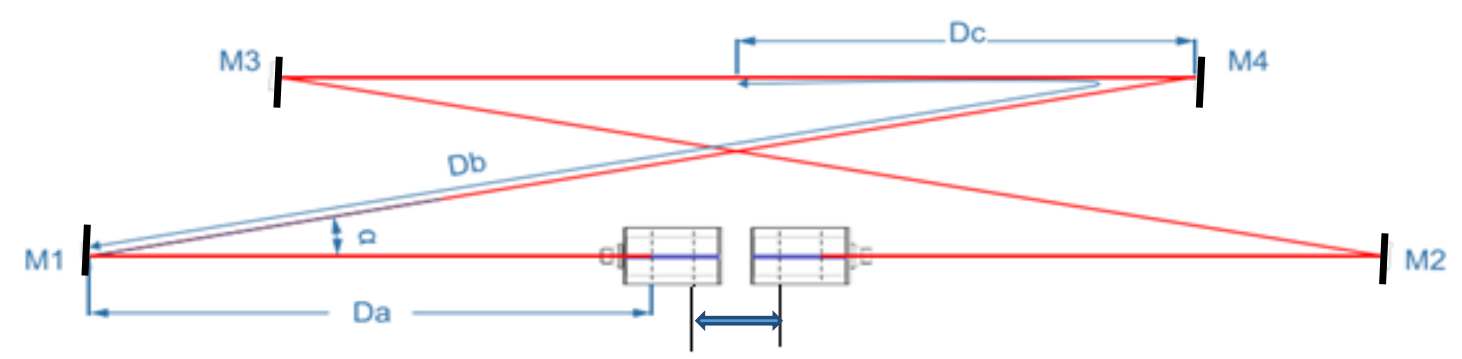

Figura 37: Esquema do ressonador laser. 


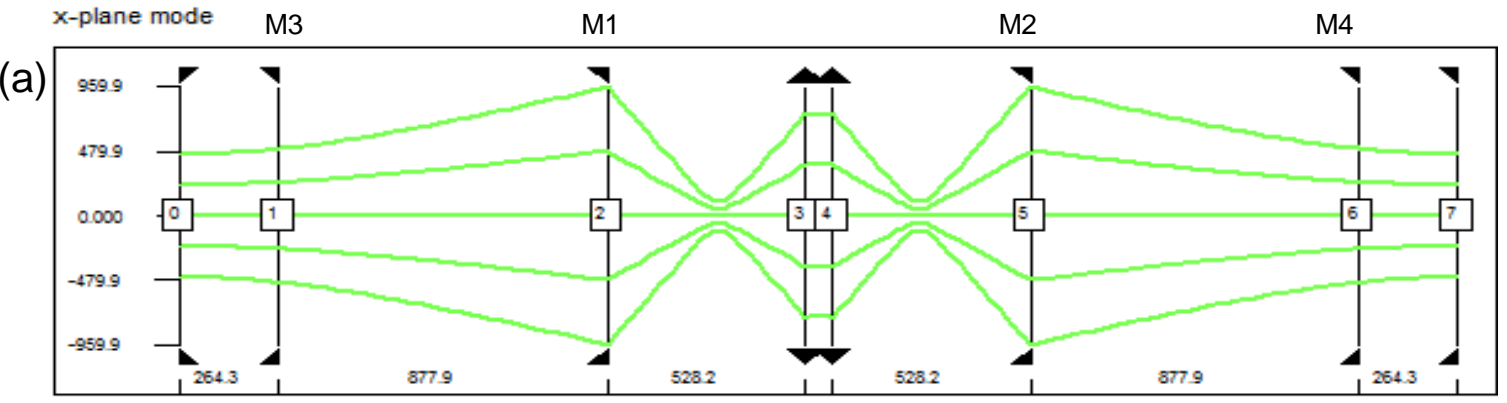

maximum spot size $(\mathrm{x}$-plane $)=959.86$

minimum spot size $(x$-plane $)=104.69$

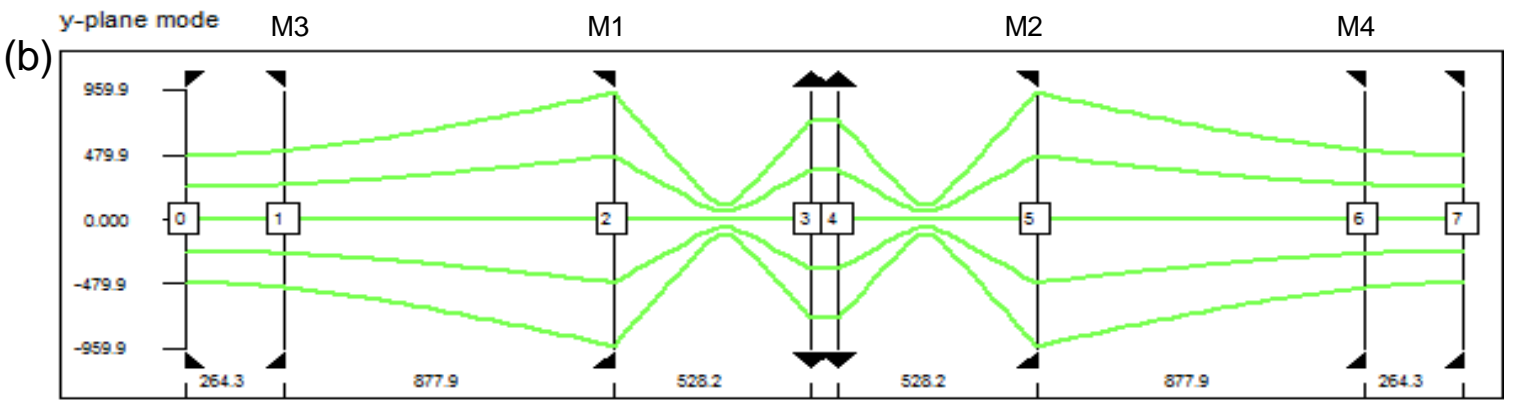

maximum spot size $(y$-plane $)=941.68$

minimum spot size $(y$-plane $)=106.9$

Figura 38: Simulação dos modos laser nos eixos $x$ (a) e y (b). Elementos 0 e 7 são elementos mudos e correspondem ao mesmo ponto, que é o ponto central entre os espelhos M3 e M4; Elementos 1 e 6 correspondem aos espelhos M3 e M4. Elementos 2 e 5 correspondem aos espelhos M1 e M2; elementos 3 e 4 correspondem aos dois bastões (representados aqui por lentes delgadas).

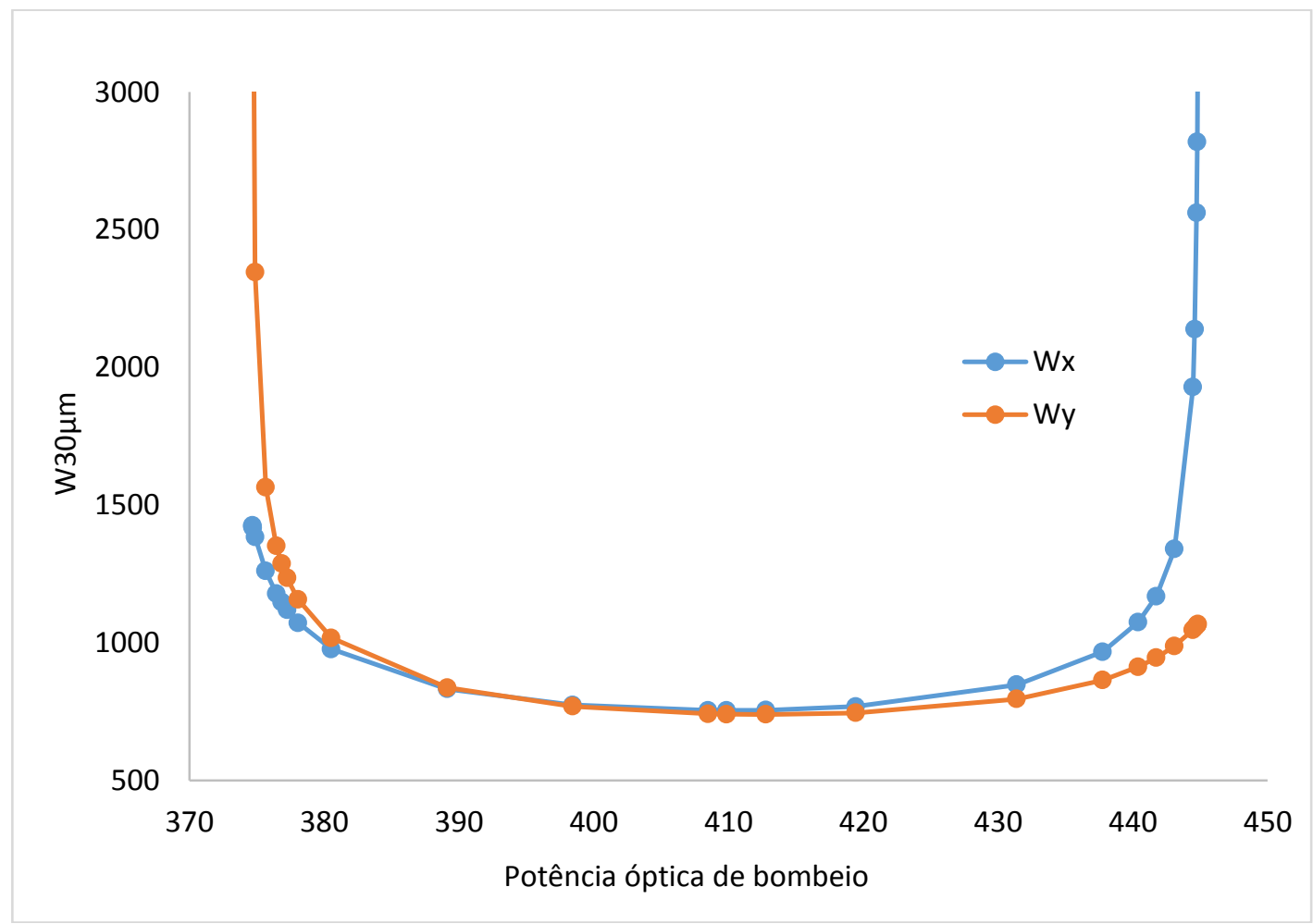

Figura 39: Simulação do intervalo de estabilidade dos módulos conforme eq. 15. 


\subsection{Maximização do acoplador de saída}

Na FIG. 40 é mostrada a potência obtida na corrente máxima e com a utilização de diversos valores de refletividade do acoplador de saída para o conjunto dos dois módulos e quatro espelhos (módulo 2 e módulo 4) usando a configuração da FIG. 37.

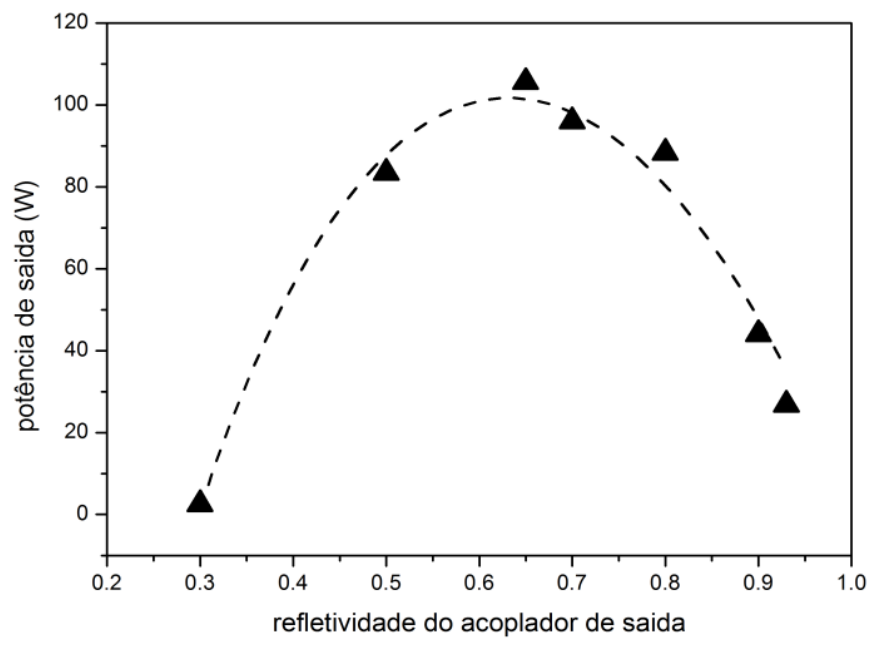

Figura 40: Otimização do acoplador de saída para operações com dois módulos

O ajuste indica o acoplador de saída de 35\% de transmitância como sendo o ideal para este ressonador laser, pois o mesmo proporcionou a maior potência entre todos os outros acopladores, que foi de 105,2 $\pm 0,9 \mathrm{~W}$. Com a placa de $\mathrm{N} / 2$ o valor médio caiu para $97,0 \pm 0,7 \mathrm{~W}$.

\subsection{Caracterização do laser}

\subsubsection{Grau de polarização do feixe}

Nas FIG. 41 é mostrado o grau de polarização (DOP - Degree of polarization) e na FIG. 42 é mostrada a porcentagem de polarização utilizando uma placa de $\lambda / 2$ entre os dois módulos e uma lâmina de Brewster intracavidade entre os dois espelhos M3 e M4 mostrado na FIG. 37 para as seguintes combinações: lâmina de Brewster e placa de $\lambda / 2$, apenas a placa de $\lambda / 2$ sem elementos polarizador. Como o espelho escolhido tinha dois feixes que saíam através do espelho mostrado na FIG. 28 medimos a polarização do feixe 1 e do feixe 2. Em cada combinação feita para analisar o feixe 1 e 2 é mostrado na FIG. 
43 os valores da soma da potência máxima de bombeio para os dois feixes que saiam do acoplador de saída que é o espelho M4 mostrado na FIG. 9.

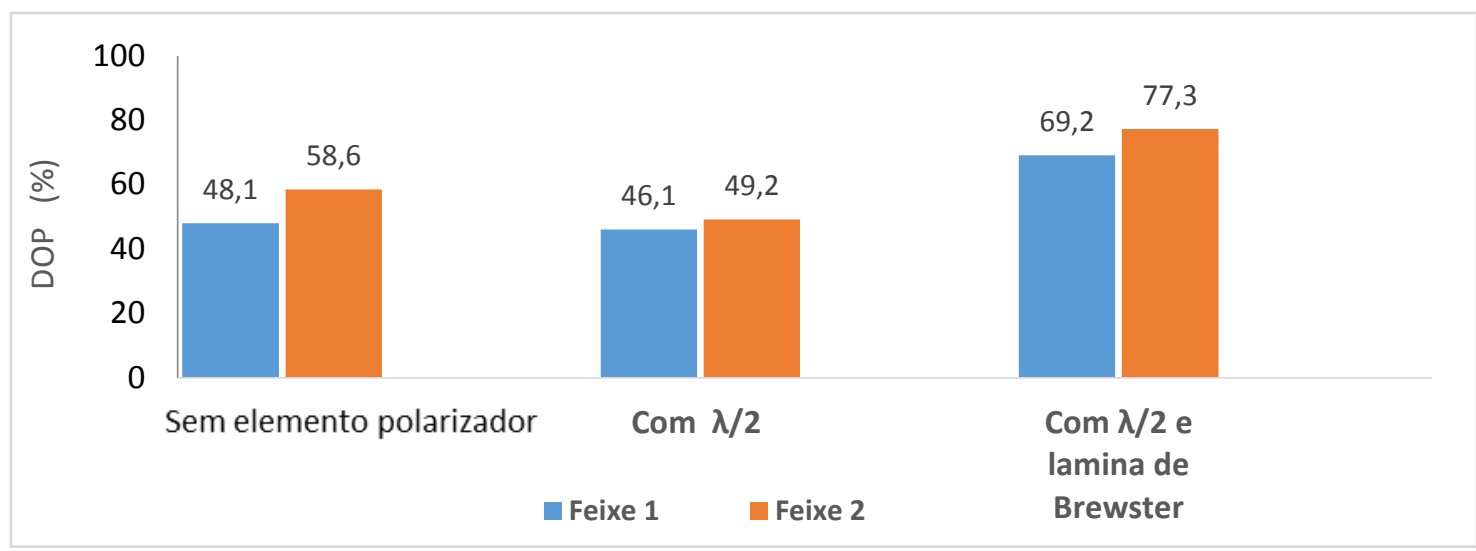

Figura 41: Medida da polarização (DOP) do feixe laser 1 e 2 com as combinações do experimental: sem elementos polarizador, com $N / 2$ e com $N / 2$ e lâmina de Brewster.

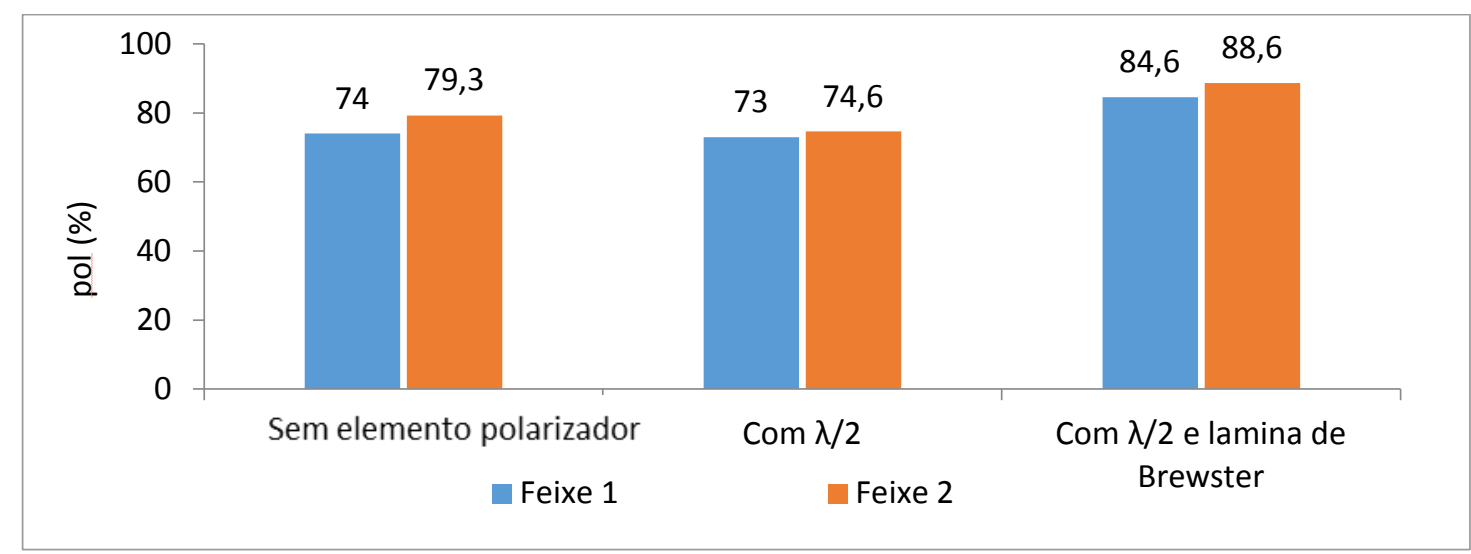

Figura 42: Medida da polarização ( $p o l)$ do feixe laser 1 e 2 com as combinações do experimental: sem elementos polarizador, com $\lambda / 2$ e com $\lambda / 2$ e lâmina de Brewster.

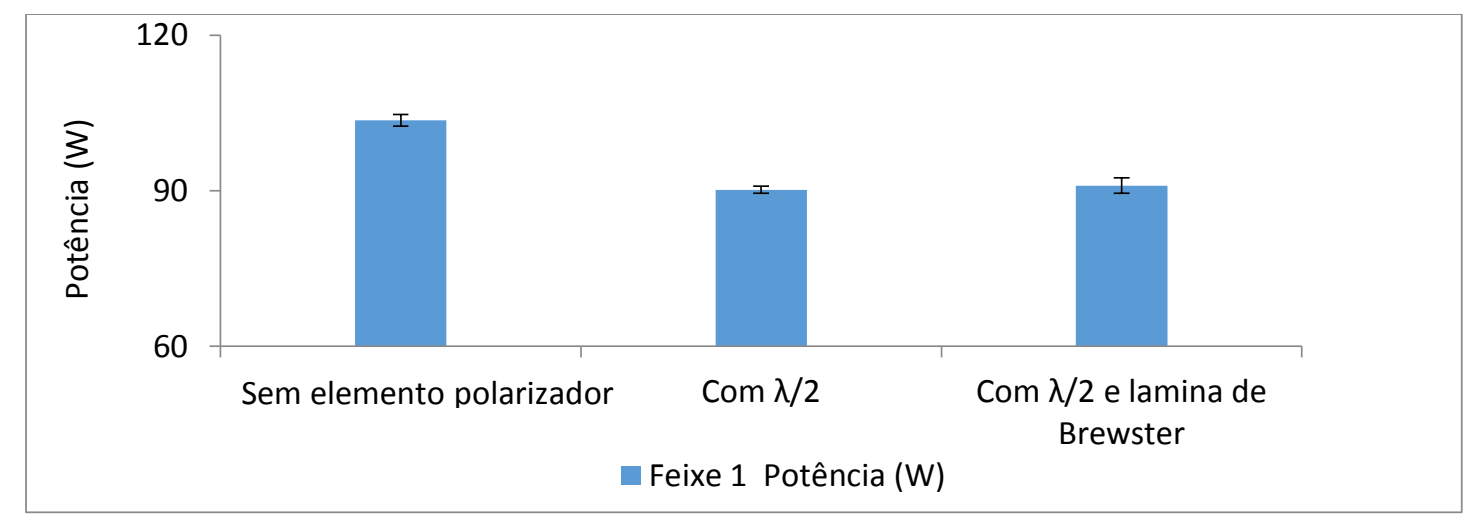

Figura 43: Medida da potência media do feixe para cada combinação do arranjo. 


\subsubsection{Fator de qualidade do feixe}

Na FIG.44, FIG.45 e FIG.46 são mostradas imagens obtidas do perfil de intensidade. Como não vimos diferença passamos a utilizar o feixe 1 utilizando o sistema de medição de varredura por fenda (Dataray Beamscope P8) que tem um software que mostra o perfil do feixe, além de fazer as medidas dos diâmetros pelo segundo momento. Utilizando uma placa de $\lambda / 2$ entre os módulos e uma lente para atenuar o feixe com uma corrente elétrica máxima, obteve-se uma potência de 96,0 \pm 0,7 W, um valor de qualidade do feixe laser sem placa de $\lambda / 2$ de $M_{u}^{2}=2,42$ e $M_{v}^{2}=4,02$ e um fator de qualidade do feixe laser não polarizado de $M_{u}^{2}=1,71$ e $M_{v}^{2}=1,56$.

(a)

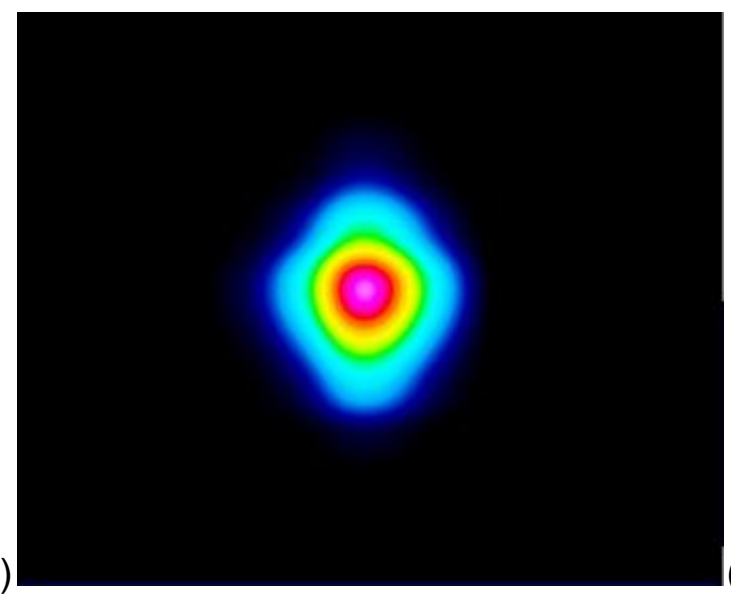

(b)

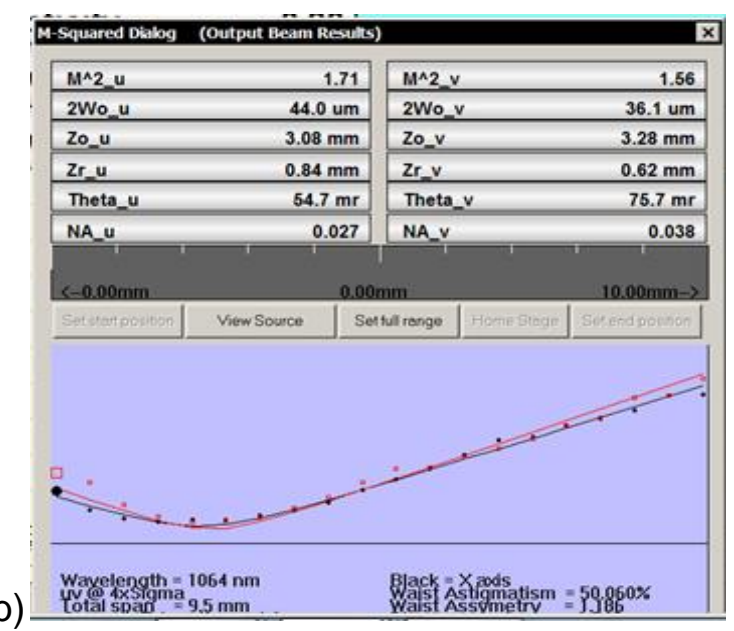

Figura 44: (a) Perfil de intensidade do feixe 1(b) Ajuste da curva para medição da qualidade do feixe com placa de meia onda.
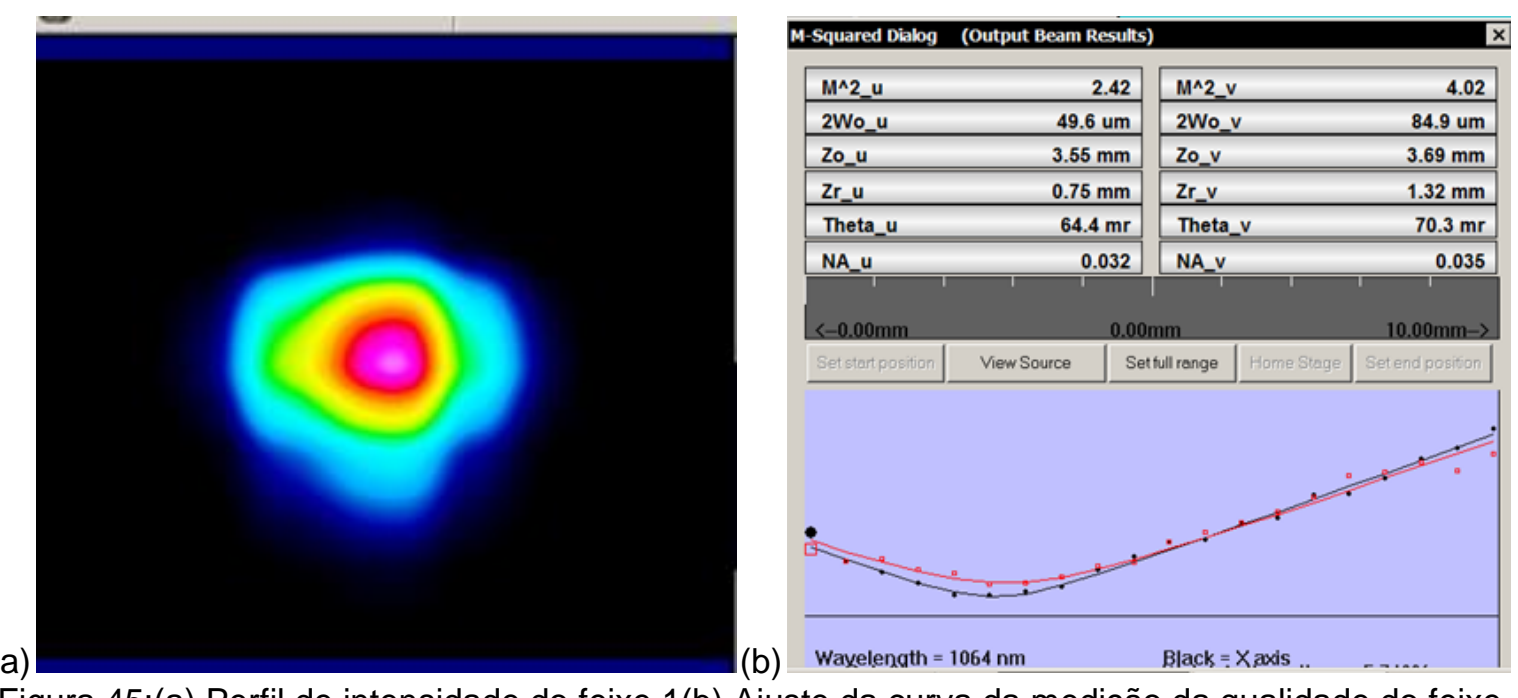

Figura 45:(a) Perfil de intensidade do feixe 1(b) Ajuste da curva da medição da qualidade do feixe sem placa de meia onda. 
Na FIG. 46 é mostrada imagem obtida do perfil de intensidade do feixe 1 depois de colocar o etalon dentro da cavidade ótica na melhor posição, ou seja, onde obtivemos a maior potência que foi de $51,60 \mathrm{~W}$ e um fator de qualidade do feixe laser não polarizado de $M_{u}^{2}=1,26$ e $M_{v}^{2}=1,49$.

(a)

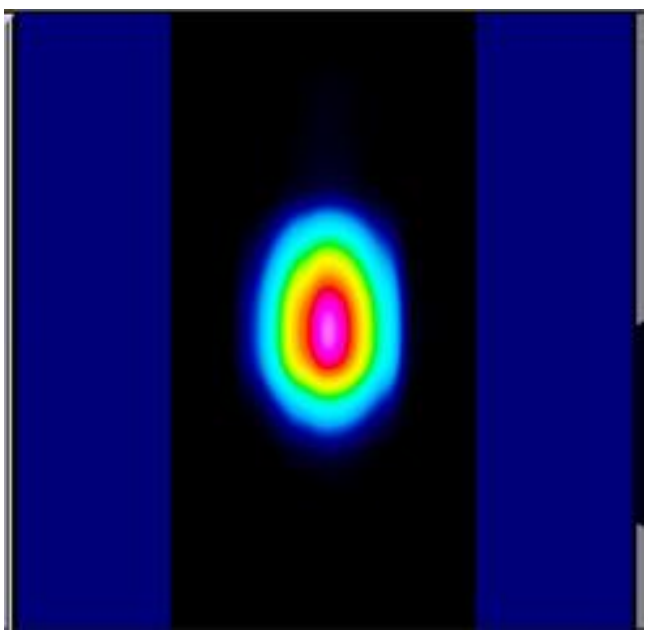

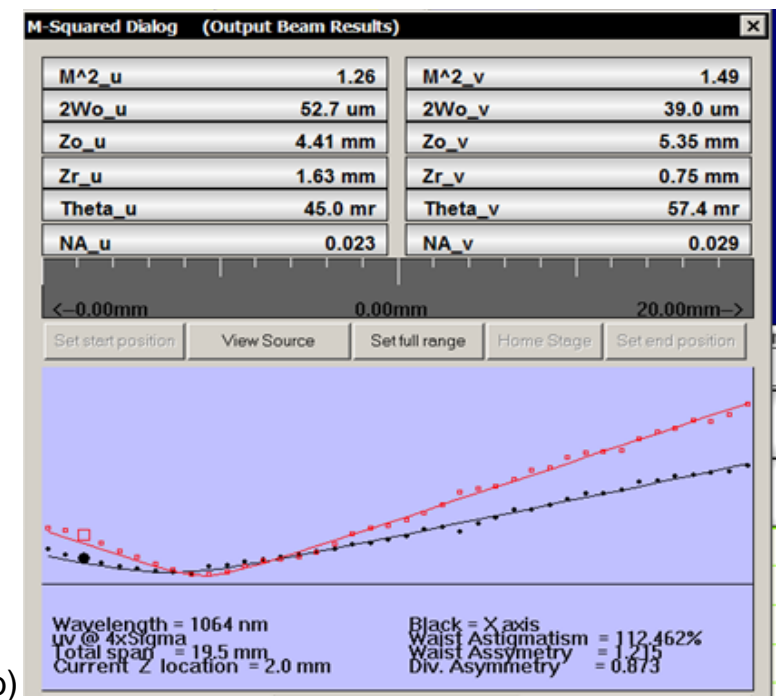

Figura 46:(a) Perfil de intensidade do feixe 1 depois de colocar o etalon dentro da cavidade ótica (b) Ajuste da curva da medição da qualidade com placa de meia onda. 


\section{Operação unidirecional}

\subsection{Operação sem o etalon}

Depois de conseguir o funcionamento unidirecional do laser utilizando um TGG cortado em ângulo de Brewster e uma placa de meia onda entre os dois bastões laser, o mesmo mostrou uma saída dominada por uma modulação de frequência com free spectral range (FSR) de 13,5 GHz como mostrado na FIG. 47 e uma potência de saída de $62 \mathrm{~W}$. Utilizando a eq. 28 e as características do TGG utilizado nesse projeto que são $n=1.95$ e comprimento de $6 \mathrm{~mm}$, temos um valor de FSR de aproximadamente $13 \mathrm{GHz}$.
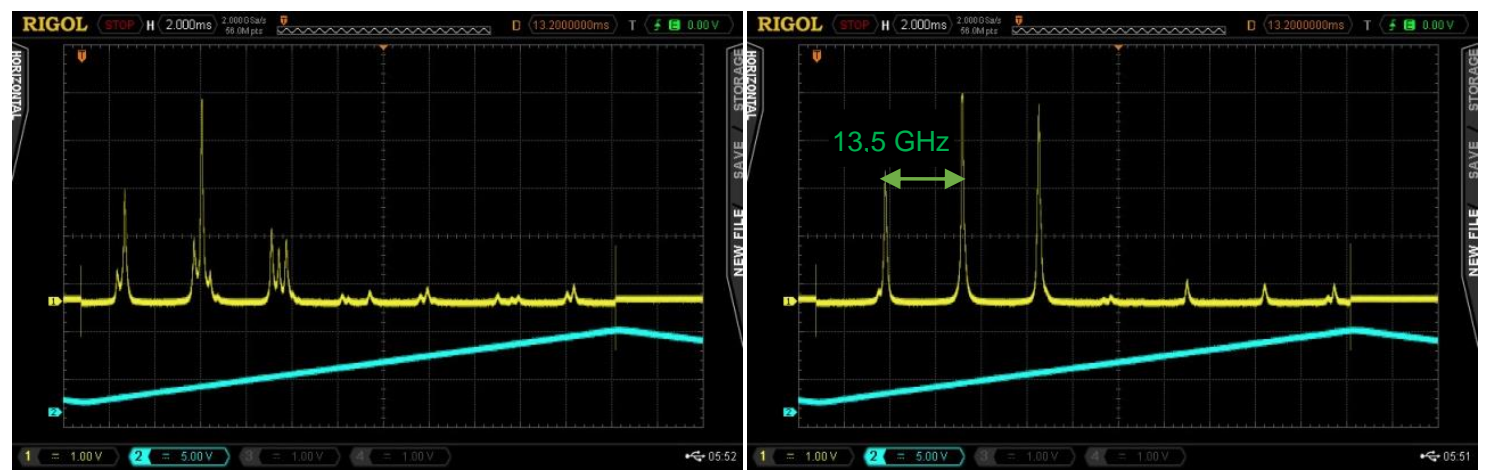

Figura 47: Diferentes instâncias da saída unidirecional espectralmente modulada (três conjuntos de picos à esquerda) medidos usando uma resolução Fabry-Perot de 7,5 MHz.

Para que o laser operasse em frequência única, foi colocado um etalon de $8 \mathrm{~mm}$ de espessura na cavidade laser, na posição mostrado na FIG 48. Adquirindo uma potência de $35 \mathrm{~W}$, porém percebemos que o feixe estava passando duas vezes pelo etalon.

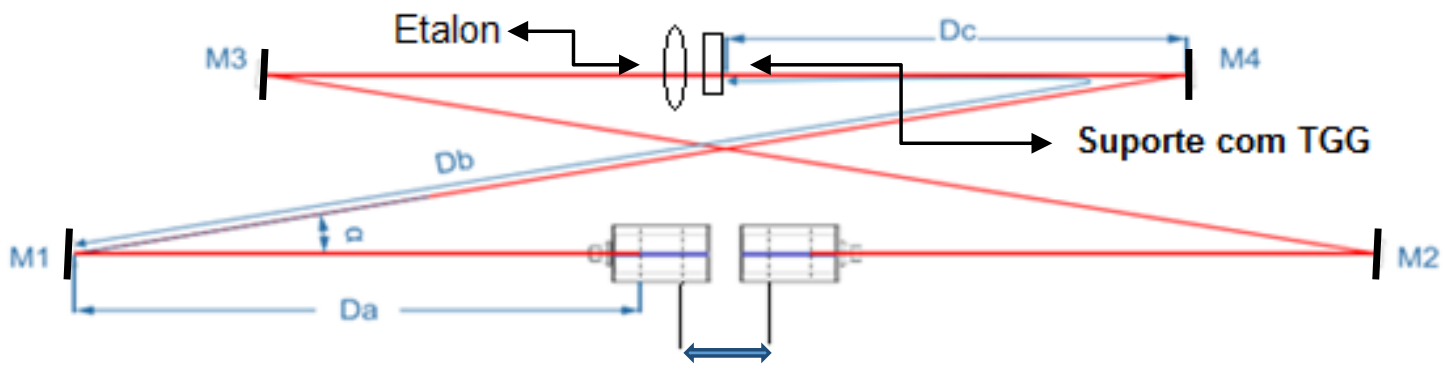

Figura 48: Desenho do ressonador laser. 


\subsection{Operação com o etalon}

Para suprimir temporariamente a modulação e o salto de modo, inserimos um etalon na cavidade (quartzo fundido não revestido de $10 \mathrm{~mm}$ de espessura), utilizando a eq. 23 e eq. 26 temos $\mathrm{FSR}=10 \mathrm{GHz}$ e finesse $=0,654$ que foi capaz de estabilizar uma única frequência dentro da cavidade por vários segundos (5-10 s). A única emissão mostrada na FIG. 49 possui uma largura a meia altura da curva (FWHM) de aproximadamente $11 \mathrm{MHz}$.

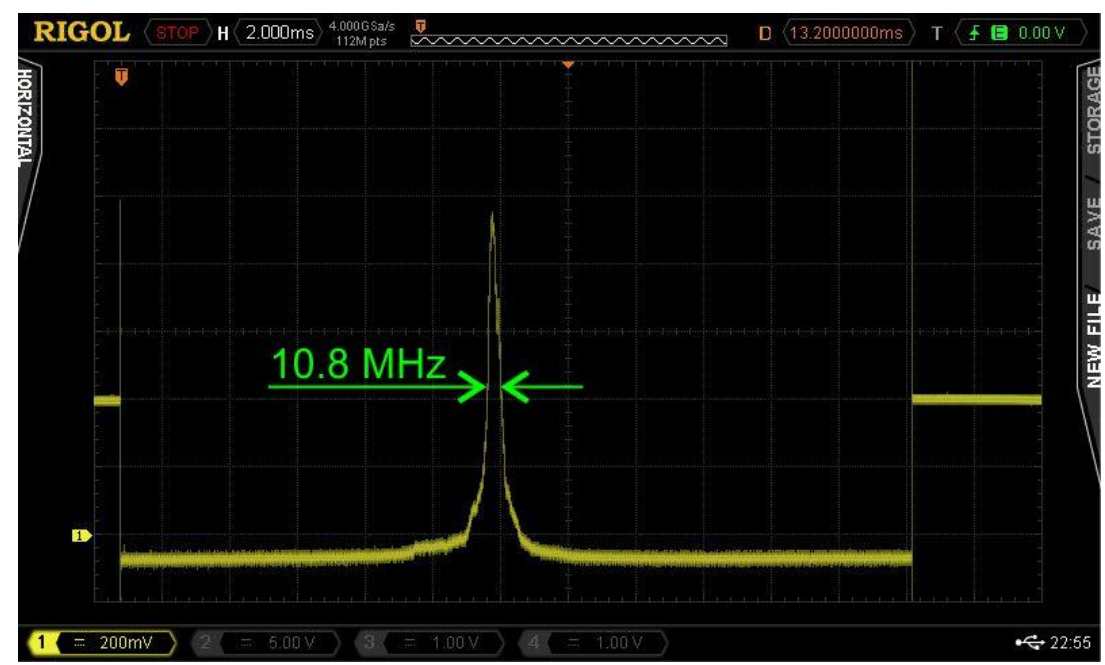

Figura 49: Saída de frequência única medida usando um Fabry-Perot de resolução de 7,5 MHz.

Analisando a simulação dos modos laser na FIG. 38 percebemos que poderíamos adquirir uma maior potência com uma melhor localização do etalon, pois existem localizações onde a cintura do feixe tem um diâmetro maior. Essa posição fica entre o espelho M1 e M4 da FIG. 50, sendo a cintura do feixe maior na posição próxima ao espelho $M 1$, que na FIG. 38 é a posição 2 e entre os espelhos M2 e M3 da FIG. 50 sendo a cintura do feixe maior na posição próxima ao espelho M2, que é a posição 5 da FIG. 50. Por motivos de espaço foi escolhida a posição próxima do espelho $M 1$ com a cintura do feixe medindo aproximadamente $900 \mu \mathrm{m}$, evitando a passagem do feixe duas vezes pelo etalon.

O etalon foi colocado na cavidade laser com inclinação em relação ao feixe laser maior que $90^{\circ}$, afim de obter um melhor selecionamento dos modos TEM $_{00}$, porém foi observado que a potência obtida era bem maior com o ângulo próxima dos $90^{\circ}$. A inclinação do etalon gera perda de potência devido diminuição da interferência dos feixes [50]. 
O etalon foi colocado na cavidade laser na posição mostrada no esquema da FIG. 50 com ângulo do feixe laser em relação ao plano do etalon de aproximadamente $90^{\circ}$ obtendo uma potência de $51,60 \mathrm{~W}$.

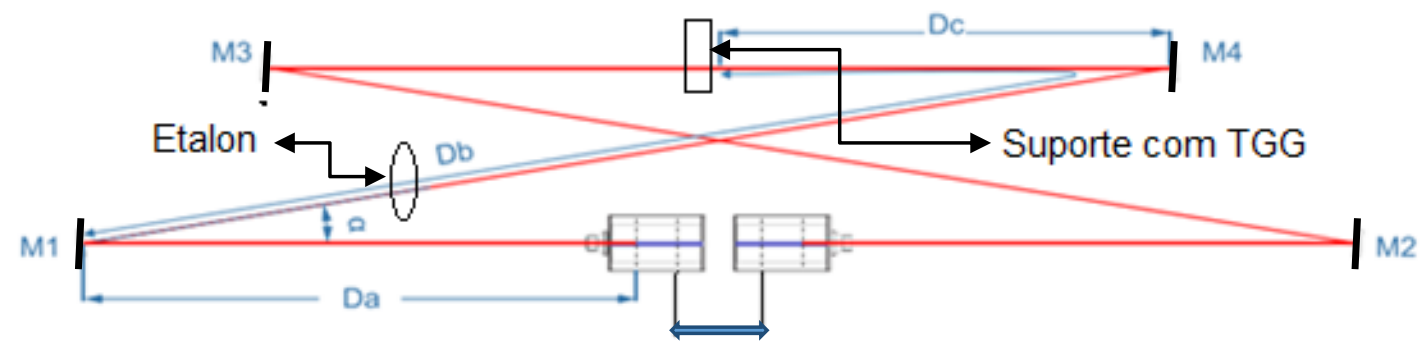

Figura 50: Desenho do ressonador laser.

A única frequência mostrada na FIG. 51 possui uma largura a meia altura da curva (FWHM) de aproximadamente $17 \mathrm{MHz}$ com uma potência de saída de 51,60 W. A FIG. 52 mostra as medidas da potência de saída em função da soma da potência de bombeio do modulo 2 e 4 calculada conforme o tópico 4.2.1 para cavidade laser sem elemento polarizador, apenas com o TGG na cavidade laser e com TGG e o etalon na posição indicada na FIG. 50.

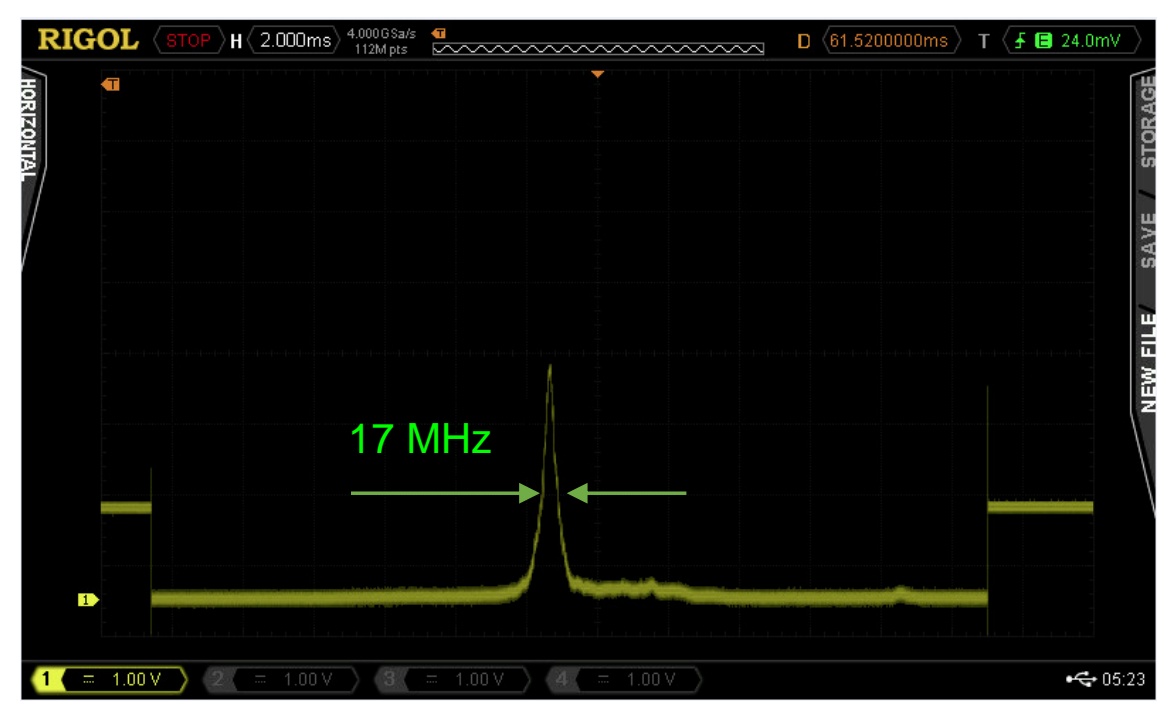

Figura 51: Saída de frequência única medida usando um Fabry-Perot de resolução de 7,5 MHz.

Na FIG 52 a parti da potência de bombeio de $395 \mathrm{~W}$ podemos ver o aumento significativo da potência de saída para a cavidade laser sem elemento polarizador em comparação com a cavidade laser com o TGG e a cavidade laser 
com TGG e o etalon na posição indicada na FIG. 50. No caso de operações no modo $\mathrm{TEM}_{00}$ as perdas por despolarização aumentam na medida em que se aumenta a potência de bombeamento e podem alcançar $25 \%$ da potência total [9]. Outro motivo é que o TGG apresenta lente térmica que não é desprezível e podem interferir na intervalo de estabilidade do laser [51].

Uma solução demostrada na literatura afim de compensar a lente térmica gerada no TGG é inserir uma fatia de cristal de fosfato de deutério de potássio (DKDP-Potassium Dideuterium Phosphate) no ressonador que é um cristal com lente térmica negativa [52].

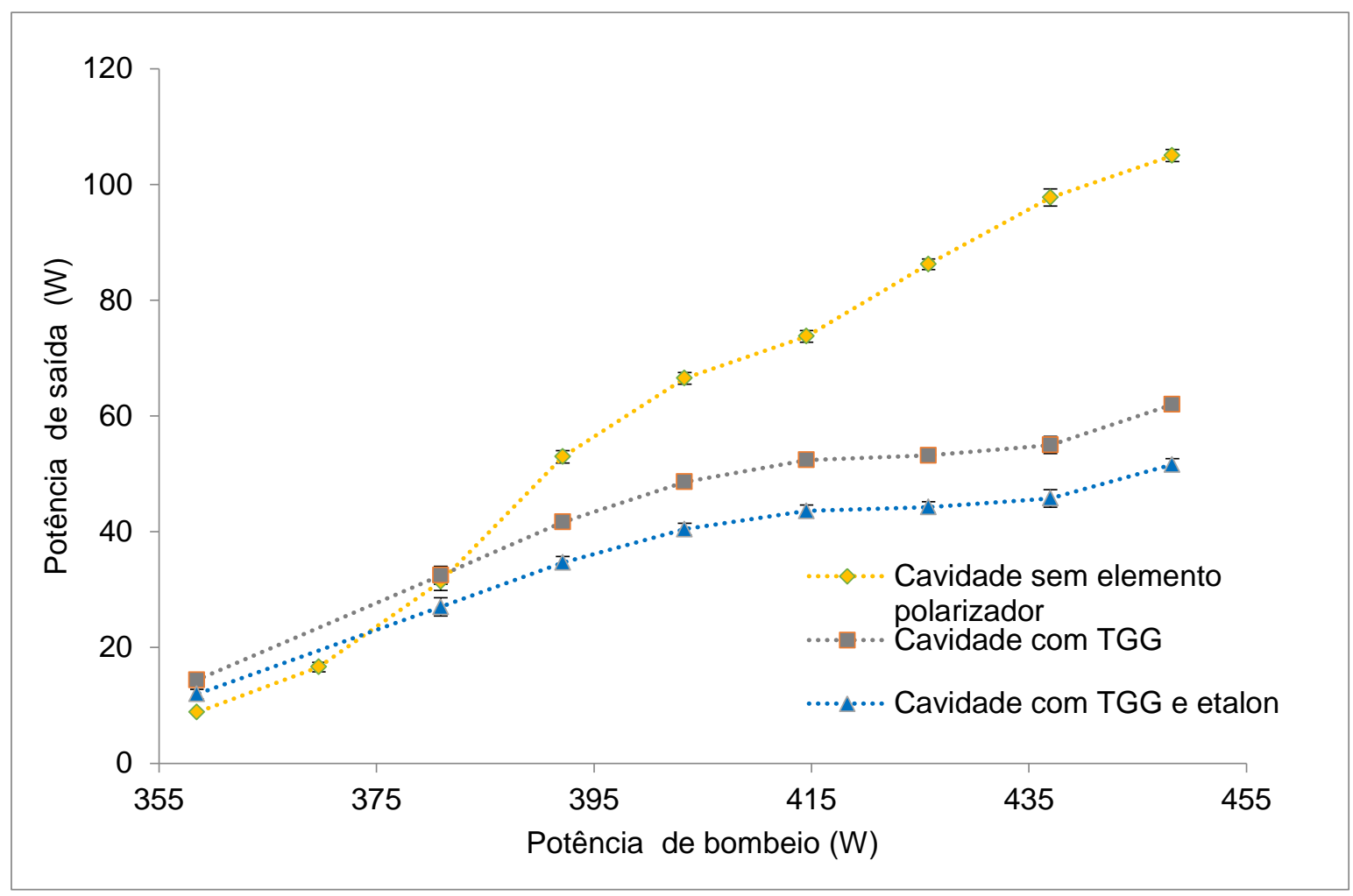

Figura 52: Medida da potência em função da corrente para cavidade laser sem elemento polarizador, com o TGG e com TGG e o etalon. 


\section{Conclusão}

Foi demonstrado um ressonador em anel polarizado $\mathrm{CW}$ com qualidade de feixe próxima de $\mathrm{TEM}_{00}$. A potência de saída alcançada é, a nosso entender, a mais alta reportada para lasers em anel de modo fundamental polarizado contínuo usando módulos de Nd:YAG com bombeio lateral.

Obteve-se um ressonador com 2 módulos DPSSL com uma potência de 105,2 W com feixe polarizado linearmente e fatores de qualidade de $M_{u}^{2}=1,71$ e $M_{v}^{2}=1,56$. Após a inserção do rotacionador de faraday no ressonador obteve-se uma potência de $62 \mathrm{~W}$. Na operação de frequência única após colocado o etalon na melhor posição dentro do ressonador obteve-se uma potência de saída de 35 W. Fazendo uso de um controlador de etalon com resolução em comprimento de onda de $7,5 \mathrm{MHz}$ para caracterização da emissão espectral do laser e demonstração da operação frequência única, foi medida uma largura de linha de 10,8 MHz. Com o intuito de melhorar a potência do laser foi feita a análise da simulação dos modos laser, então percebemos que podíamos adquirir uma potência maior mudando a posição do etalon dentro da cavidade laser. Obtivemos um melhor resultado adquirindo uma potência de 51,60 W, um fator de qualidade do feixe laser não polarizado de $M_{u}^{2}=1,26$ e $M_{v}^{2}=1,49$, o que indica modo transversal fundamental, e uma largura a meia altura da curva ( $F W H M)$ de aproximadamente $17 \mathrm{MHz}$.

Até a presente data o laser com a maior potência encontrado na literatura de estado sólido utilizando como meio ativo o cristal de $\mathrm{Nd}: \mathrm{YVO}_{4}$ emitindo no comprimento de onda de 1064 nm em ressonador único sem amplificador, obteve uma potência de 50,3 W[53]. 


\section{REFERÊNCIAS BIBLIOGRÁFICAS}

1 BERECZKI, A.; WETTER, N. U. $100 \mathrm{~W}$ continuous linearly polarized, high beam quality output from standard side-pumped Nd:YAG laser modules. Optics and Laser Technology, v. 96, p. 271-275, 2017. Disponível em: <http://dx.doi.org/10.1016/j.optlastec.2017.05.020>.

$2 \mathrm{LI}, \mathrm{L}$. The advances and characteristics of high-power diode laser materials processing. Optics and Lasers in Engineering, v. 34, p. 231-253, 2000.

3 GRECHIN, S. G.; NIKOLAEV, P. P. Diode-side-pumped laser heads for solidstate lasers. Quantum Electronics, v. 39, n. 1, p. 1-17, 2009. Disponível em: $<$ http://stacks.iop.org/1063-

7818/39/i=1/a=R01 ?key=crossref.a6fd498a4098693672dbabcbe1be21c1 >.

4 WETTER, N. U. Three-fold effective brightness increase of laser diode bar emission by assessment and correction of diode array curvature. Optics and Laser Technology, v. 33, n. 3, p. 181-187, 2001.

5 MURDOUGH, M. P.; DENMAN, C. a. Mode-volume and pump-power limitations in injection-locked TEM(00) Nd:YAG rod lasers. Applied optics, v. 35,n. 30, p. 5925-36, 1996. Disponível em: <http://www.ncbi.nlm.nih.gov/pubmed/21127604>.

6 EISENHARDT, H. J.; HENNECKEN, H.; KLEIN, P. J.; PICHLMAIER, H. Experiences $\mathrm{w}$ i t h of microvascular anastomosis. v. 25, p. 341-350, 1980.

7 BERECZKI, A.; APARÍCIO LOPEZ, M. A. P.; WETTER, N. U. Dynamically stable $\mathrm{Nd}$ :YAG resonators with beam quality beyond the birefringence limit and pumping of a singly resonant optical parametric oscillator. Optics Letters, v. 43 , n. 4 , p. $4-7,2018$.

8 PINTO, R. S.; WETTER, N. U. Highly efficient, dynamically stable Nd: YAG single-rod resonators with 60\% TEM00 extraction efficiency and high misalignment stability. Laser Physics, v. 24, n. 8, 2014.

9 KRASINSKI, J. S.; PEARSON, G. W. Optical Nonreciprocal Devices and Their Applications. Acta Physica Polonica, v. 86, n. 1, p. 245-255, 1994. 
10 KUPERMAN, M.; SANDÁ, S. R. Efecto Faraday: determinaci ' on de la constante de Verdet. Applied optics, 2015.

11 MAIMAN, T. H. Stimulated optical radiation in Ruby. Nature, v. 187, n. 4736, p. 493-494, 1960.

12 KEYES, R. J.; QUIST, T. M. Injection luminescent pumping of CaF2:U3+ with GaAs diode lasers. Applied Physics Letters, v. 4, n. 3, p. 50-52, 1964.

13 SEBASTIAN, J.; BEISTER, G.; BUGGE, F.; BUHRANDT, F.; ERBERT, G.; MEMBER, A.; HÄNSEL, H. G.; HÜLSEWEDE, R.; KNAUER, A.; PITTROFF, W.; STASKE, R.; SCHRÖDER, M.; WENZEL, H.; WEYERS, M.; TRÄNKLE, G. High-Power 810-nm GaAsP - AIGaAs Diode. v. 7, n. 2, p. 334-339, 2001.

14 AL-MUHANNA, A.; MAWST, L. J.; BOTEZ, D.; GARBUZOV, D. Z.; MARTINELLI, R. U.; CONNOLLY, J. C. High-power (>10 W) continuous-wave operation from 100- $\mu \mathrm{m}$-aperture $0.97-\mu \mathrm{m}$-emitting Al-free diode lasers. Applied Physics Letters, v. 73, n. 9, p. 1182-1184, 1998.

15 ORAZIO, S. Lasers, Principles of. 5. ed. [s.I.] Springer, 2010.

16 WETTER, N. U.; DEANA, A. M. Diode-side-pumped Nd:YLiF4 laser emitting at $1053 \mathrm{~nm}$ with 53.6\% optical efficiency and diffraction-limited beam quality. Laser Physics Letters, v. 10, n. 3, 2013.

17 BASS, M.; KOECHNER, W. Solid-State Lasers: A Graduate Text. [s.I.] Springer, 2002.

18 GEUSIC, J. E.; MARCOS, H. M.; VAN UITERT, L. G. Laser oscillations in nddoped yttrium aluminum, yttrium gallium and gadolinium garnets. Applied Physics Letters, v. 4, n. 10, p. 182-184, 1964.

19 KANCHANAVALEERAT, E.; COCHET-MUCHY, D.; KOKTA, M.; STONESUNDBERG, J.; SARKIES, P.; SARKIES, J.; SARKIES, J. Crystal growth of high doped Nd:YAG. Optical Materials, v. 26, n. 4, p. 337-341, 2004.

20 PASCHOTTA, R. YAG Lasers. Disponível em: <https://www.rpphotonics.com/yag_lasers.html>. Acesso em: 13 jul. 2018. 
21 GUY, S.; BONNER, C. L.; SHEPHERD, D. P.; HANNA, D. C.; TROPPER, a. C.; FERRAND, B. High-inversion densities in Nd:YAG-upconversion and bleaching. IEEE Journal of Quantum Electronics, v. 34, n. 5, p. 900-909, 1998.

22 KOGELNIK, H.; LI, T. Laser Beams and Resonators. Applied optics, v. 54, n. 10, p. 1312-1329, 1966.

23 ASAKURA, T.; KAMIYA, T.; KRAUSZ, F.; MONEMAR, B.; VENGHAUS, H.; WEBER, H.; WEINFURTER, H. Solid-State Laser Engineering. 6. ed. [s.l.] Springer, [s.d.]

24 DANIELMEYER, H. G. Stabilized Efficient Single-Frequency Nd:YAG Laser. IEEE Journal of Quantum Electronics, v. 6, n. 2, p. 101-104, 1970.

25 XU, Y.-T.; XU, J.-L.; GUO, Y.-D.; YANG, F.-T.; CHEN, Y.-Z.; XU, J.; XIE, S.Y.; BO, Y.; PENG, Q.-J.; CUI, D.; XU, Z.-Y. Compact high-efficiency 100-Wlevel diode-side-pumped Nd:YAG laser with linearly polarized TEM00 mode output. Appl. Opt., v. 49, n. 24, p. 4576-4580, 2010. Disponível em: <http://ao.osa.org/abstract.cfm?URI=ao-49-24-4576>.

26 LIU, W.; ZHANG, D.; LI, J.; PAN, Y.; BO, Y.; LI, C.; WANG, B.; PENG, Q.; CUI, D.; XU, Z. High power single wavelength ceramic Nd:YAG laser at 1116 nm. Optics and Laser Technology, v. 46, n. 1, p. 139-141, 2013. Disponível em: <http://dx.doi.org/10.1016/j.optlastec.2012.05.027>.

27 HUA, R.; WADA, S.; TASHIRO, H. Principles and limitations of a quarter-wave plate for reducing the depolarization loss from thermally induced birefringence in Nd:YAG lasers. Optics Communications, v. 175, n. 1, p. 189-200, 2000.

28 KANDASAMY, R.; YAMANAKA, M.; IZAWA, Y.; NAKAI, S. Analysis of birefringence compensation using a quarter-wave plate in solid-state lasers. Optical Review, v. 7, n. 2, p. 149-151, 2000.

29 CLARKSON, W. A.; FELGATE, N. S.; HANNA, D. C. Simple method for reducing the depolarization loss resulting from thermally induced birefringence in solid-state lasers. Optics letters, v. 24, n. 12, p. 820-822, 1999.

30 FUJIKAWA, S.; KOJIMA, T.; YASUI, K. High-power and high-efficiency operation of a CW-diode-side-pumped Nd:YAG rod laser. IEEE Journal of 
Selected Topics in Quantum Electronics, v. 3, n. 1, p. 40-44, 1997. Disponível em: <http://ieeexplore.ieee.org/document/585812/>.

31 LIU, C.; RIESBECK, T.; WANG, X.; XIANG, Z.; CHEN, J.; EICHLER, H. J. Asymmetric TEM 00 -Mode Cavity for Solid-State Lasers. IEEE Journal of Quantum Electronics, v. 44, n. 11, p. 1107-1115, 2008.

32 MAGNI, V. Resonators for solid-state lasers with large-volume fundamental mode and high alignment stability: errata. Applied optics, v. 25, n. 13, p. 2039, 1986.

33 SIEGMAN, E. A. Lasers. [s.I.] University Science Books, 1986.

34 GERRARD, A.; BURCH, J. M. Introduction to Matrix Methods in Optics. 1. ed. [s.I.] John Wiley \& Sons, London and New York, 1976. v. 23

35 SILVESTRI, S. DE.;LAPORTA, P.; MAGNI, V. Rod thermal lensing effects in solid-state laser Rring resonators. Optics Communications, v. 65, n. 5, p. 373-376, 1988. Disponível em: <https://doi.org/10.1016/0030-4018(88)90106$X>$.

36 GRAF, T.; BALMER, J. E.; WEBER, R.; WEBER, H. P. Multi-Nd: YAG-rod variable-configuration resonator (VCR) end pumped by multiple diode-laser bars. Optics Communications, v. 135, n. 1-3, 1997.

37 TAI, P.; HSIEH, W. Suppression of spatial hole burning in a solid- state laser with the degenerate resonator configuration. v. 13, n. 5, p. 6001-6006, 2005.

38 KIMURA, T.; OTSUKA, K.; SARUWATARI, M. Spatial Hole-Burning Effects in a Nd3+:YAG Laser. IEEE Journal of Quantum Electronics, v. 7, n. 6, p. 225-230, 1971.

39 JULSGAARD, B.; WALTHER, A.; KRÖLL, S.; RIPPE, L. Understanding laser stabilization using spectral hole burning. Optics Express, v. 15, n. 18, p. 11444, $2007 . \quad$ Disponível em: <https://www.osapublishing.org/oe/abstract.cfm?uri=oe-15-18-11444>.

40 VOLKER, S. Hole-burning spectroscopy. v. 40, p. 499-530, 1989. Disponível 
em:

<https://www.annualreviews.org/doi/pdf/10.1146/annurev.pc.40.100189.00243

5>. Acesso em: 22 mar. 2018.

41 PASCHOTTA, R. Single-Frequency Operation Stabilized by Spatial Hole Burning. Disponível em: <https://www.rpphotonics.com/spotlight_2006_09_03b.html>.

42 NASCIMENTO, E. M. O Efeito Faraday. p. 7, 2006. Disponível em: $<$ http://www2.fis.ufba.br/dfes/estrutura1/roteiros/EfeitoFaraday.pdf>. Acesso em: 22 mar. 2018.

43 SPEARS, T. G. The Verdet Constant of Light Flint Glass. v. 44691, p. 1-4, 2003. Disponível em: <http://physics.wooster.edu/JrIS/Files/Spears.pdf>.

44 SYTCHEVA, A.; LÖW, U.; YASIN, S.; WOSNITZA, J.; ZHERLITSYN, S.; GOTO, T.; WYDER, P.; LÜTHI, B. Magneto-acoustic faraday effect in Tb3Ga5O12. Journal of Low Temperature Physics, v. 159, n. 1-2, p. 126129, 2010.

45 TRÉNEC, G.; VOLONDAT, W.; CUGAT, O.; VIGUÉ, J. Permanent magnets for Faraday rotators inspired by the design of the magic sphere. Applied Optics, v. 50, n. 24, p. 4788, 2011. Disponível em: <https://www.osapublishing.org/abstract.cfm?URI=ao-50-24-4788>.

46 WETTER, N. U.; MALDONADO, E. P.; VIEIRA, N. D. Enhanced efficiency of a continuous-wave mode-locked Nd:YAG laser by compensation of the thermally induced, polarization-dependent bifocal lens. Applied optics, v. 32, n. 27, p. 5280-4, 1993. Disponível em: <http://ao.osa.org/abstract.cfm?URI=ao-32-27-5280>.

47 GOLDSTEIN, D. H. Polarized light. [s.I.] CRC Press, 2011.

48 SANTISTEBAN N.; DE LA ROSA, N.; ARENAS, R. G.; FAJARDO, F. Medida De La Constante De Verdet En El Efecto Faraday Con Un Equipo De Bajo Costo . Revista Bistua, v. 7, n. 1, p. 1-6, 2009.

49 Burleigh-Fabry-Perot-Instruction-Manual. v. 1, 1994. Disponível em: <http://www.lasershs.com/DownLoads/Burleigh FP TechNote.pdf>. 
50 LEEB, W. R. Losses Introduced by Tilting Intracavity Etalons. Applied Physics, v. 272, p. 267-272, 1974.

51 YIN, Q.; LU, H.; PENG, K. Investigation of the thermal lens effect of the TGG crystal in high-power frequency-doubled laser with single frequency operation Abstract: Optics Express, v. 23, n. 4, p. 1793-1801, 2015.

52 YIN, Q.; LU, H.; PENG, K. High power single-frequency and frequencydoubled laser with active compensation for the thermal lens effect of terbium gallium garnet crystal. Optics letters, v. 41, n. 9, p. 1-4, 2016.

53 GUO, Y.;LU, H.; XU, M.; SU, J.; PENG, K. Investigation about the influence of longitudinal-mode structure of the laser on the relative intensity noise properties. Optics Express, v. 26, n. 16, p. 21108-21118, 2018. Disponível em: <https://doi.org/10.1364/OE.26.021108>. 